Florida International University FIU Digital Commons

$3-31-2005$

\title{
Quality of student involvement and college contribution toward development of traditional and nontraditional undergraduate students
}

Dawn Marie Broschard

Florida International University

DOI: $10.25148 /$ etd.FI14051849

Follow this and additional works at: https://digitalcommons.fiu.edu/etd

Part of the Higher Education Commons

\section{Recommended Citation}

Broschard, Dawn Marie, "Quality of student involvement and college contribution toward development of traditional and nontraditional undergraduate students" (2005). FIU Electronic Theses and Dissertations. 1813.

https://digitalcommons.fiu.edu/etd/1813 


\section{FLORIDA INTERNATIONAL UNIVERSITY}

Miami, Florida

QUALITY OF STUDENT INVOLVEMENT AND COLLEGE CONTRIBUTION TOWARD DEVELOPMENT OF TRADITIONAL AND NONTRADITIONAL UNDERGRADUATE STUDENTS

A dissertation submitted in partial fulfillment of the

requirements for the degree of

DOCTOR OF EDUCATION

in

HIGHER EDUCATION

by

Dawn Marie Broschard

2005 
To: Dean Linda Blanton

College of Education

This dissertation, written by Dawn Marie Broschard, and entitled Quality of Student Involvement and College Contribution toward Development of Traditional and Nontraditional Undergraduate Students, having been approved in respect to style and intellectual content, is referred to you for judgment.

We have read this dissertation and recommend that it be approved.

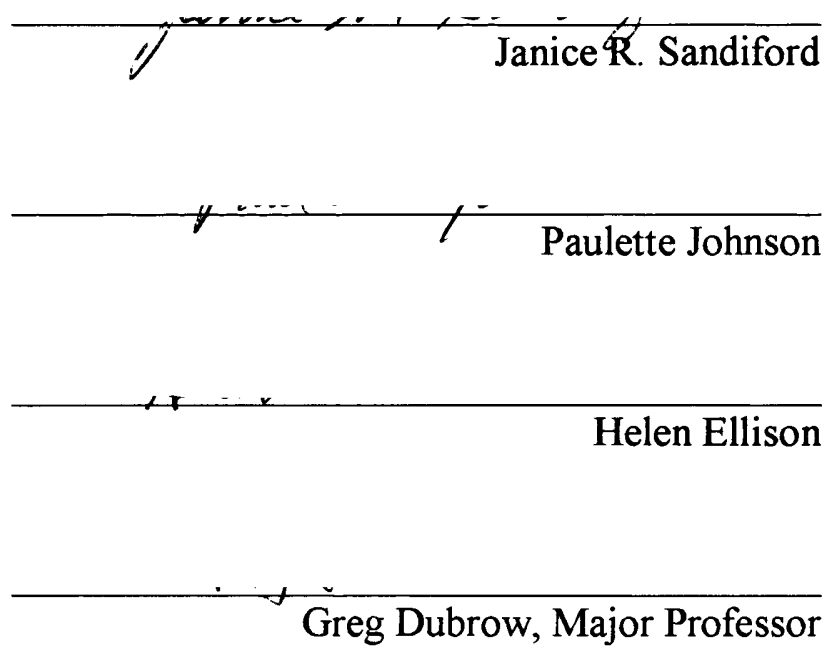

Date of Defense: March 31, 2005

The dissertation of Dawn Marie Broschard is approved.
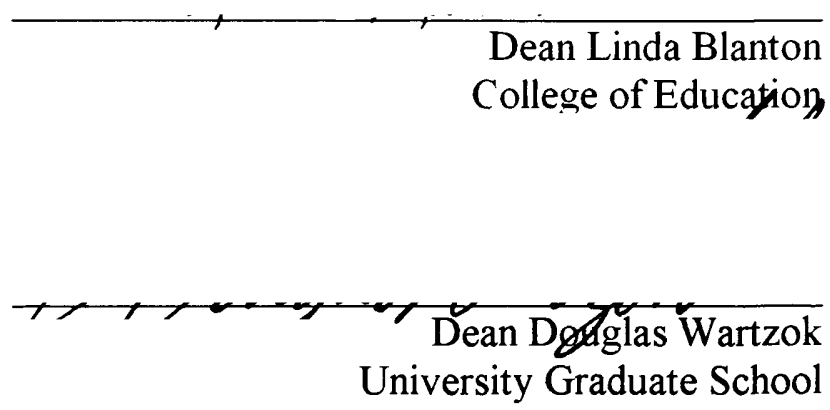

Florida International University, 2005 
C Copyright 2005 by Dawn Marie Broschard

All rights reserved. 


\section{DEDICATION}

To my beautiful, wise, and talented daughter Arianna, whose patience, understanding, and support through this process helped make this possible. I love you very much. 


\section{ACKNOWLEDGMENTS}

I would like to extend my appreciation to the members of my dissertation committee: Dr. Greg Dubrow, Major Professor, Dr. Janice Sandiford, Dr. Paulette Johnson, and Dr. Helen Ellison. Each of you had such a unique role in my intellectual and personal development. Dr. Sandiford was the first professor I saw when I stepped into my first doctoral course. She was there, teaching, guiding and supporting the whole way. Special thanks to Dr. Johnson for all of her statistical help and editing. Dr. Ellison, I could not have gotten through this without your calming presence and your words of support along the way. My deepest thanks to Dr. Dubrow, for his encouragement and for making me stretch and go beyond what I thought I was capable of.

Thank you to Dr. Sandiford, Dr. Keim, and my fellow "boot campers" for providing valuable recommendations for other components of the research process. My sincere gratitude to Dr. Keim for reading my chapters and suggest editorial and content changes.

Special thanks to Dr. Frank Di Vesta who facilitated useful workshops, provided valuable feedback on my proposal and dissertation, and wrote on my behalf to Dr. Pace regarding an appropriate survey instrument.

My deepest gratitude goes to my dear friend Tiffany who helped with edits/reading and kept me going. A special thanks to Omar for your love and for keeping me in one piece. To Sr. Candace and Sr. Peggy, I extend my deepest appreciation for the valuable time that you gave me to work on my dissertation. 


\section{ABSTRACT OF THE DISSERTATION \\ QUALITY OF STUDENT INVOLVEMENT AND COLLEGE CONTRIBUTION \\ TOWARD DEVELOPMENT OF TRADITIONAL AND NONTRADITIONAL \\ UNDERGRADUATE STUDENTS}

by

Dawn Marie Broschard

Florida International University, 2005

Miami, Florida

Professor Greg Dubrow, Major Professor

Nontraditional students differ from traditional students on characteristics such as age, employment status, marital status, and parental status. The quality of a student's experience is important as it relates to his or her transformation and is a reflection of the quality of the college.

Using theory of involvement as a framework, the purpose of this study was to test if there were differences between traditional and nontraditional undergraduate students in their ratings of quality of college involvement (academic, co-curricular, student interactions, and faculty interactions) and perceptions of college contribution toward development (intellectual, personal, social, and career). A two part survey was distributed to a random cluster sample of sophomore and higher level undergraduate classes equaling 400 undergraduate students.

Results of a $2 \times 4$ repeated measures ANOVA indicated that traditional students rated quality for co-curricular involvement and student involvement significantly higher than nontraditional students. Both traditional and nontraditional students had similar 
ratings of college contribution toward development. There were different patterns of correlations between involvement and development. Traditional students' ratings of academic and student involvement were more highly correlated with development than were the ratings of nontraditional students. However, nontraditional students' ratings of academic and faculty involvement were more highly correlated with development. When testing for differences in correlations between quality of involvement and college contribution toward development, the largest observed differences were quality of student involvement and college contribution toward personal and social development. Although not significantly different, traditional students had stronger correlations between those factors than did the nontraditional students.

This research demonstrates the importance of using social role when defining student type. It contributes to involvement theory by explaining how traditional and nontraditional students differ in their ratings of quality of involvement. Further, it identifies different patterns of correlations between ratings of quality of involvement and college contribution toward development for the two types of students. While traditional students may need a more rounded college experience that includes more social and cocurricular experiences, nontraditional students use the classroom as their stage for learning. 


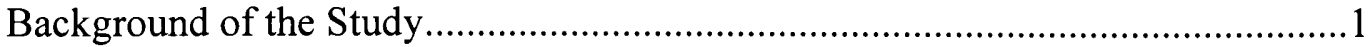

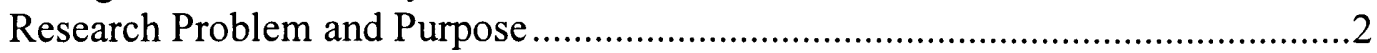

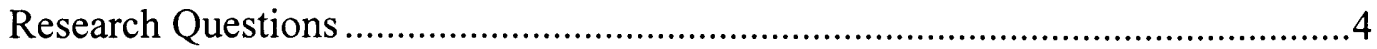

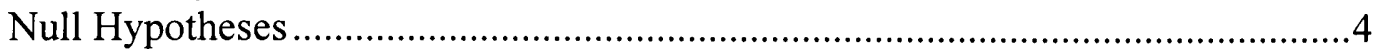

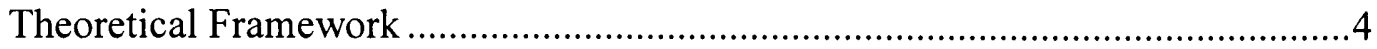

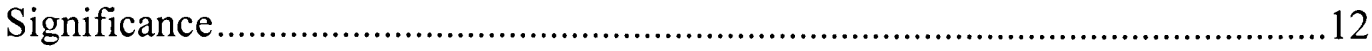

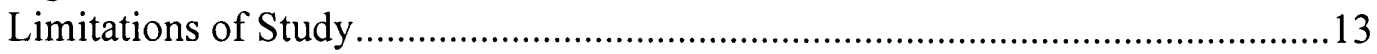

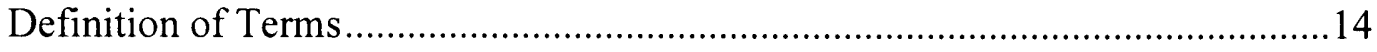

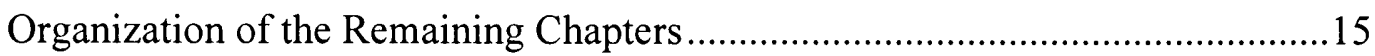

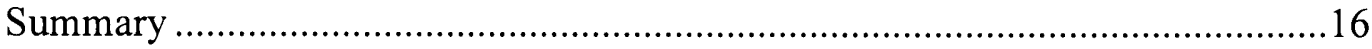

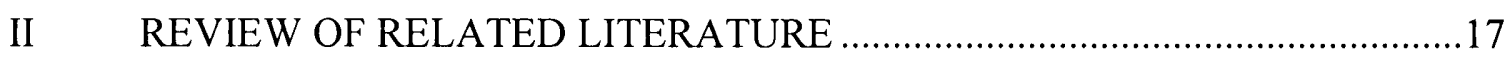

Defining Traditional and Nontraditional Students...........................................17

College Involvement and Student Development ..............................................20

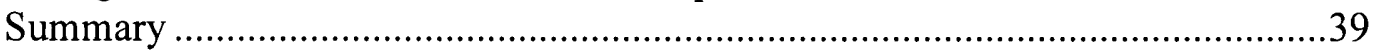

Organization of Remaining Chapters.............................................................

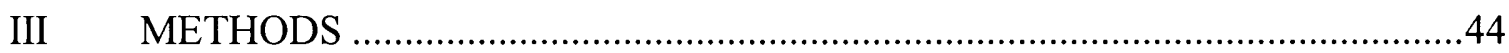

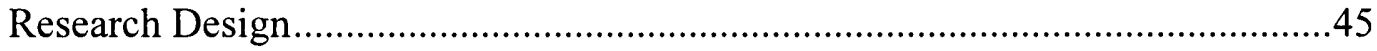

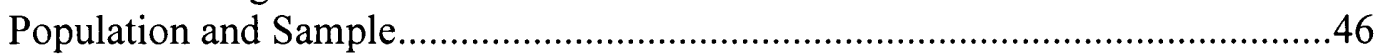

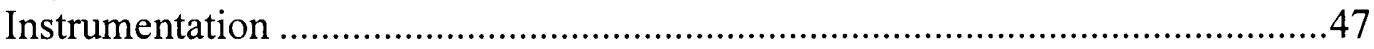

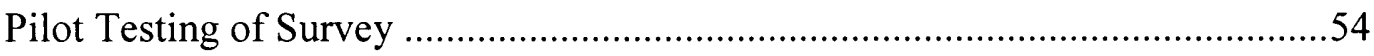

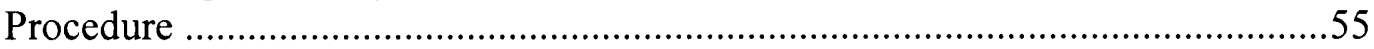

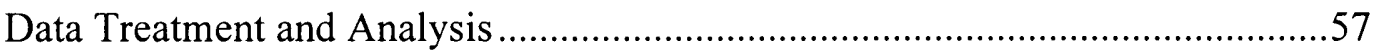

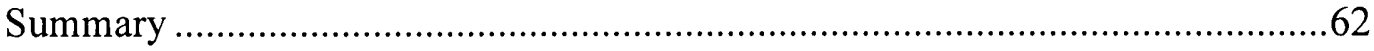

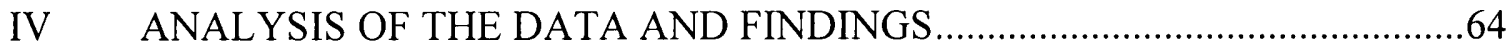

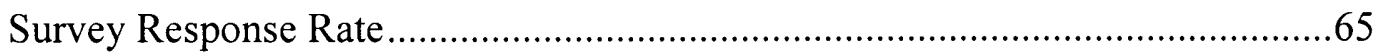

Description of the Respondents .....................................................................66

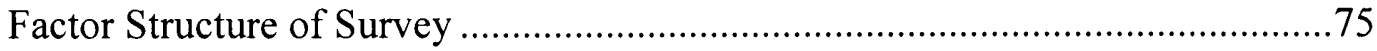

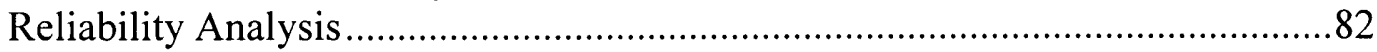

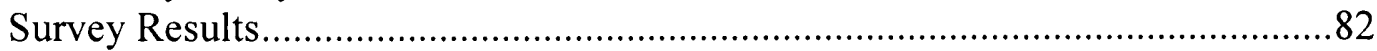

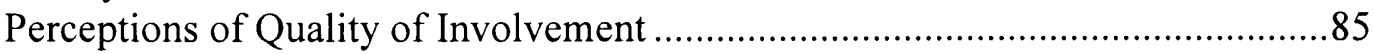

Perceptions of College Contribution toward Development ..................................87

Correlations between Involvement Variables and Development Variables ..........88

Findings of the Paired Comparisons of Correlations ............................................. 90

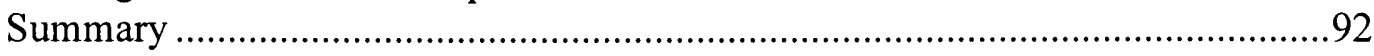

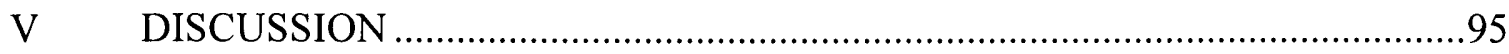

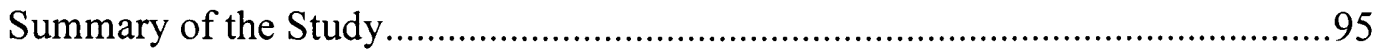




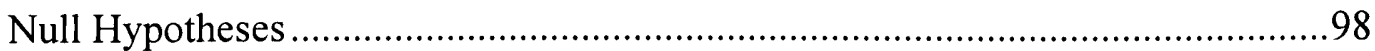

Perceptions of Quality of Involvement ...........................................................99

Perceptions of College Contribution toward Development ...............................103

Quality of Student Involvement and College Contribution toward

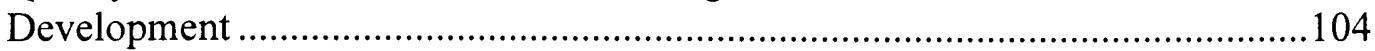

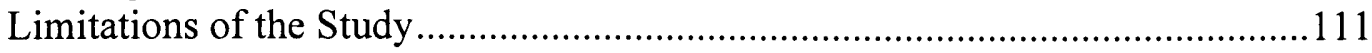

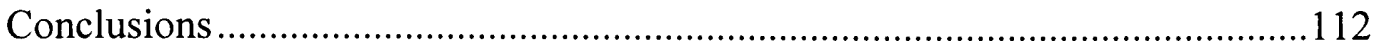

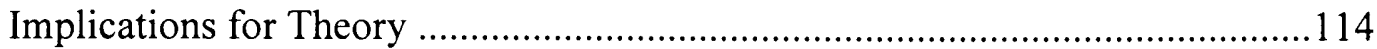

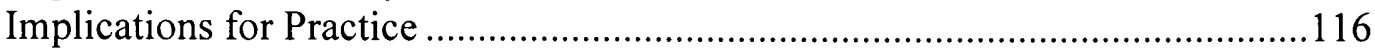

Recommendations for Future Research ............................................................117

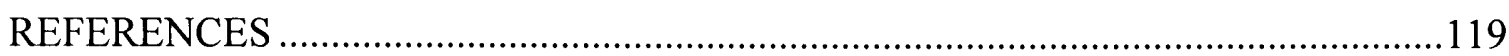

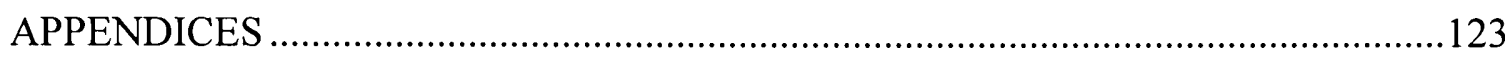

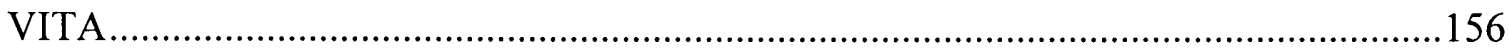


1. Alpha Coefficients for Student Involvement and Student

Development Constructs.

2. Survey Responses 66

3. Gender of the Respondents 67

4. Ethnicity of the Respondents 68

5. Attendance and Resident Status 69

6. School of the Respondents and Populations. 70

7. Marital Status and Number of Dependents of the Respondents 71

8. Completion of High School College Start Date 72

9. Part-time Enrollment Answers of the Respondents. 72

10. Respondents' Employment Status and Financial Independence 73

11. Traditional and Nontraditional Status of the Respondents 74

12. Number of Nontraditional Characteristics of the Respondents 75

13. Principal Components Factor Loadings for Quality of Development Items

14. Principal Components Factor Loadings for College Contribution toward Development Items

15. Alpha Coefficients for Quality of Student Involvement and College Contribution toward Development Constructs

16. Means and Standard Errors for Quality of Student Involvement Variables 86

17. Means and Standard Errors for College Contribution toward Development Variables 
18. Correlations and Tests of Difference between Quality of Student Involvement and Contribution toward Development for Traditional and

Nontraditional Students

19. Correlations between Quality of Student Involvement and College Contribution toward Development 
CHAPTER I

\section{INTRODUCTION}

This dissertation consists of a description of a research study on traditional and nontraditional students' perceptions on quality of college involvement and college contribution toward development and how those perceptions might differ. The data gathered for the study were based on a self-reporting survey. Chapter I of the study includes a background of the study, research problem and purpose, research questions and hypotheses, significance of the study, theoretical framework, limitations, and definitions of the terms used in the study. This chapter concludes with an overview of the format of this dissertation.

\section{Background of the Study}

Student involvement in college is comprised of the physical and emotional effort that a student contributes to his or her college experience. The greater the level of a student's involvement in college, the greater the student's academic and personal development (Astin, 1993). Involvement includes academic and co-curricular experiences, as well as, interactions with other students and faculty. These types of involvement have been positively correlated with positive developmental outcomes such as intellectual, personal, social and career success (Astin, 1993; Graham, 1998; Graham \& Gisi, 2000; Kuh, 1995).

There has been an extensive amount of research examining how student involvement contributes to the intellectual, personal, social and career development of undergraduate students (Astin, 1975, 1985, 1993; Feldman, 1969; Pascarella \& Terenzini, 1991). Much of this research is limited to traditional students. Although nontraditional 
students make up a large part of the undergraduate population today, there has been little research on the effect of college involvement on nontraditional students. However in order for theory and practice to truly address all students, research should include examination of students with diverse backgrounds such as race, gender and nontraditional attendance patterns.

According to Horn (1996), a nontraditional student is defined as an undergraduate student who has at least one or more of the following characteristics: (a) Does not begin college in the same calendar year that he or she completes high school, (b) attends part time for at least part of the academic year, (c) is financially independent when determining financial aid eligibility, (d) works full-time while enrolled, (e) has dependents other than a spouse, (f) is a single parent, (g) does not have a high school diploma and completed high school with a GED or other completion or did not complete high school.

The nontraditional student population continues to grow, thus adding to the complexity of research and practice in higher education. According to the National Center for Education Statistics (NCES), in 1999-2000, 27\% of all undergraduates were traditional. Another $28 \%$ were considered highly nontraditional and $28 \%$ were moderately nontraditional. The remaining $17 \%$ were considered minimally nontraditional. This shift in demographics warrants research in higher education that takes into account these growing populations.

\section{Research Problem and Purpose}

In existing involvement theory research, the definition of traditional and nontraditional is defined solely by age and does not include important social role 
characteristics such as employment, marital status and children (Graham, 1998; Graham \& Gisi, 2000). Different types of students have different needs. Therefore, it is important to incorporate and understand characteristics such as social role when researching or applying involvement theory. Finally, quality of involvement is a value laden term and difficult to define (Harvey \& Green, 1993a). Therefore, researchers examining involvement theory have focused on quantity, or numbers of college involvement activity experiences related to intellectual, personal, social and career development rather than the quality of those experiences.

Using the rationale of involvement theory as a foundation, the purpose of this study was to determine if there were differences between traditional and nontraditional undergraduate students in their perceptions of quality of college involvement and college contribution toward development. More specifically, using a social role score (Horn, 1996; Senter \& Senter, 1998) to define traditional and nontraditional students at a private Catholic university in South Florida, the objective of this research was to (a) examine if perceptions of quality of college involvement differ for nontraditional undergraduate and traditional undergraduate students and, (b) examine if perceptions of college contribution toward intellectual, personal, social and career development differ for traditional undergraduate and nontraditional undergraduate students and, (c) examine if the relationships between quality of college involvement (academic activities, co-curricular activities, student interactions, and faculty interactions) and college contribution toward development (intellectual, personal, social and career) differ for traditional undergraduate and nontraditional undergraduate students. 
Research Questions

The research questions guiding this study are as follows:

1. Do the perceptions of quality of college involvement (academic activities, cocurricular activities, student interactions, and faculty interactions) differ for traditional and nontraditional undergraduate students?

2. Do perceptions of college contribution toward development (intellectual, personal, social and career) differ for traditional and nontraditional undergraduate students?

3. Do the relationships between the quality of college involvement (academic activities, co-curricular activities, student interactions, and faculty interactions) and perceived college contribution toward development (intellectual, personal, social and career) differ for traditional and nontraditional students?

Null Hypotheses

Following are the null hypotheses used to test the research questions of the study.

$\mathrm{H}_{01}$ : There are no interaction effects due to the four involvement types and student type (traditional vs. nontraditional).

$\mathrm{H}_{02}$ : There are no interaction effects due to the four development types and student type (traditional vs. nontraditional).

$\mathrm{H}_{03}$ : The correlation coefficients between the four involvement types and the four development types for traditional students are equal to those for nontraditional students.

Theoretical Framework

Developmental theories are essential to higher education practitioners. Understanding how college students think, feel and behave is helpful in establishing 
programs and services that will help students reach their goals. "Understanding developmental theory is at the heart of effective educational practice" (Baxter Magolda, 1992, p. 3). The following is a presentation of the theory relevant to this research study. It includes topics on person-environment theories and quality with particular emphasis on involvement theory and transformative quality.

\section{Person-Environment Theories}

According to Knefelkamp, Widick, and Parker (1978), student development theory should address four issues: (a) The personal changes that occur while the student is in college, (b) incidents that facilitate that development, (c) facets of the collegiate environment that encourage or hinder growth (d) developmental outcomes that students should accomplish in college. Rarely is an issue in student affairs so straightforward that one theory will adequately explain it or provide sufficient guidance to address it (Evans, Forney \& Guido-DiBrito, 1998). There are many factors involved in the higher educational process. It is critical to look at an issue from a variety of perspectives such as developmental theory (Chickering, 1969), which explains academic, personal, and social growth or development that takes place during college. Another important perspective is person-environment theory such as involvement theory (Astin, 1975, 1999), which explains what types of activities and experiences facilitate development.

Person-environment theories are one way at attempting to answer these questions. Person-environment theories are student development theories that examine the interaction of the student with his or her environment (Evans et al., 1998). Students arrive at college with a given background, ability, motivation, personality, and external demands. Each student is unique. In order for students to successfully transition into 
college, many factors are involved. The college environment consists of programs, attitudes, expectations, and many characteristics particular to an individual institution.

Each student's experience in the college setting impacts his or her growth.

Sanford (1962) was one of the first developmental theorists to pay attention to the idea of student development as a function of person, environment and interaction. His work on developmental theory, often described in terms of the balance between challenge and support, could be used to explain the demands on institutional programming. Students need enough challenge, coupled with enough support, to stimulate critical thinking. In addition, students should feel they matter as individuals to the institution. Sanford (1962) found the following:

When an education produces important effects, it is likely to alter what is valued; in turn, changes in values influence attitudes and interests. In the actual developmental process the reverse also occurs, because new experience leads to modifications of interests and attitudes, and over a period of time the central values also become involved (p. 822).

Involvement Theory

Perhaps one of the most influential person-environment theories is the theory on involvement. Involvement theory examines environmental factors influencing development. This theory has its roots in a longitudinal study of college dropouts that was conducted by Astin (1975). In this particular study, Astin sought to identify the factors in the college environment that significantly affect the student's persistence in college. Simply stated, "student involvement refers to the amount of physical and psychological energy that the student devotes to the academic experience" (Astin, 1999, p. 518). This theory does not seek to explain development per se. Instead, it examines the factors that facilitate development. 
Astin $(1975,1999)$ argued that students must be actively engaged in their

environment in order for student learning to take place. Student affairs professionals and other educators need to create opportunities for involvement to occur, both in and out of the classroom. At this stage in its development, the involvement theory has five basic postulates (Astin, 1999):

1. Involvement refers to the investment of physical and psychological energy in various objects. The objects may be highly generalized (the student experience) or highly specific (preparing for a chemistry exam).

2. Regardless of its object, involvement occurs along a continuum; that is, different students manifest different degrees of involvement in a given object, and the same students manifest different degrees of involvement in different objects at different times.

3. Involvement has both quantitative and qualitative features. The extent of a student's involvement in academic work, for instance, can be measured quantitatively (how many hours the student spends studying) and qualitatively (whether the student reviews and comprehends reading assignments or simply stares at the textbook and daydreams).

4. The amount of student learning and personal development associated with any educational program is directly proportional to the quality and quantity of student involvement in that program. 
5. The effectiveness of any educational policy or practice is directly related to the capacity of that policy or practice to increase student involvement (p. 520).

Although Astin (1999) explained involvement theory in the context of pedagogical theory, academic development and retention, this theory can also be coupled with psychosocial developmental theories and outcomes in terms of values and interests as well. Theory and application can help create a good fit between a student and the institution. Knowing how the different experiences can foster development will provide a framework to provide experiences that are inclusive of all types of students.

It is important to keep in mind that the theory of student involvement is qualitatively different from the developmental theories that look at student development in terms of stages such as Chickering's (1969) seven vectors. Whereas Chickering's theory focuses primarily on developmental outcomes (the what of student development), Astin's (1999) student involvement theory focuses on the behavioral mechanisms or processes that facilitate student development (the how of student development). However, these two types of theories can be used together to provide a framework to investigate how involvement affects development. Astin (1999) discussed numerous research possibilities with regard to involvement theory. One area he identified as needing to be addressed is regarding the connection between particular forms of involvement and particular developmental outcomes. For example, Astin (1999) asked, "What particular forms of involvement facilitate student development among dimensions postulated by theorists such as Chickering, Loevinger, Heath, Perry and Kohlberg” (p. $525) ?$ 
What is quality? The topic of defining quality is one that is still discussed and debated throughout higher education. Defining quality is difficult because it is a relative concept. It means different things to different people and is therefore subjective to the user. Second, quality can be viewed as an 'absolute' ideal like truth or beauty or it can also be viewed in terms of thresholds that need to be exceeded to receive a quality rating (Harvey \& Green, 1993a). Furthermore one must consider the perspective of the different stakeholders in higher education - students, teaching staff, non-teaching staff, employers, accrediting agencies, government and so on (Green, 1994). Each stakeholder may hold a different view on quality. For example, a student might view quality in terms of being prepared for a career while a government role might view quality in terms of accountability issues such as graduation rates or finance indicators.

Barnett (1992) provided a concept of quality that focused on student experiences such as the process and experience of pursuing knowledge, development of students' autonomy and integrity, cultivation of general intellectual abilities, and development of critical reason. However, Barnett (1992) explained that although these concepts are important, they are not reflected in the concept of quality assurance nor are they easily captured system-wide to create performance indicators.

Harvey and Green (1993a) proposed another view of quality in higher education. They grouped quality into five discrete but interrelated ways of thinking about quality:

1. Quality as Exceptional, which views quality as something distinct or special, exceeding high standards, or passing a set of requirements. 
2. Quality as Perfection, or Consistency, which focuses on process and setting criteria that it aims to meet such as getting zero defects.

3. Quality as Fitness for Purpose, which has a functional definition of quality and examines the extent to which the product or service fits its purpose.

4. Quality as Value for Money, which stems from accountability and is linked to performance indicators.

5. Quality as Transformation, which explains quality in terms of ongoing transformation or development as a result of the student's college experience. Assessing Quality

Quality is value-laden in term. "For this reason, linking an activity to quality may serve to validate or justify it irrespective of what the notion of quality might mean" (Harvey \& Green, 1993a, p. 9). Input and output indicators cannot really speak to the quality of a student's experience, particularly as it relates to his or her transformation, in higher education. In order for quantities to tell anything about qualities, some sort of judgment must take place (Barnett, 1992). Further, it is necessary to clearly define, as much as possible, the criteria used by each interest group when judging quality (Harvey \& Green, 1993b). When researching quality for student stakeholders, "learners should be both at the center of the process by which learning is evaluated and at the center of the learning process" (Harvey \& Green, 1993a, p. 23).

Quality needs to be measured by more than graduation or success rates and should include the student perceptions on the quality of their college experiences. As Tam (2001) pointed out, 
any measurement of quality in higher education that falls short of the centrality of student's experience is bound to be peripheral and fail to provide information about how students find the experience and how much they are learning and progressing both intellectually and emotionally throughout their years in university (p. 53).

Further, the fact that colleges can be said to facilitate the holistic development of students including personal, social, emotional and cultural development necessitates attention to measurement of quality as a kind of "transformation" (Harvey \& Green, 1993b).

\section{Connection of Transformative Quality and Involvement Theory}

As indicated earlier, quality as transformation explains quality in terms of ongoing transformation or development as a result of the student's college experience. This concept fits into involvement theory as it relates to maintaining a quality institution that meets the needs of students. Figure 1 illustrates the connection between the concept of transformative quality and involvement theory. Quality as transformation is a valueadded term that measures quality in terms of the extent to which the educational experience enhances the knowledge, abilities and skills of students (Harvey \& Green, 1993a). Not only does education enhance and effect change in the students, it also empowers the students and allows them to influence their own transformation. This particular definition of quality ties into Astin's involvement theory. Involvement theory explains that the experiences of students during college contribute to their academic and personal development. A high quality institution is one that would greatly enhance its students (Astin, 1993).

Research investigating involvement typically measures involvement by the number of times a student is involved in activities (Astin, 1993; 1999; Donaldson \& 


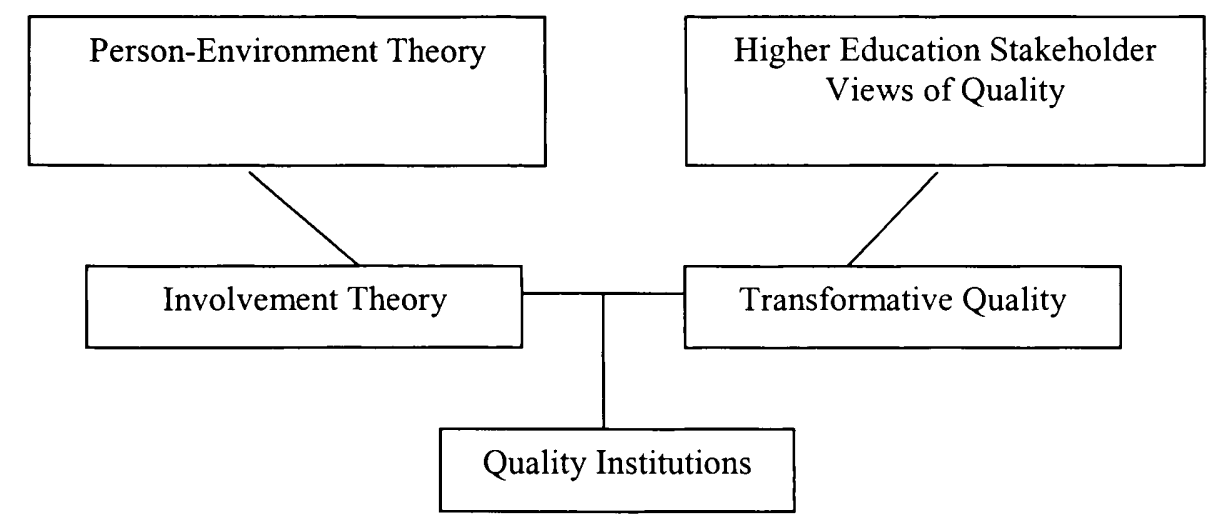

Figure 1. Connection of person-environment theory and quality.

Graham, 1999; Kuh, 1995). The reason involvement theory has focused on quantity rather than quality of involvement is due to the difficulty in defining quality. The definition of quality is complex and subjective to the numerous stakeholders. However, the transformative view explains quality in terms of ongoing transformation or development as a result of the student's college experience. This view of quality ties directly to Astin's $(1975,1999)$ involvement theory. Astin's (1985) theory focuses directly on the institution's ability to impact students and explains that "the most excellent institutions are those that have the greatest impact on a student's knowledge and personal development" (pp. 60-61). These types of institutions offer quality academics and activities along with quality interactions with faculty and other students.

\section{Significance}

This study may provide several contributions to theory and practice. From a theoretical standpoint, the results of this study may contribute to the student involvement and nontraditional literature that exists. Measuring perceptions of the quality of college 
involvement is unique to this study and has not been examined in other research due to the difficulty defining quality in measurable terms. This study may add to the research literature on involvement by examining the quality of experiences in the framework of how they contribute to the transformation of student development (Harvey \& Green, 1993a). Further, since much of the nontraditional literature that exists defines nontraditional students by age, this study may contribute to the nontraditional undergraduate literature by utilizing social role (Horn, 1996; Senter \& Senter, 1998) to define nontraditional students rather than age.

From a more practical perspective, the results of this study may provide data on the way traditional and nontraditional students perceive the quality of their college involvement (academic involvement, co-curricular involvement, social interactions, and faculty interactions) and college contribution toward their development (intellectual development, personal development, social development, and career development). This would contribute to understanding the relationship between quality of involvement and college contribution toward development. In addition, it may provide data on how these perceptions differ. Understanding these relationships and differences can facilitate the development of programs that would benefit each type of student. Furthermore, the perceptions of students gathered in this research can be used for planning by professionals in student services at the participating university.

\section{Limitations of the Study}

The limitations of this study are described below.

1. The sample $(n=400)$ selected for this study comes from one private Catholic liberal arts university in the Southeast. This allows for limited generalization. No 
attempts will be made to generalize beyond the institution being studied.

However, the research could still be useful to the participating institution's efforts to learn more about the perceptions of quality of involvement and college contribution toward development of its students.

2. The researcher's involvement in the study may be a limitation since the research is being conducted at the University where the investigator is employed. To avoid bias, the random selection of courses for participation was provided by the Office of the Registrar rather than through the researcher's office.

Furthermore, the researcher does not work directly with students, particularly in the classroom or with any student activities. Therefore, the likelihood that the students would be less critical in there responses is somewhat less. The researcher was clear in communication with students that this study was being conducted as part of her doctoral requirements at Florida International University. 3. The instrument being used gathers self-reported data from the participants. 4. This study included only successful students at the institution students with 24 or more credits completed at the institution.

\section{Definition of Terms}

Following are the definition of terms used for this research.

Nontraditional student. An undergraduate student who has at least one or more of Horn's (1996) characteristics defining nontraditional students presented on page two.

Traditional student. An undergraduate student who has zero of Horn's (1996) characteristics defining nontraditional students presented on page two. 
College involvement. Involvement in college is comprised of the physical and emotional effort that a student contributes to his or her college experience. Involvement includes academic and co-curricular experiences, as well as experiences with other students and faculty (Astin, 1975, 1999) and are sometimes referred to as college experiences in this study.

Quality. For the purpose of this research, quality refers to the ongoing transformation or development as a result of the student's college experience. Quality as transformation is a value-added term that measures quality in terms of the extent to which the educational experience enhances the knowledge, abilities and skills of students (Harvey \& Green, 1993a).

College contribution toward development. For the purpose of this research college contribution toward development consists of the institution's ability to impact, or contribute toward, student's knowledge and personal development (Astin, 1985). Further, the extent to which the college contribution enhances the knowledge, abilities and skills of students is viewed as a type of transformation (Harvey \& Green, 1993a). Organization of the Remaining Chapters

The remainder of the research study is presented in the following format. Chapter II consists of a literature review of the research related to the involvement of traditional and nontraditional students, as well as, the definition of these two types of students. Chapter III includes a description of the research methods and data used in the study. This description includes the sample, survey instrument, and statistical methods. Chapter IV of the study is composed of the results of the statistical analysis of the data in the study. Finally, Chapter V consists of a summary of the study, conclusions drawn in the 
study and discussion of findings, limitations, implications for theory and literature, and recommendations made for future student development research on nontraditional students.

\section{Summary}

While research exists on student involvement, much of the research on the impact of student involvement on student development is limited to traditional students. Furthermore, the quality of involvement experiences is not examined. The purpose of this study is to determine if there are differences between traditional and nontraditional undergraduate students in their perceptions of quality of college involvement and college contribution toward development. The framework for this study is based on the theory of student involvement and views of higher education quality, particularly transformative quality. 


\section{CHAPTER II}

\section{REVIEW OF RELATED LITERATURE}

The extensive amount of literature on student development theory in higher education can be perplexing. Astin (1999) pointed out,

One finds not only that the problems being studied are highly diverse but also that investigators who claim to be studying the same problem frequently do not look at the same variables or employ the same methodologies. And even when they are investigating the same variables, different investigators may use completely different terms to describe and discuss these variables (p. 518).

However, according to Pascarella and Terenzini (1991), research on efforts by student affairs organizations aimed at student development, once viewed as secondary, demonstrates increasing importance to an institution's vitality.

In this chapter, the past decade's research is presented that defines nontraditional students and how these students differ from traditional students in the way they experience college. Then, the existing research examining traditional and nontraditional college involvement (academic activities, co-curricular activities, student interactions, and faculty interactions) and its contribution towards development (intellectual, personal, social and career) is presented. At the conclusion of the chapter, a review and critique of the research literature is provided and followed by a brief summary and description of the remaining study.

\section{Defining Traditional and Nontraditional Students}

There are a number of parameters to consider when determining the difference between traditional and nontraditional students. First, specific characteristics that are paramount to the nontraditional student population should be considered when defining the nontraditional student. These characteristics should be inclusive of a student's social 
role. Furthermore, how traditional and nontraditional students differ in their college experiences should also be considered when examining what type of effect those experiences have on student development.

The most common use of the term 'nontraditional student' refers to older students, specifically over the age of 25 (Bishop-Clark \& Lynch, 1992). Many researchers define students using different age ranges such as age 25 and older, age 27 and older, or even age 30 and older (Donaldson, Graham, Martindill \& Long, 1999; Kasworm, 2003; Spitzer, 2000) while other researchers (Graham, 1998; Graham \& Gisi, 2000 ) group traditional as age 23 or younger and nontraditional as age 27 and older. Students age 24 to 26 are deleted, leaving out a significant population. Age is, however, too limiting a characteristic to use as the sole measure of "non-traditional." For example, a married student, age 23 , who works full-time might be defined as a traditional student if classifying by age alone.

Few studies go beyond using age when defining nontraditional students. Among them, Senter and Senter (1990) used an index scale when defining the nontraditional student. The research was based on a survey that was conducted in 1990 at a comprehensive state university in the midwest. The 1,687 surveys mailed yielded a $63 \%$ usable response. They examined and compared the needs and identities of traditional and nontraditional undergraduate students. These scores were on a 4-point scale (0-3) that included employment status, marital status, and parental status.

The nontraditional and traditional groups had very different objective social role index scores; a total of only $9.5 \%$ traditional undergraduates scored 1 to 3 on this index, while $77.6 \%$ of the nontraditional undergraduates had such scores (Senter \& Senter, 
1990). These results provide support that factors outside of age delineate traditional and nontraditional students. Further, certain needs were identified for nontraditional students. Senter \& Senter (1990) found that contrary to expectations, traditional students expressed higher levels of need for advisement than nontraditional students. They also expressed a need for evening and weekend courses and nontraditional student services (childcare, family recreation, and a nontraditional office) with the greatest need being an office that offers student services at nontraditional hours. Nontraditional students expressed less of a need for certain non-academic support services - career planning assistance, housing on campus, part-time work on campus, and orientation programs - than traditional students.

Another important finding that supports using social role to define nontraditional students was that nontraditional students who did not fit the social role of a nontraditional student and who viewed themselves as traditional students expressed the needs that were similar to traditional students as well. In other words, even though older in age, students who were single, had no dependents, and did not work viewed themselves and educational needs as a traditional student.

In a 1996 NCES study, Horn identified nontraditional students as having one or more of the following characteristics: (a) A student who delays enrollment and does not begin college in the same calendar year that he or she completes high school, (b) a student who attends part time for at least part of the academic year, (c) a student who is considered financially independent when determining financial aid eligibility, (d) a student who works full-time (at least 35 hours per week) while enrolled, (e) a student who has dependents other than a spouse, (f) a student who is a single parent (this includes married but separated with dependents), (g) a student who does not have a high school 
diploma and completed high school with a GED or other completion or did not complete high school. These criteria, not age, were used to identify students as traditional (zero characteristics), minimally nontraditional (one characteristic), moderately nontraditional (two to three characteristics), and highly nontraditional (four or more characteristics) (Horn, 1996). Using a method such as Horn's to define nontraditional student could be beneficial because it incorporates characteristics that are unique to this type of student. Further, it will help when conducting research that would provide information on how to meet the needs of these students.

College Involvement and Student Development

Several researchers have examined how college involvement contributes to the intellectual, personal, social and career development of undergraduate students (Cooper Healy \& Simpson, 1994; Graham \& Gisi, 2000; House, 2000; Kuh, 1995; Spitzer, 2000) particularly with regard to academic activities, co-curricular activities, peer interactions and faculty interactions of traditional students. It is critical to understand the importance of individuals with diverse backgrounds such as race, gender and nontraditional student status with regard to applying student development theories. A number of researchers have examined how traditional and nontraditional students' differ in the way they experience college (Bishop-Clark \& Lynch, 1992; Brookfied, 1999; Donaldson, Graham, Martindill \& Long; Kasworm, 2003; Meehan \& Negy, 2003; Woodside, Wong \& Dudley, 1999). The following is a review of the literature examining undergraduate students' academic involvement, co-curricular involvement, peer interactions, and faculty interactions. In addition to reviewing how these types of involvement contribute towards 
development, particular emphasis is placed on how these types of involvement differ for traditional and nontraditional students.

\section{Academic Involvement and Student Development}

A number of studies point out the impact of academic involvement on student development. Academic involvement includes both in-class and out-of-class activities related to coursework or learning. Kuh (1995) examined the out-of-class experiences that seniors associated with learning and personal development. This study contributed to the literature by identifying how involvement impacts student development. Kuh identified two research questions : (a) "To what activities, events, and people do students attribute their intellectual, social, and emotional development?" and (b) "Do the types of out-ofclass experiences associated with various outcomes differ by type of institution attended and such student characteristics as sex and ethnicity?" (p. 125). Participants consisted of 149 seniors from 12 institutions throughout the United States. Eighty-seven percent of participants were age 18-23. Kuh (1995) found gains in Knowledge and Academic Skills were associated primarily with academic activities (58.1\%) and faculty content (14.2\%). Furthermore, $20.8 \%$ of gains in Cognitive Complexity (thought and knowledge application) resulted from academic activities with the remainder coming from peers (21.5\%), other (17.3\%), ethos (14.9\%) and leadership responsibilities $(12.8 \%)$.

While Kuh's (1995) study was useful in identifying outcomes as a result of involvement, only $13 \%$ of the students were older than age 24 . Thus, it did not capture which out-of-class experiences were associated with the outcomes of more mature students. Furthermore, the study examined involvement within the context of a student's 
frequency of participation in experiences. It did not examine the effect of the student's perception of the quality of those experiences.

Another study, although examining traditional students, contributed to research on student involvement and outcomes. This study by House (2000) examined both class related experiences and out-of-class experiences and showed that student involvement was significantly related to drive to achieve in college, mathematical ability and writing ability. Participants were 2,134 college freshmen in the United States enrolled at a large university in the same fall semester. The students completed the Cooperative Institutional Research Program (CIRP) Annual Freshman Survey during an on-campus orientation. Data were collected on the number of hours per week spent doing the following four activities in the previous year: (a) Talking with teachers outside class, studying or doing homework, (b) reading for pleasure, (c) doing volunteer work, and (d) participating in student clubs and groups. Results indicated the following significant findings.

1. The number of hours per week spent reading was positively related to selfperceptions on writing ability, $r(2132)=.218, p<.01$.

2. Those who spent more hours reading the previous year had lower selfperceptions on their math ability, $r(2132)=.116, p<.01$.

3. Students who spent more hours per week during the previous year studying and doing homework had higher levels of drive to achieve, $r(2132)=-.124, p<.01$. These findings are beneficial in supporting the relationship of student involvement and developmental outcomes. However, this study did not examine the nontraditional student population nor did it examine the quality of students' experiences. 
While the findings of Kuh (1995) and House (2000) provide a foundation for research on student involvement and development, the nontraditional student is not considered. One study by Graham and Gisi (2000) did examine the effect of age on student involvement and development. In this study, they examined involvement on perceptions of academic outcomes. Data were collected from 64,647 college students at 154 colleges and universities in 35 states over a three year period from 1993 to 1996. Students completed the American College Testing (ACT) College Outcomes Survey (COS). Response rate was $55 \%$ (median across institutions). For students age 23 to 26 , records were deleted. This created a group of younger students less than 23 years old and a group of adult students age 27 or older. Students who completed less than 50 hours of credit were deleted from the sample (since looking for intellectual and cognitive changes during college). The final subgroup was 19,015 students. Involvement was measured by 11 items on the COS and categorized into four areas: course and other related learning, college organizations and activities, on- and off-campus work, off-campus community or cultural activities.

Course related activities had the highest percentage of participation in 11 or more hours per week for both younger (71.6\%) and adult (69.29\%) students. Results indicated that involvement in course related activities had a significant effect on gains in intellectual growth, $F(1,17297)=17.48, p<.0001$, for all students. Of the various developments being measured, both adult $(M=3.45)$ and younger $(M=3.42)$ rated intellectual development the highest. However, there was no significant interaction effect of age and involvement in course related activities on gains in intellectual growth, $F(1$, $17297)=0.86, p>.05$. In addition, involvement in course related activities also had a 
significant impact on gains in scientific reasoning, $F(1,17494)=50.27, p<.0001$, but no interaction effect with age, $F(1,17494)=0.61, p>.05$. Of the development items being measured, ratings of career development were similar for adult $(M=3.66)$ and younger $(M=3.60)$ students. Course related activities also had a significant impact on gains in career development, $F(1,17464)=47.25, p<.0001$, and again, no interaction effect with age, $F(1,17464)=2.15, p>.05$. Perhaps one reason for the lack of an interaction effect with age was due in part to the way Graham and Gisi (2000) grouped the students. Students age 23 to 26 were not examined because they were deleted. Thus, while this study examined adult students as compared to younger students, it cut out a population that would be defined as traditional and nontraditional by other standards such as Senter and Senter (1990) or Horn (1996), and whose responses may have made a difference in the research findings.

When considering nontraditional students' academic involvement, it is important to consider how their experiences might be unique. Bishop-Clark and Lynch (1992) found differences between the way in which nontraditional and traditional student experience academic involvement. The purpose of their study was to learn how nontraditional students, defined as age 25 or older, perceived their learning experiences and how to create a classroom environment that benefited both age groups. They conducted three focus groups with approximately five students in each group. An open ended discussion included topics on their most positive and negative experience in the classroom, the strengths and weaknesses that they brought to the college campus, their preferred method of learning, and their perception of the relationship between themselves, the faculty and younger students. 
Five themes were identified with regard to how adult students perceived their learning experiences. These themes were (a) feeling uncomfortable, (b) different orientations toward professors, (c) older students as authorities, (d) different learning styles, and (e) hostility between the age groups. Two of those themes tied directly to academic experiences. One theme, different learning styles, acknowledged that older students ranked the importance of subject matter by ability to further their goals and that job or life-related skills were important and they were less interested than traditional students in activities that were designed to increase general problem-solving skills (Bishop-Clark \& Lynch, 1992). While these themes were distinct, there were only 15 students contributing their perceptions.

Other research on academic experiences of nontraditional students reported support this relationship of work orientation and learning in the classroom. Kasworm (2003) also described differences in the way that nontraditional students interacted and experienced college. In her research, she investigated the perceptions of adult nontraditional students. Kasworm's specific research question was, "How do adults describe their learning engagement in the classroom and its relationship to their broader life involvements?” (p. 82). She interviewed 90 adult students (29 community college, 38 private liberal arts college and 23 university students). Focal points of the interview included: key beliefs, actions, and relationships associated with classroom learning. Kasworm also inquired about instructor and student relationships in and out of class. In addition, experiences reflecting the nature, relationships, and application of knowledge between collegiate learning and adult roles were examined. 
Three main constructs of meaning for these adult learners were found. The first construct was, "collegiate classrooms as the main focal point." In other words, for adult students the classroom was the main stage for the creation and negotiating of the meanings of collegiate learning. The second construct was, "learner views of knowledge in relationship to their adult life words." Adults described their learning in terms of different types of knowledge (i.e., academic, which included theory, concepts, etc. and real-world, which had immediate application and was learned by doing). The third construct was, "instructor actions and related program design elements." Students felt that meaning making was enhanced by instructors who integrated adult-identified prior knowledge (either in course or interpersonal engagements).

Adult learners negotiate the meaning of their undergraduate learning in elaborate and complex patterns, reflective of adults' epistemological beliefs that Kasworm (2003) identified as knowledge voices. She wrote,

These knowledge voices are characterized as academic and real-world knowledge, by individual adult goals for learning and related instructor actions and program context, and by the adult's sense of identities situated within life roles as the student role. In other words, the adult student's sense of identity is situated within the adult life (with multiple roles) and this carries over into the student role. Thus, students give meaning to negotiate sense of self and meaning based on multiple realities. Therefore, knowledge, to the adult student, is often categorized as academic or realworld by individual goals for learning (p. 92).

The academic literature reviewed here demonstrates that a number of academic experiences contribute toward intellectual development, math and writing ability, gains in cognitive complexity, and drive to achieve in college. However, the quality of students' experiences and how that impacts development needs to be examined. Furthermore, research on nontraditional students has indicated that their academic experiences differ 
from traditional students (Bishop-Clark \& Lynch, 1992; Kasworm, 2003). The classroom is the focal point for the nontraditional student. In addition, the nontraditional students focus on learning as it relates to work and advancing their goals. Since the literature points out these differences for nontraditional students, these parameters should be considered when understanding the literature that exists on college involvement and student development.

\section{Co-curricular Activities and Student Development}

Co-curricular activities have also been found to have an impact on student development (Cooper, Healy \& Simpson, 1994; Graham \& Gisi, 2000; House, 2000; Kuh, 1995). Co-curricular activities are comprised of out-of-class experiences such as clubs/organizations and cultural events. Cooper, Healy, and Simpson (1994) designed a study to examine the ways that students who are involved in student organizations and leadership positions change as they go through college. They found that students who were members of student organizations scored higher on developing purpose and autonomy compared to students with no extra-curricular involvement. They had all $(n=$ 1,193) first-time, traditional age students at a doctoral-level institution in the southeast complete the Student Developmental Task and Lifestyle Inventory (SDTLI) to measure developmental tasks such as Establishing and Clarifying Purpose, Developing Mature Interpersonal Relationships, and Academic Autonomy. When this group entered their third year of college, those students still enrolled $(n=752)$ were asked to complete the SDTLI Inventory again.

Results indicated that, as freshmen, students who planned to be involved in campus organizations scored higher on a Life Management, a subscale of Developing 
Purpose than those who did not plan to be members of organizations. As juniors, more significant differences surfaced. In addition to the Life Management, $F(1,247)=17.26$, $p<.05$, differences found in the freshmen year, members of student organizations scored higher on the subscales of Educational Involvement, $F(1,247)=22.19, p,<.0001$; Career Planning, $F(1,247)=9.46, p,<.05$; Lifestyle Planning $F(1,247)=21.04, p,<$ .0001; Cultural Participation, $F(1,247)=28.91, p,<.0001$; and Academic Autonomy, $F(1,247)=9.36, p,<.05$ (Cooper, Healy, \& Simpson, 1994). Furthermore, leadership experiences showed similar results with the exception that students who entered as leaders had significant scores across the subscales as freshmen and continued growth as juniors. While this study contributed findings that show the differences in leadership over time as a result of co-curricular experiences, it focused more on traditional students. Kuh's (1995) research (149 seniors from 12 institutions), mentioned earlier in the literature review, also demonstrated how co-curricular activities contribute to outcomes. His work showed that leadership responsibilities (49.0\%) and work (19.9\%) contributed to gains in practical competence. Leadership responsibilities also contributed to $12.8 \%$ of gains in cognitive complexity (though and knowledge application). Further, compared with students of color (38.9\%), white students $(54.5 \%)$ attributed more gains in practical competence to leadership abilities. As pointed out earlier, these findings contribute to literature on student development and involvement, but have a small proportion of mature students. Also the study examined frequency of involvement in activities rather than students' perceptions of the quality of those experiences.

In his research of 2,134 college freshmen from a large university, House (2000) also found gains related to co-curricular activities. His research showed that increased 
participation in student clubs/groups had slight correlations with self-perceptions on drive to achieve, $r(2132)=.146, p<.01$, writing ability, $r(2132)=.144, p<.01$, and with their self-confidence in their intellectual ability, $r(2132)=.141, p<.01$. In addition, increased involvement in volunteer work was related to self-perceptions of their drive to achieve, $r(2132)=.124, p<.01$, and to their self-confidence in their intellectual ability, $r(2132)=$ $.141, p<.01$ (House, 2000). Again, while these findings support the importance of involvement toward student development, the nontraditional student was not included in the research. As with Kuh's (1995) research, the study looked at the frequency of involvement in activities rather than students' perceptions of the quality of those activities.

Research has shown that even small amounts of participation have a positive impact on student development. When examining types of involvement, Graham and Gisi (2000) found that involvement in college clubs and organizations had one of the lowest percentages of participation in 11 or more hours per week for both younger $(9.08 \%)$ and adult $(2.33 \%)$ students. Still, although low in terms of the amount of time spent participating, they found that involvement in college organizations and activities along with off-campus community or cultural activities had an impact on gains in intellectual growth, $F(1,17232)=133.86, p<.0001$, for both traditional and nontraditional students. There was also a significant interaction effect of involvement and age, $F(1,17232)=6.99, p<.0001$. Adult students reported greater intellectual development as a result of college organizations/activities and off-campus community or cultural activities. However, when asked to report the amount of time per week devoted to these activities ( 1 to 5 hours, 6 to 10 hours, or 11 or more hours), $32 \%$ of adults 
invested as few as 1 to 5 hours per week toward clubs/organizations. Forty-three percent of adults spent only 1 to 5 hours per week for off-campus community and $46 \%$ of adults spent 1 to 5 hours a week toward cultural activities. On the other hand, $72 \%$ adult students spent 11 or more hours per week caring for family. Although the adult students spent more time with family obligations and less time involved in clubs/organizations and cultural activities, the small amount of time they did spend had a significant relationship with development, greater than for traditional students. Perhaps another aspect, such as quality of those experiences, plays a role in this development.

\section{Student Interactions and Student Development}

A number of researchers have examined peer interactions and impact on student development. These student interactions include interactions in and out of the classroom for both academic and social reasons. In examining out-of-class experiences associated with student learning and personal development, Kuh (1995) (149 seniors from 12 institutions) found that the strongest gains in interpersonal competence (self-awareness, social competence, self-esteem, and autonomy) were associated with student peer interactions (24.3\%), followed by specific leadership responsibilities $(20.9 \%)$. This was especially true for traditional aged students. The largest proportion $(21.5 \%)$ of gains in cognitive complexity (reflective thought and knowledge application) was associated with peers. Further, gains in humanitarianism (heightened concern for the welfare of others) were attributed primarily to interactions with peers (45.4\%) and leadership responsibilities $(27.1 \%)$.

Whitt, Edison, Pascarella, Nora and Terenzini (1999) also found that interactions with peers had significant relationships to cognitive outcomes. They randomly sampled 
3,840 first-year students at 23 colleges and universities. Using a number of assessment methods including the National Study of Student Learning (NSSL) and the College Student Experience Questionnaire (CSEQ) they conducted a longitudinal study of the factors that influence learning and cognitive development. Results indicated that peer interactions focusing on course-related issues had significant positive effects on gains in thinking and writing skills, understanding science, and academic preparation for career (Whitt, et. al. 1999). Furthermore, peer interactions focusing on non-course related issues had significant positive effects on understanding the arts and humanities, and on understanding self and others. These findings support the importance of student interactions and their relationship with student development. However, as with Kuh's (1995) research, the findings are limited to traditional students.

Spitzer (2000) also found that social interactions, in the form of support, contribute to student outcomes. He examined traditional and nontraditional students with regard to student success. Prior to this study, the variables of academic self-efficacy, intrinsic motivation, and self-regulation had only been researched with traditional college students and younger students. The purpose of Spitzer's (2000) study was to predict college grade point average (GPA) and career decidedness (an individual's certainty with their career decision) for both traditional and nontraditional students. The predictor variables used were five personal dimension variables (academic self-efficacy, global self-worth, social acceptance, career decision making self-efficacy, and social support) and two learning dimension variables (intrinsic motivation and self-regulation).

Participants were 355 full-time undergraduate students at a private liberal arts college. There were 267 traditional (age 23 and under) students and 88 nontraditional 
(age 25 and older) students. Participants completed seven questionnaires and a demographic sheet. Spitzer (2000) found that when predicting career decidedness, social support and being female were positive predictors for both traditional and nontraditional students, $F(4,340)=39.48, p<.0001$. However, results also indicated that being a traditional student, scoring high on both global self-worth and social acceptance negatively influenced GPA. In addition those traditional students who reported high social acceptance (good social skills) had the most indecision with regard to their career.

A study by Lundberg (2004) demonstrated similar findings regarding students frequency and quality of peer and faculty interactions and learning development of employed students. She used a national sample of 3,774 undergraduate students to compare students who were not employed, students who were employed 20 or fewer hours a week, and students who were employed more than 20 hours a week. Overall, results indicated that students who were employed more than 20 hours a week were less engaged with peers and faculty than students who worked less than 20 hours a week or did not work at all. The one exception was regarding 'discussing ideas with others.' Lundberg (2004) found no difference in the reported amount of 'discussing ideas with others' based on work status. Furthermore, although the students who worked more than 20 hours were less involved, there was no difference in learning outcomes.

As demonstrated by Kuh (1995) Whitt et. al. (1999), Spitzer (2000), and Lundberg (2004), social interactions contribute to the development of traditional and nontraditional students. However, Spitzer's research also showed that higher social acceptance of traditional students had some negative effects on GPA and career decidedness. This might be due, in part, to the fact that traditional and nontraditional 
students differ in how they experience social interactions. For nontraditional students, peer relationships are critical to receiving the necessary moral support to succeed in college (Brookfield, 1999). He created themes of adult students' experiences on campus. These themes appeared over and over across the diverse populations and educational settings that he surveyed. Further, they spoke to issues and concerns of adult students that "contradicted 'inspirational rhetoric' that surrounds discourse on adult learning (a smoothly flowing voyage along a river of increased self-actualization...learners wreathed in smiles of beatific gratitude for how teachers have transformed their lives" (Brookfield, 1999, p. 11).

One of the most significant themes was regarding what Brookfield called "community." He found that adults attested to the importance of belonging to an emotionally sustaining peer learning community. This was a group of peers who had undergone similar experiences and shared similar feelings in college. This "membership in a learning community" was spoken of by adult students as a second family and was mentioned more consistently than anything else. Adult students felt that the peers in their community were the only people who really understood what one another was going through and the community served as a support to their college success.

This theme of community and how it contributes to college success was also found and described in research of adult students conducted by Donaldson, Graham, Martindill and Long (1999). They interviewed seven students, age 27 years or older, at a Baccalaureate College II institution and six students at a Research I institution to find out (a) how adult undergraduate students defined success in college, and (b) what factors adult undergraduate students believed contributed to their success as they defined it. 
These students defined success in two distinct ways. First, they defined what Donaldson, et. al. (1999) call college success. This type of success included external judgments for success such as completing a degree, making good grades, meeting instructor's expectations, etc. Second, students defined success in learning in terms of their own ownership of knowledge and standards and the degree to which they actualized this learning. Students described the importance of peer-relationships that were developed in the classroom. Donaldson, et. al. (1999) pointed out:

Although these peer relationships provided them with a way to engage socially, they also noted that before class, in class, during breaks, and after class, interactions with peers went beyond the social to focus on learning course subject matter. They recounted experiences of talking about content during breaks, and learning from peer descriptions of how content manifested itself in work experiences (p. 18).

The nature of those relationships was clearly oriented towards success in learning. Students characterized those interactions as social interactions that revolved around learning and class rather than to develop social relationships (Donaldson, Graham, Martindill \& Long, 1999).

Social or peer relationships are also critical to the academic adjustment of married students. A study of undergraduate students conducted by Meehan and Negy (2003), revealed significant findings regarding social interactions of students. Seventy-nine married and 192 unmarried undergraduate students from a public, metropolitan university completed a number of instruments measuring adaptation to college, marital/relationship satisfaction, social support and life stressors. With a cutoff correlation of .30 for interpretation of the structure coefficients, MANOVA results indicated that married students who had relatively high levels of social support from friends and family had 
better academic adjustment, $r(79)=.52, p<.05$; social adjustment, $r(79)=.91, p<.05$; and personal-emotional adjustment, $r(79)=.82, p<.05$; relative to married students with less social support (Meehan \& Negy, 2003). This social support for married students, was attributed to family, $r(79)=.52, p<.05$, and friends, $r(79)=.90, p<.05$, while support from the married student's spouse did not have a significant correlation with adjustment to college, $r(79)=.22, \mathrm{p}>.05$. Thus, social support is essential to the adjustment to college for married students.

While the findings of Kuh (1995) and House (2000) provide evidence that social interactions are related to student development, they did not examine nontraditional students or quality of experiences. However, other research (Brookfield, 1999; Donaldson, et. al.1999; Meehan \& Negy, 2003; Spitzer, 1999) that includes nontraditional students demonstrates that social interactions are important to student development and success. In addition, these studies show that the way in which traditional and nontraditional students interact with other students is different. Nontraditional student interactions are more oriented towards community and support as it relates to the college experience.

\section{Faculty Interactions and Student Development}

Student-faculty interactions also have an impact on student development. These in-class and out-of-class interactions occur for course learning, advising, or social reasons. These interactions could also be social in nature. When looking at traditional students, Kuh (1995) found that the smallest amounts of growth in cognitive complexity were associated with academics and faculty contact. However, women (27.1\%) reported more contacts than men $(16.9 \%)$ with faculty and with gains in cognitive complexity 
(reflective thought and knowledge application). Only about five percent of the outcomes reported by the students were attributed to contacts with faculty. Students of color attributed a higher proportion of their gains in knowledge and academic skills to contacts with faculty than their white counterparts ( $7.0 \%$ and $4.4 \%$ respectively). Further, the research conducted by House (2000) showed that the number of hours spent talking with teachers outside of class had a weak relationship with self-perceptions of creativity, $r(2132)=.147, p<.01$, drive to achieve $r(2132)=.138, p<.01$, and to self-confidence in their intellectual ability, $r(2132)=.134, p<.01$. As mentioned previously, House's (2000) study contributed to the literature on student development. However, like Kuh's (1995) research, House's (2000) study did not include nontraditional students in the sample nor did it examine quality of experiences.

In another study that did examine traditional and nontraditional students on student-faculty interactions, Woodside, Wong and Dudley (1999) surveyed students age 18 to 56 to examine how interactions with faculty were related to student self-concept. Participants included 106 females and 70 males from a mid-sized university in southern California. Students completed a survey that asked them to describe teacher verbal and nonverbal immediacy behaviors (e.g., smiles, gestures, uses humor). The students also answered questions on academic performance (most recent midterm score). Results showed that teacher behaviors significantly predicted students' midterm scores, $F(2,173)$ $=7.838, p<.01$, and students' perceptions of scholastic confidence $F(2,173)=11.802, p$ $<.01$. There was no analysis done to account for differences between traditional and nontraditional students. 
A study conducted by Rosenthal, Folse and Alleman (2000) found no difference in the way traditional and nontraditional students initiate student-faculty interactions. The purpose of their research was twofold. First, to determine if students felt that one-toone interactions affected their performance in the course and evaluation of the professor. Second, to compare the responses of traditional and nontraditional students.

Nontraditional students were defined according to a sorority for non-traditional students, Order of Athena, as students over age 25, and/or married, and/or with children. Subjects $(n=193)$ were volunteer undergraduates at a small southern university. Some received extra credit for their participation. Students wrote narratives describing their most positive and negative interactions with a faculty member.

Rosenthal, et. al. (2000) reported that there was no difference in the tendency to initiate student-faculty contact between students who experienced positive interactions with faculty and students who did not experience positive interactions. Also, students who recorded a positive interaction reported significantly higher satisfaction with interactions with all faculty, $F(1,189)=8.30, p<.01$. Likewise, students who reported negative experiences reported lower satisfaction, $F(1,189)=10.64, p<.01$. There was no significant difference between traditional and nontraditional students in tendencies to initiate one-to-one interactions or with satisfaction with faculty. Further, there was no difference between either group to the extent they felt a positive or negative interaction would affect their performance for the course or affect their student evaluations of the professor. In fact, Rosenthal, et. al. (2000) concluded that nontraditional and traditional students may be more similar than thought of with regard to faculty interaction variables. 
While traditional and nontraditional students did not differ in the patterns of initiating student-faculty interactions, when examining peer-faculty interactions by work status, rather than age, Lundberg (2004) found that students who worked 20 or more hours a week were less engaged with faculty than those who worked fewer than 20 hours per week or did not work at all.

Furthermore, there are differences in the way nontraditional students perceive the nature of these interactions. A study mentioned earlier by Lynch and Bishop-Clark (1998) examined the experiences of nontraditional students at a large Midwestern university on the main campus (where only $5 \%$ of the population is age 25 or older) and on two branch campuses (where $40 \%$ of the population is age 25 or older). They conducted a telephone survey of 272 students, age 25 or older, asking questions regarding three categories: comfort in the mixed-age classroom, perceptions of student-professor relationships with traditional and nontraditional students, and attitudes toward traditional and nontraditional students. Lynch and Bishop-Clark (1998) found significant differences in the perceptions of the student-professor relationship between main and branch campus students. Students on the main campus felt that professors treated younger students differently, geared the design of classes toward younger students, geared lectures toward younger students, and did not realize the out-of-class responsibilities of older students.

The findings of Kuh (1995) and House (2000) reveal the importance of studentfaculty interactions as it relates to knowledge, intellectual ability, drive to achieve and other outcomes. However, both studies focused primarily on traditional students. Neither study examined quality of experiences. Furthermore, while student-faculty 
interactions demonstrate success in academic performance (Woodside, et. al. 1999) and satisfaction with professors (Rosenthal, et. al. 2000), there was no difference found in initiation patterns of these types of interactions (Rosenthal, et. al. 2000).

\section{Summary}

Literature defining nontraditional students was presented in this review and followed with an examination of how they differ from traditional undergraduate students in the way they experience involvement in college. Findings presented in this review identified four involvement variables (academic activities, co-curricular activities, student interactions and faculty interactions) and four areas of student development (intellectual, personal, social and career) that college involvement contributes toward. Research identifying how nontraditional students are unique in their college experiences was also presented. Following is a brief summary of the literature that has been presented as it relates to the rationale for conducting this study.

\section{Nontraditional Students}

It is critical to understand the importance of individuals with diverse backgrounds such as race, gender and age when applying student development theories. As Strange (1999) pointed out, students differ in how they construct and interpret their experiences, and such differences offer important guides for structuring the educational process. These different interactions need to be understood in order to create programs and services that foster student development.

As indicated earlier, the nontraditional student population continues to grow. These students, aside from being different in age, differ on other characteristics as well. They differ on employment status, marital status, and parental status (Senter \& Senter, 
1998), as well as financial status and enrollment styles (Horn, 1996). According to the results of Senter and Senter's (1998) social role index to measure nontraditional status, $77.6 \%$ of nontraditional undergraduate students typically had characteristics such as being employed full-time, being married, and being a parent while only $9.5 \%$ of traditional students had at least one of these characteristics. In rare instances, researchers defined nontraditional students according to age and social characteristics (Rosenthal, et. al. 2000; Senter \& Senter, 1998). Current research is needed that examines the nontraditional student by characteristics typical of these students rather than age alone. This will help in identifying and understanding these students as well as in developing programs that meet the actual needs of nontraditional students.

Although the college population has changed in terms of demographics, research has not kept up with the change to address the various populations such as nontraditional students. Rather, insights on student involvement are still drawn from the traditional student population (House, 2000; Kuh, 1995), while nontraditional has not been addressed as much. Even with recent studies of nontraditional students, researchers are still categorizing nontraditional students solely by age (Graham, 1998; Graham \& Gisi, 2000), particularly with regard to research on involvement theory. Even those studies that have examined traditional versus nontraditional students by age, the cut off age that determines traditional or nontraditional has varied from study to study. Graham and Gisi (2000) defined traditional as students age 22 and under and nontraditional as age 27 or older. Students age 23 to 26 were deleted from the study. Meanwhile, Donohue and Wong (1997) defined the nontraditional student as age 25 and older. For the purpose of this research, social role will be used to define traditional and nontraditional students. In 
doing so, all ages would be represented and the results would be more useful in helping to better understand how involvement contributes toward development.

\section{Student Involvement}

Among those who have researched involvement, the amount of involvement activities a student engages in has been found to be positively related to growth in development (Astin, 1993; Astin, 1999; Donaldson \& Graham, 1999; Kuh, 1995). However, because quality can be difficult to define, research has been limited to measuring the numbers of activities rather than measuring some form of quality of those experiences (Astin, 1993; 1999; Donaldson \& Graham, 1999; Kuh, 1995). For example, Graham and Gisi (2000) stated limitations due to the fact that they looked at quantity/time of involvement, not quality of those experiences. Only one study, by Lundberg (2004) examined quality of student relationships to faculty, peers and administrators. However this study did not examine the quality of students college experiences. As indicated in Chapter I, the quality of a student's experience is important as it relates to their transformation (Harvey \& Green, 1993a) and is a reflection of the quality of the college (Astin, 1985). Thus, more research is needed examining the quality of students' experiences and development.

It is clear that the needs and experiences of the nontraditional student differ from traditional students (Bishop-Clark \& Lynch, 1992; Donaldson \& Graham, 1999; Kasworm, 2003; Senter \& Senter, 1998). Nontraditional students differ in the way they get involved, in the way they interact with faculty and in the classroom, and the way they make meaning of their college experiences. The small amount of research conducted on this population (Graham, 1998; Graham \& Gisi, 2000) indicated positive relationship 
between involvement and academic development. More research of nontraditional students is needed to examine the relationship of quality of involvement and development.

Studies on involvement of nontraditional students are usually investigated within the framework of traditional students (Donaldson \& Graham, 1999). While both the traditional and nontraditional student will be involved, the ways in which they will be involved can differ. For example, when involved with peers, traditional students interact in a more social role whereas nontraditional look to "communities" for learning and support. Because of this difference, traditional and nontraditional students may differ in the way they perceive the quality of involvement as well. Therefore, measurement of involvement should include items that take into account the ways in which the nontraditional student is involved and how that might make a difference in his or her development and seek to examine perceptions of quality of those experiences.

\section{Organization of Remaining Chapters}

Research of perceptions of quality of student involvement and perceptions of college contribution toward development is presented in the remainder of this study. Measuring perceptions of quality of college involvement is unique to this study as well as the way in which nontraditional and traditional students will be defined using social role. How quality of involvement impacts college contribution toward development will be explored. Chapter III of the study includes a description of the research methods followed in the study. The methods described include the research design, population and sample, instrumentation, pilot testing, procedures, treatment and coding of the data, and analysis of data. Chapter IV of the study is composed of the results of the statistical 
analysis of the data in the study. Finally, Chapter V provides a discussion of the conclusions drawn in the study, implications for theory, implications for practice, and recommendations made for future student development research on nontraditional students. 


\section{CHAPTER III}

\section{METHODS}

Using the rationale of involvement theory as a foundation, the purpose of this study was to determine if there are differences between traditional and nontraditional undergraduate students in their perceptions of quality of college involvement and college contribution toward development. More specifically, using a social role score (Horn, 1996; Senter \& Senter, 1998) to define traditional and nontraditional students at a private Catholic university in South Florida, the objective of this research was to (a) examine if perceptions of the quality of college involvement differ for nontraditional undergraduate and traditional undergraduate students and, (b) examine if perceptions of college contribution toward intellectual, personal, social and career development differ for traditional undergraduate and nontraditional undergraduate students and, (c) examine if the relationships between the quality of college involvement (academic activities, cocurricular activities, student interactions, and faculty interactions) and college contribution toward development (intellectual, personal, social and career) differ for traditional undergraduate and nontraditional undergraduate students.

The specific research questions are as follows:

1. Do perceptions of quality of college involvement (academic activities, cocurricular activities, student interactions, and faculty interactions) differ for traditional and nontraditional undergraduate students?

2. Do perceptions of college contribution toward development (intellectual, personal, social and career) differ for traditional and nontraditional undergraduate students? 
3. Do the relationships between quality of college involvement (academic activities, co-curricular activities, student interactions, and faculty interactions) and perceived college contribution toward development (intellectual, personal, social and career) differ for traditional and nontraditional students?

This chapter includes the methods used to answer the aforementioned research questions. The methods described include the research design, population and sample, instrumentation, pilot testing, procedures, and treatment and analysis of data.

\section{Research Design}

The type of research design selected for this research was an ex post facto $2 \times 4$ repeated measures Analysis of Variance (ANOVA) study. ANOVA is used to identify relationships between criterion variables and predictor variables and is used to identify and measure the various sources of variation within a collection of data (Kachigan, 1991). For this study, the effect of one factor on two criterion variables was examined. For the first question, the effect of student type (traditional vs. nontraditional) on quality of involvement types (academic, co-curricular, interactions with other students, and interactions with faculty) was examined. For the second question, the effect of student type (traditional vs. nontraditional) on college contribution toward development (intellectual, personal, social and career) was examined. For the third question, correlations between quality of involvement and college contribution toward development were calculated and compared for traditional and nontraditional students.

This study was based on earlier research done on involvement theory (Astin, 1993; Graham, 1998; Graham \& Gisi, 2000; and Kuh, 1995). This study differed from previous work by using a definition of nontraditional students that was based on social 
role characteristics. In addition, students' perceptions of quality of involvement were measured rather than the numbers of times they get involved in different experiences. This research also measured how quality of involvement relates to college contribution toward development.

\section{Population and Sample}

The site chosen for this study conducted in 2004 was a private, liberal arts, Master's I Catholic university located in South Florida. There are 8,649 students with an undergraduate population of 2,595 enrolled in the regular semester system on the main campus. The university has a diverse undergraduate student body. The gender composition on the main campus is $72.8 \%$ female and $27.2 \%$ male. The ethnic classification is $18.2 \%$ black non-Hispanic, $1.6 \%$ Asian/Pacific Islander, $34.7 \%$ Hispanic, $27.2 \%$ white non-Hispanic, and $10.3 \%$ unknown. The distribution of class level is $27.5 \%$ first year, $18 \%$ second year, $26.1 \%$ third year, and $28.4 \%$ fourth year with $90 \%$ of the students attending full-time. Sixty-five percent of the students are commuters with the remaining $35 \%$ living on campus. Enrollment by school on the main campus is $40 \%$ Arts and Sciences, $14.5 \%$ Business, 3.3\% Education, 9.5\% Human Performance and Leisure Sciences, $15.3 \%$ Natural and Health Sciences, $16 \%$ Nursing, and $1.4 \%$ Social Work. With regard to enrollment status, $89.8 \%$ of undergraduates are enrolled full-time and $9.2 \%$ are enrolled part-time.

From this population, a random cluster sample of classes equaling 400 undergraduate students was selected for participation. Using PASS (a power program) to find sample sizes for a correlational analysis where correlations were at least $.3\left(r^{2}=\right.$ 
$10 \%)$, and controlling for Type I error at .005 (.05/16 correlations), sample sizes of 200

for each group of traditional and nontraditional students yielded $84 \%$ power.

Since the purpose of the study was to examine undergraduate students'

perceptions of college contribution toward development, it was necessary to survey students who have had at least completed their first year at the college. Therefore, only sophomore level and higher courses were selected. In addition, students who had not completed 24 or more credits at the institution were instructed not to complete the survey. Finally, since the nature of varied length semester programs are different, to avoid confounding, only courses in the regular semester system were included in the sample.

Courses in the trimester or quarterly semester terms were excluded from the selection of courses.

\section{Instrumentation}

As Strange (1999) pointed out, students differ in how they construct and interpret their experiences, and such differences offer important guides for structuring the educational process. Students' self-reported perceptions of their academic ability and development (House, 2000; Terenzini, Theophilides \& Lorang, 1984; Pike, 1995) have been reliably related to their college experiences. Further, when it comes to measuring quality, particularly transformative quality, feedback from the learners is a crucial aspect of evaluation. "Students should be both at the center of the process by which learning is evaluated and at the center of the learning process" (Harvey \& Green, 1993b, p. 23).

Outcomes such as changes in attitudes and values and gains in development cannot be measured by achievement tests (Gonyea, Kish, Kuh, Muthiah \& Thomas, 2003).

Therefore, students were asked to complete a two-part survey. 
The items used to identify involvement and college contribution toward development were selected based on previous research conducted (Astin, 1993; Graham, 1998; Graham \& Gisi, 2000; Kuh, 1995). The College Involvement and Student Outcomes Survey used to collect data consists of a two-part survey instrument that measures perceptions of quality of involvement and college contribution toward development. Items for both the involvement variables (academic activities, cocurricular activities, student interactions, and faculty interactions) and development variables (intellectual development, personal development, social development, and career development) originated from the fourth edition of the College Student Experiences Questionnaire (CSEQ) (Pace \& Kuh, 1998). Permission was granted to use the selected items and modify the instructions for the purpose of this research. The permission letter can be found in Appendix A.

Reliability and Validity of CSEQ Items

The CSEQ has demonstrated evidence of reliability with the experience scale alpha coefficients ranging from .74 to .92 and developmental gains factor alphas ranging from .78 to .87 . Furthermore, content validity and construct validity were also demonstrated using factor analysis and correlations between experience and outcome items (Gonyea, et. al. 2003). They also confirmed the validity of self-reported data and stated:

Student self-reports are valid under five conditions: 1 . respondents should be able and willing to provide accurate information, 2. questions should be about recent behavior, 3 . questions should not explore sensitive, potentially embarrassing areas, 4 . questions should be phrased clearly and unambiguously, and 5. respondents should take the questions seriously and thoughtfully. Experience over two decades indicates that these conditions are met by the CSEQ (p. 24-25). 
A description of items pulled from the CSEQ to create parts A and B of the College Involvement and Student Outcomes Survey is presented below. The items for parts A and B of the survey are presented here by variable. However, since respondents rate similar items of a similar topic the same when formatted within a section, the items were not grouped together on the survey instrument. A table of specific survey items, grouped by construct, can be found in Appendix B.

\section{College Involvement and Student Outcomes Survey Part A}

To measure the independent variables of the study, part A of the instrument contains 37 items that measure the quality of involvement (academic involvement, cocurricular involvement, student interactions, and faculty interactions).

Following is a summary of the items that were used:

1. To measure quality of academic activities, nine items were used from the "College Activities Course Learning" section of the CSEQ. These items include questions about experiences related to: completing assignments for class, fitting facts and ideas together, applying class material, etc.

2. To measure quality of co-curricular activities, five items were used from the “College Activities Campus Facilities" and "College Activities Clubs \& Organizations" sections of the CSEQ. These items included questions about experiences related to: attending cultural events, attending campus club/organization meetings, using campus recreational facilities, etc.

3. To measure quality of student interactions, students were asked 10 items that came from the "College Activities Student Acquaintances" section of the CSEQ. 
These items included questions about experiences related to: interacting with students from a different culture, types of discussions with students, etc. In addition, two student created items were added regarding interactions with students socially and for moral support. These items were added based on research of Brookfield (1999) that indicated that nontraditional students' interactions with other students were more supportive than social.

4. To measure quality of faculty interactions, students were asked 10 items that came from the "College Activities Experiences with Faculty" section of the CSEQ. These items included questions about experiences related to: discussions with faculty members, types of feedback from faculty, etc.

\section{Part A Survey Modifications}

As indicated earlier, quality is a value-laden term. "For this reason, linking an activity to quality may serve to validate or justify it irrespective of what the notion of quality might mean” (Harvey \& Green, 1993a, p. 9). Input and output indicators cannot really provide information regarding quality of a student's experience, particularly as it relates to his or her transformation, in higher education. In order for quantities to tell anything about qualities, some sort of judgment must take place (Barnett, 1992). Further, it is necessary to clearly define, as much as possible, the criteria used by each interest group when judging quality (Harvey \& Green, 1993b).

Therefore, the following two modifications were made to the instructions and scale on the items used from the CSEQ in order to fit the purpose of this research. First, the original CSEQ items instructed the student to report how often he or she had participated (very often, often, occasionally, never) in the involvement activities. Since 
the purpose of this research was to examine perceptions of quality of those experiences, the instructions were changed to read "In your experience at this institution up to this point in time, how would you rate the overall quality of the following activities/experiences as they relate to contributing to the transformation of your overall development? Using a scale of 1 to 7 , where 1 is poor quality and 7 excellent quality, indicate your response by shading one of the boxes to the right of each statement. Please answer all questions." Second, the original CSEQ rating scale was changed from a 4point scale (never, occasionally, often very often) to a 7-point scale with 1 being poor quality and 7 being excellent quality. The revised scale was based on other CSEQ items that asked students to rate quality of interactions with students, faculty and advisors.

\section{College Involvement and Student Outcomes Survey Part B}

To measure the dependent variables of the study, part B of the instrument was created to collect data on college contribution toward development (intellectual development, personal development, social development, and career development). Following is a summary of the 21 items that were used:

1. To measure intellectual development, seven items from the "Estimate of Gains" section of the CSEQ were used. These items included questions about acquiring knowledge, thinking analytically and logically, etc.

2. To measure personal development, three items from the "Estimate of Gains" section from the CSEQ. These items included questions about developing ethics and standards, and understanding abilities, etc. In addition to expand the items for personal development, two student created items were added regarding taking responsibility for one's own behavior and increasing spiritual maturity. 
3. To measure social development, two items from the "Estimate of Gains" section of the CSEQ were used. These questions were about getting along with other people and functioning as a member of a team. In addition, to expand on social development, four student created items were added regarding the ability to get along with other cultures, acquiring social skills to interact with others, etc.

4. To measure career development, three items were used from the "Estimate of Gains" section of the CSEQ. These items were regarding knowledge and information gained toward a vocation or career.

\section{Part B Survey Modifications}

Since the purpose of this survey instrument was to gather information on perceptions of the college contribution toward development, two modifications were made to the instructions for these items. First, the instructions asked the student to report the extent to which he or she made progress in development (very much, quite a bit, some, very little). Since the purpose of this research was to have the student rate the extent that the college contributed to his or her development, the instructions were modified to read "In thinking about your college experience up to now, please indicate the extent of the college's contribution (through your college experiences both in and out of class) toward your development of the following items. Indicate your responses by shading in one of the boxes to the right of each statement. Please answer all questions." Second, the original rating scale was changed from a 4-point scale (very little, some, quite a bit, very much) to a 5-point Likert scale by adding 'none' as an option. This change was warranted because the purpose of this research was to gather perceptions of college contribution toward development. Therefore, the possibility might exist that a 
student felt that the college did not contribute toward his or her development on a particular item. Should the student perceive that the college did not contribute toward a particular area of development, those perceptions wanted to be captured by the researcher.

\section{Additional Survey Items}

Based on the nontraditional characteristics used by Senter (1998) and Horn (1996) to define nontraditional students, the survey also included one question about employment status (full-time, part-time, or not employed) and seven dichotomous questions: (a) Did you start college during the same calendar year that you finished high school? (yes or no); (b) Do you attend college at least part-time for at least part of the academic year? (yes or no); (c) What is your marital status (married or not married); (d) Do you have dependents other than a spouse? (yes or no); (e) Are you considered financially independent for purposes of being eligible for financial aid? (yes or no); (f) How did you complete high school? (Diploma or GED/Other).

These criteria were used to identify students as traditional (zero characteristics), minimally nontraditional (one characteristic), moderately nontraditional (two to three characteristics), and highly nontraditional (four or more characteristics) (Horn, 1996). For the purposes of this research, groupings will consist of traditional (zero characteristics) or nontraditional (one or more characteristics).

Finally, this instrument also contained basic demographic items such as gender, race/ethnicity, school affiliation, class level, type of student (resident/commuter) and fullor part-time status variables to ensure that the sample is representative of the population it 
was drawn from. The College Involvement and Student Development Outcomes Survey can be found in Appendix C.

\section{Pilot Testing of Survey}

Since modifications were made to the instructions and scales of the survey instrument, a face validity test was deemed necessary in order to ensure that the general format of the instrument, its instructions, and wording of the items were clear, unambiguous and relevant to the purposes of the investigation. Therefore, a pilot test was done with the survey. Following is a description of the procedures for testing. Procedures for Pilot Testing

The 35 pilot survey participants were randomly selected from four undergraduate courses at a private university in South Florida. These courses were volunteered by a professor for participation. Students were given a "Pilot Instructions Sheet" that provided information on the intended use of the survey and asking them to complete the survey being aware of the clarity of wording for instructions and items along with the importance and relevance of each item. Students were also given a rating sheet to rate instructions and wording, add additional questions and make any other modifications or deletions. Pilot Instructions Sheet and Pilot Rating Sheet can be found in Appendices D and $\mathrm{E}$.

Response Rate and Results of Pilot Study

Thirty of 35 surveys were completed and returned creating a response rate of $85.7 \%$ (Five students chose not to complete the survey). For the 30 surveys returned, 28 pilot rating sheets were completed and two were returned blank. Twenty-seven of the 28 participants responded 'Yes' to the question, "Are the instructions and wording of the 
items on the survey clear?" One student responded "No." In addition, students were asked to note any changes that they thought were necessary. One comment asked for clarification on how to mark the response scale. Therefore, text, at the end of the instructions was added to the instrument stating "Indicate your response by shading in one of the boxes to the right of each statement." Students were also asked to list any additional items that they believed were important college experiences or important development. Comments indicated that the items in the survey were adequate and no additions were needed. Lastly, students were asked to indicate other modifications, additions or deletions, that they felt should be made to the survey. Comments indicated that the survey needed no additional modifications, additions, or deletions. All comments for the pilot rating sheet can be found in Appendix F.

Due to the modifications made to the instrument, it was necessary to assess reliability of how each set of individual items measures the four involvement and four development variables outlined previously in the Instrumentation section. Cronbach alpha coefficients were produced for all complete cases of the pilot responses. All coefficients were higher than .7 indicating moderate or higher reliability. Table 1 displays the results of this analysis.

Procedure

Before starting the research, the application for approval of research involving human subjects and research proposal were submitted to the both the researcher's University and the participating University's Institutional Review Board for approval. The research was deemed exempt by both institutions and approved. Letters can be found in Appendix G. 
Table 1

Alpha Coefficients for Student Involvement and Student Development Constructs

\begin{tabular}{lll}
\hline Construct & Number of Items & Coefficient
\end{tabular}

Academic Activities

Co-curricular Activities

Student Interactions

Faculty Interactions

Intellectual Development

Personal Development

Social Development

Following approval to begin research, 19 course sections of sophomore and upper level classes were selected from the University Registrar's course listings. These sections equaled 400 enrolled students. In order to keep the sample size 400 , only 12 of the 23 students enrolled in one class were surveyed. The instructors of the courses selected were contacted by the researcher via telephone or email providing information on the study and the date that the researcher would like to distribute the surveys in class. In addition, they were informed that participation was voluntary and should they choose not to include their class, another would be randomly selected.

Upon approval from the instructor, the surveys were distributed by the researcher, completed by the students in the class, and collected in class on the date specified. In some cases, the instructor chose to let the researcher distribute the surveys but collection 
would be done by the instructor during the next class. Each student received an envelope containing the two-part College Involvement and Student Development Survey, a cover letter, and a pencil to complete the survey. The cover letter notified the participants of the purpose of the study, explained that participation was voluntary and that responses would be anonymous, that is, no names or other identifiers would be collected on any of the instruments used.

The cover letter informed the student that he or she had been selected for participation in the study and that participation was voluntary. It described the nature of the study and asked them to complete the survey. It provided instructions for completing and returning the survey to the researcher. It also instructed the students not to write their name or student ID on the survey in order to keep the responses anonymous. The cover letter is found in Appendix $\mathrm{H}$.

At the request of the institution where the research is being conducted, the data collected is to be kept for a period of five years in a locked file cabinet located in the researcher's office. Data will be used by the institution to examine aggregate perceptions of quality on individual items such as classroom and co-curricular activities. At the end of five years, the data will be destroyed.

\section{Data Treatment and Analysis}

SPSS for Windows (version 12.0) was used for recoding data, analyzing descriptive statistics and analyzing inferential statistics in this study. Descriptive statistics were created using the variables of gender, race/ethnicity, age, school affiliation, class level, and full- or part-time status variables. This allowed the researcher to compare the sample from the population from which it was drawn to ensure that the sample is 
representative of the population it was drawn from. Frequencies were also conducted for each of the variables that were used to define the nontraditional student (employment status, marital status, dependents, completion of high school, financial independence, and enrollment status). In addition, after recoding, frequencies were run for student type and for number of nontraditional characteristics that the students had.

Since the factors suggested by the CSEQ were being examined for confirmatory purposes and the instrument was modified, the principle components extraction method with oblimin rotation method (delta set at .0 ) was employed. A factor analysis was used to confirm the structures used to form the involvement variables (academic activities, cocurricular activities, student interactions, and faculty interactions) and the development variables (intellectual development, personal development, social development, and career development). The principle components extraction method determines the factors that account for the total variance in a set of variables and is appropriate for most social science research purposes (University of Wisconsin-Milwaukee, 2002). The oblimin rotation method is an oblique rotation procedure that is used in confirmatory factor analysis when theory suggests that factors are correlated (University of WisconsinMilwaukee, 2002).

To establish inter-item reliabilities, Cronbach alpha coefficients were used on the survey items with complete cases. This allowed the researcher to assess reliability of how each set of individual items measures the four involvement and four development variables. The value of the coefficient is a function of the reliability among items within a construct. If the items are ambiguous or lack consistency, the coefficient values should be smaller (Green, Salkind, \& Akey, 2000). 
Data Coding

Following is a description of the data coding.

Type of student. Variables were created for type of student (Nontraditional and Traditional). Nontraditional students were coded as 1 . These students had at least one or more of the following characteristics: (a) Did not begin college in the same calendar year that he or she completed high school, (b) attended part time for at least part of the academic year, (c) was financially independent when determining financial aid eligibility; (d) worked full-time while enrolled, (e) had dependents other than a spouse, (f) was a single parent, (g) did not have a high school diploma and completed high school with a GED or other completion or did not complete high school. Traditional students, those who had zero of the aforementioned characteristics, were coded as 2 .

Student involvement variables. In order to conduct statistical tests, four student involvement variables were created by computing four separate scores for academic activities, co-curricular activities, student interactions, and faculty interactions. The academic activities score was computed by averaging the scores of the nine questions pertaining to that item. The co-curricular activities score was computed by averaging the scores of the five questions pertaining to that item. The student interactions score was computed by averaging the scores of the 10 questions pertaining to that item. The faculty interactions score was computed by averaging the scores of the 10 questions pertaining to that item. This resulted in an average score for each variable.

Student development variables. In order to be able to conduct statistical tests, the same procedures done to create the involvement variables were applied to the development variables. Four student development variables were created by computing 
four separate scores for intellectual development, personal development, social development, and career development. This was done by averaging the scores of the items pertaining to each development variable (intellectual development had eight items, personal development had nine items, social development had six items, and career development had three items).

\section{Null Hypotheses}

Based on the review of the literature, the following null hypotheses were used to test the research questions of the study.

$\mathrm{H}_{01}$ : There are no interaction effects due to the four involvement types and student type (traditional vs. nontraditional).

$\mathrm{H}_{02}$ : There are no interaction effects due to the four development types and student type (traditional vs. nontraditional).

$\mathrm{H}_{03}$ : The correlation coefficients between the four involvement types and the four development types for traditional students are equal to those for nontraditional students.

\section{Data Analysis}

To determine if nontraditional students differed from traditional students in the way quality of involvement is perceived for the four involvement types, a $2 \times 4$ repeated measures ANOVA using the General Linear Model repeated measures analysis was employed with type of student as the between-subjects factor and the four involvement types (academic, co-curricular activities, other students, and faculty) as the withinsubjects factor. A Mauchly's Test of Sphericity was conducted to test the sphericity assumption. If the assumption is satisfied, the $p$ value would be greater than .05 and sphericity is assumed. The results of the test showed that the sphericity assumption was 
not satisfied, $W_{M}(5)=.74, p<.05$. Therefore, a Huynh-Feldt correction was used to produce a valid F-ratio. Tests were declared significant if $p<.05$. When one or more of the main effects were significant, post-hoc Holm's Sequential Bonferroni pairwise comparisons were conducted.

To determine if nontraditional students differed from traditional students in the way college contribution toward development is perceived for the four development types, a 2 X 4 repeated measures ANOVA using the General Linear Model repeated measures analysis was employed with type of student as the between-subjects factor and the four development types (intellectual growth, personal growth, social growth, and preparation for career) as the within-subjects factor. A Mauchly's Test of Sphericity was conducted to test the sphericity assumption. If the assumption is satisfied, the $p$ value would be greater than .05 and sphericity is assumed. The results of the test showed that the sphericity assumption is not satisfied, $W_{M}(5)=.81, p<.05$. Therefore, a HuynhFeldt correction was used to produce a valid F-ratio. Tests were declared significant if $p$ $<.05$. When one or more of the main effects were significant, post-hoc Holm's Sequential Bonferroni pairwise comparisons were conducted.

To determine if the relationships between quality of college involvement (academic, co-curricular activities, student interactions, and faculty interactions) and perceived college contribution toward development (intellectual, personal, social and career) differed for traditional and nontraditional students, Pearson correlations were computed between the four involvement types and the four development types for each student type (traditional and nontraditional) and tested for significance. Then each correlation was transformed to a normalized distribution using the Fisher's $r$-to- $z$ 
transformation (Wendorf, 1997). This was calculated by using the following formula where $\log _{\mathrm{e}}$ is the natural logarithm and $r$ is the sample correlation: $z^{\prime}=.5 \log _{\mathrm{e}}(1+r) /(1-$ $r$ ). The standardized scores for both traditional and nontraditional students were tested for differences using the following formula: $z=\left(z_{1}^{\prime}-z_{2}^{\prime}\right) / \sqrt{\left(1 / n_{1}-3\right)+\left(n_{2}-3\right)}$ (Wendorf, 2004). Since multiple comparisons were being conducted, the Holm's Sequential Bonferroni method was used for control of Type 1 errors (Green, et. al. 2000).

\section{Summary}

This chapter consisted of methods used to test the hypotheses and investigate the perceptions of quality of college involvement on perceptions of college contribution toward development of traditional and nontraditional students. Student involvement (academic activities, co-curricular activities, student interactions, and faculty interactions) and development items (intellectual, personal, social, and career) were selected from the CSEQ and created into a survey instrument to gather the data for the study. The instructions of the instrument were modified to ask students to rate the quality of the experience rather than report the number of times they participated in the activity. The survey was piloted to 35 students to ensure that the general format of the instrument, its instructions, and wording of the items were clear, unambiguous and relevant to the purposes of the investigation. The survey was distributed to a random cluster sample of sophomore and higher level undergraduate classes equaling 400 undergraduate students. SPSS for Windows (version 12.0) was used for analyzing descriptive and inferential statistics in this study. To establish inter-item reliabilities, Cronbach alpha coefficients were used on the survey items with complete cases. A factor analysis was used to provide the structures that will form the involvement factors and the development factors. 
The null hypotheses for the research questions were tested using $2 \times 4$ repeated measures ANOVAs and Fisher tests using $r$ to $z$ transformations. Chapter IV of the study consists of the results of the statistical analysis of the data in the study. 


\section{CHAPTER IV}

\section{ANALYSIS OF THE DATA AND FINDINGS}

The type of research design selected for this research was an ex post facto $2 \mathrm{X} 4$ repeated measures Analysis of Variance (ANOVA) study. The data were gathered with self-reported survey items originating from the fourth edition of the College Student Experiences Questionnaire (CSEQ) (Pace \& Kuh, 1998). A list of the items selected can be found in Appendix A. The purpose of this study was to determine if there were differences between traditional and nontraditional undergraduate students in their perceptions of quality of college involvement and college contribution toward their development. The involvement variables included in the analyses were academic involvement, co-curricular involvement, student involvement, and faculty involvement. The development variables included in the analyses were intellectual, personal, social, and career.

The specific research questions are as follows:

1. Do perceptions of quality of college involvement (academic activities, cocurricular activities, student interactions, and faculty interactions) differ for traditional and nontraditional undergraduate students?

2. Do perceptions of college contribution toward development (intellectual, personal, social and career) differ for traditional and nontraditional undergraduate students?

3. Do the relationships between quality of college involvement (academic activities, co-curricular activities, student interactions, and faculty interactions) 
and perceived college contribution toward development (intellectual, personal, social and career) differ for traditional and nontraditional students?

This chapter presents data gathered to address the aforementioned research questions. First, the survey response rate is presented and is followed by an overview of the demographic characteristics of the respondents. Second, the factor analysis of the survey is presented and followed by the Cronbach alpha coefficients for each factor. Third, results of a $2 \times 4$ repeated ANOVA conducted to compare traditional and nontraditional students on the involvement variables are presented. Fourth, results of a 2 X 4 ANOVA conducted to compare traditional and nontraditional students on the development variables are compared. Fifth, correlation matrices are presented for the quality of college involvement factors with the college contribution toward development factors for traditional and nontraditional students and tested for differences by type of student (traditional versus nontraditional).

\section{Survey Response Rate}

This research study surveyed 400 students enrolled in the regular semester courses of a private, liberal arts, Master's I university located in South Florida. Of the 400 surveys distributed, 257 were returned. Of the surveys returned, 26 were excluded for being blank (12), having very few questions answered (3), or the student indicated he or she was a first year student (11). After exclusions, there were 241 usable surveys for this study. As indicated in Table 2, the response rate was $60 \%$. Weather conditions of 2004 hampered the ability to get more than a $60 \%$ response rate. Faculty agreed to allow the researcher to survey students in their courses over a two week period. Halfway through data collection, the university where data were being gathered closed two days 
Table 2

Survey Responses

Type of Response Number Percent

Surveys distributed

400

100

Surveys returned

257

64

Surveys excluded

26

7

Usable surveys

241

60

for hurricanes and then had a holiday closing. During the third week faculty allowed the researcher to collect data for classes that had been missed due to closing. Because of time missed in class, the majority of the instructors chose to allow the researcher to distribute the survey in class but not collect them. The faculty member agreed to collect the surveys back during the next class and return them to the researcher. During the fourth week classes were closed again for two days due to another hurricane. At the start of each week, for the fourth through eighth week following survey distribution, a reminder was made to faculty who had not returned surveys for their class. By the ninth week, no surveys had been returned for a two week period. To avoid any further disturbance to the faculty, the researcher decided to close the collection period and begin analysis.

\section{Description of the Respondents}

The last page of the survey had 7 questions that asked demographic information. Among the 241 usable returned surveys, 4 were missing the answer to the gender 
question, 12 were missing the answer to the ethnicity question, 5 were missing answers to the student status question, 6 were missing answers to the class question, and 3 were missing answers to the credit hours question. Tables 3 through 6 display the demographic characteristics.

As shown in Table 3, there were a higher proportion of female respondents than male respondents. This distribution reflects the composition of the population from which it was sampled. Of undergraduate population, $72.8 \%$ are female and $27.2 \%$ male. Table 3

Gender of the Respondents

\begin{tabular}{lcc}
\hline Gender & Number & Percent \\
\hline Male & 55 & 23.2 \\
Female & 182 & 76.8 \\
Total & 237 & 100.0 \\
\hline
\end{tabular}

Table 4 shows that the respondents' diverse ethnic composition is representative of the undergraduate body at the Hispanic Serving Institution from which the sample was drawn. The Integrated Postsecondary Education Data System (IPEDS) enrollment report for the university showed that ethnicity classifications were $18.2 \%$ black non-Hispanic, $1.6 \%$ Asian/Pacific Islander, $34.7 \%$ Hispanic, $27.2 \%$ white non-Hispanic, and $10.3 \%$ other/unknown. While the sample appears to be lower in terms of Hispanic/Latino/Chicano, this research has more classifications than the IPEDS system and the IPEDS report has a much larger "other/unknown" proportion. Overall, the 
Table 4

Ethnicity of the Respondents

Ethnic Category Number Percent

$\begin{array}{lcr}\text { African American/Black } & 44 & 19.2 \\ \text { American Indian/Alaskan Native } & 0 & 0.0 \\ \text { Asian American/Pacific Islander } & 3 & 1.3 \\ \text { Caribbean/Atlantic Islander } & 26 & 10.8 \\ \text { Caucasian/White } & 73 & 30.3 \\ \text { Hispanic/Latino/Chicano } & 52 & 21.6 \\ \text { Multi-racial/Multi-ethnic } & 22 & 9.1 \\ \text { Other } & 9 & 3.7 \\ \text { Total } & 229 & 100.0\end{array}$

sample is representative in terms of diversity.

Table 5 presents the respondent data with respect to attendance and resident status. Student status was also representative of the population from which it was drawn. At the participating institution, sixty-five percent of the undergraduate population commutes while $35 \%$ are resident students. The question asking, "How many credits are you enrolled for this semester?" was used to determine full- or part-time status. Students enrolled in less that 12 credits were considered part-time. Students enrolled for 12 or more credits were considered full-time. The part-time status of the respondents was underrepresented by approximately $5 \%$. At the institution where the research was 


\section{Table 5}

Attendance and Resident Status

\begin{tabular}{lcc}
\hline Status & Number & Percent \\
\hline Attendance & & \\
Full-Time & 55 & 3.8 \\
Part-Time & 229 & 97.2 \\
Total & 238 & 100.0 \\
Residence & & \\
Resident & 91 & 38.6 \\
Commuter & 145 & 61.4 \\
Total & 236 & 100.0 \\
\hline
\end{tabular}

conducted, undergraduate students were enrolled full-time and $9.2 \%$ were enrolled parttime.

Table 6 shows the school representation of the respondents. While all schools were represented, Arts \& Sciences and Natural \& Health Sciences were slightly overrepresented while Business and Nursing were under-represented. The university undergraduate enrollment percentages for each school are as follows: $40 \%$ Arts and Sciences, $14.5 \%$ Business, 3.3\% Education, 9.5\% Human Performance and Leisure Sciences, $15.3 \%$ Natural and Health Sciences, $16 \%$ Nursing, and $1.4 \%$ Social Work. In addition to the demographic items, the last page of the survey included 7 items that were used to determine traditional or nontraditional student type. Among the 241 
Table 6

School of the Respondents and Population

School

Number

Percent

Population Percent

Arts \& Sciences

109

46.6

40.0

Business

16

6.8

14.5

Education

6

2.6

3.3

Human Performance \& Leisure

Sciences

19

8.1

9.5

Natural \& Health Sciences

51

21.8

15.3

Nursing

30

12.8

16.0

Social Work

3

1.3

1.4

Total

100.0

100.0

usable returned surveys, 4 were missing the answer to the marital status, 18 were missing the answer to dependent status, 5 were missing the answer to the start college question, 6 were missing the answer to the employment question, 5 were missing the answer to the attend part-time question, 3 were missing the answer to the financially independent question, and 4 were missing the answer to the high school completion question. Tables 7 through 10 show the frequencies for those items.

Table 7 presents the marital status and number of dependents of the respondents. The responses of the students indicated that $89.5 \%$ of the respondents were not married while $10.5 \%$ were married or had been married. Respondents were also asked the question, "Other than a spouse, do you have one or more dependents?" Eighty-four 
Table 7

Marital Status and Number of Dependents of the Respondents

\begin{tabular}{lcc}
\hline Status & Number & Percent \\
\hline Marital Status & & \\
Not Married & 212 & 89.5 \\
Married & 18 & 7.6 \\
Separated & 1 & 0.4 \\
Divorced & 6 & 2.5 \\
Widowed & 0 & 0.0 \\
Total & 238 & 100.0 \\
Dependents & & \\
Yes & 33 & 14.8 \\
No & 190 & 84.2 \\
Total & 223 & 100.0 \\
\hline
\end{tabular}

$(84.2 \%)$ of respondents did not have one or more dependents other than a spouse, while only $14.8 \%$ had or more dependents.

Table 8 presents how the respondents completed high school and when they started college. All but two students received a high school diploma and three-quarters $(75.4 \%)$ indicated that they did not start college in the same calendar year that they finished high school. Table 9 shows that $87.3 \%$ of respondents indicated they attended college part-time at some point during the academic year. 
Table 8

Completion of High School College Start Date

\begin{tabular}{lcc}
\hline Answer & Number & Percent \\
\hline High School & & \\
Diploma & 235 & 99.2 \\
GED/Other & 2 & 0.8 \\
Total & 237 & 100.0 \\
Started College & & \\
Yes & 178 & 75.4 \\
No & 58 & 24.6 \\
Total & 236 & 100.0 \\
\hline
\end{tabular}

Table 9

Part-Time Enrollment of the Respondents

\begin{tabular}{|c|c|c|}
\hline Answer & Number & Percent \\
\hline Yes & 206 & 87.3 \\
\hline No & 30 & 12.7 \\
\hline Total & 236 & 100.0 \\
\hline
\end{tabular}

Table 10 shows the employment status and financial independence of the respondents. More than half (59.1\%) were employed either part-time or full-time while $40.9 \%$ were not employed. Respondents were asked the question, "Are you considered 
Table 10

Respondents' Employment Status and Financial

Independence

\begin{tabular}{lcc}
\hline Status & Number & Percent \\
\hline Employment & & \\
Not employed & 96 & 40.9 \\
Part-Time & 111 & 47.2 \\
Full-Time & 28 & 11.9 \\
Total & 235 & 100.0 \\
Financial Independence & & \\
Yes & 46 & 19.3 \\
No & 192 & 80.7 \\
Total & 238 & 100.0 \\
\hline
\end{tabular}

financially independent for purposes of being eligible for financial aid?" Eighty-one (80.7\%) percent of the respondents were not considered financially independent for financial aid eligibility purposes.

In order to compare students by student type, students needed to be coded as traditional or nontraditional. Table 11 shows the number of traditional and nontraditional students after classification based on social role characteristics. Half of the respondents (51.9\%) had at least one of the nontraditional student characteristics. Of the 241 surveys, 27 could not be coded as traditional or nontraditional due to missing values. 
Table 11

Traditional and Nontraditional Status of the Respondents

\begin{tabular}{lcc}
\hline \multicolumn{1}{c}{ Status } & Number & Percent \\
\hline Traditional & 103 & 48.1 \\
Nontraditional & 111 & 51.9 \\
Total & 214 & 100.0 \\
\hline
\end{tabular}

Rather than using age, students were defined as traditional or nontraditional based on the following nontraditional characteristics identified by Senter and Senter (1998) and Horn (1996): (a) He or she is employed full-time, (b) he or she did not start college during the same calendar year that he or she finished high school, (c) he or she attends college at least part-time for at least part of the academic year, (d) he or she is or has been married; (e) he or she has at least one or more dependents other than a spouse, (f) he or she is considered financially independent for purposes of being eligible for financial aid, and $(\mathrm{g})$ he or she completed high school by other means than a diploma. Students having none of these characteristics were defined as traditional. Students with one or more of these characteristics were defined as nontraditional.

Table 12 shows the number of nontraditional characteristics of the respondents. Slightly under half of the respondents $(48.1 \%)$ had zero characteristics. These students were nontraditional. However, $24.8 \%$ of the respondents had one of the nontraditional characteristics while and $24.8 \%$ had two characteristics. Although some students had 
Table 12

Number of Nontraditional Characteristics of the Respondents

\begin{tabular}{lcc}
\hline \multicolumn{1}{c}{ Characteristics } & Number & Percent \\
\hline Zero & 103 & 48.1 \\
One & 53 & 24.8 \\
Two & 32 & 15.0 \\
Three & 14 & 6.5 \\
Four & 8 & 3.7 \\
Five & 3 & 1.4 \\
Six & 1 & 0.5 \\
Seven & 0 & 0.0 \\
Total & 214 & 100.0 \\
\hline
\end{tabular}

three or four characteristics $(10.2 \%)$, very few had 5 characteristics or more $(1.9 \%)$. All students with one or more characteristics were considered nontraditional.

Factor Structure of the Survey

The instructions and scales for the involvement items pulled from the fourth edition of the CSEQ instrument were modified. Therefore, a principal component factor analysis was applied to the 37 items related to the involvement variables included in the survey (i.e., 9 items measuring academic, 5 items measuring co-curricular, 12 items measuring student, and 10 items measuring faculty). Tables 13 and 14 display the factor loadings for the involvement variables. 
For the involvement items, initially 9 factors resulted with eigenvalues greater than or equal to one. After examination of sharp declines in the scree plot and initial interpretation of the factors, the factor analysis was re-run with extraction for five variables. As a result of this analysis, five factors were obtained. Table 13 displays the loadings for the involvement factors. Eight items measuring academic involvement loaded on the second factor and showed coefficients of correlation with the factor from .43 to .71 . Five co-curricular involvement items loaded on the fifth factor and showed coefficients of correlation from .37 to .84 . Seven items measuring social student involvement ("became acquainted with") loaded on the fourth factor and showed coefficients of correlation with the factor from .52 to .74 . Five items measuring more serious types of student involvement (i.e. "had serious discussions") loaded on the first factor with coefficients of correlation with the factor from .75 to .87 . Nine items measuring faculty involvement loaded on the third factor and showed coefficients of correlation with the factor from .25 to .62 .

Overall the items loaded on the same factor as they did with the CSEQ with one exception. While the results of the CSEQ formed four factors for these items (academic, co-curricular, student interactions, and faculty interactions), the results of this factor analysis formed two student interaction factors. One factor represented more serious interactions with other students (i.e., "had serious discussions") while the other student interaction factor represented more social types of interactions with other students (i.e., "became acquainted with" or "interacted for social reasons"). However, both of these factors include student interactions, albeit two types of interactions. The results of this analysis provide evidence to confirm validity for the scales measuring the involvement 


\section{Table 13}

Principle Components Factor Loadings for Involvement Items

Factor Item

Loading

Involvement Factor 1 (Academic)

Developed a role play, case study, or simulation for class.

0.71

Summarized major points and information from your class notes or readings.

Tried to see how different facts and ideas fit together.

Applied material learned in a class to other areas (your job or internship, other courses, relationships with friends, family, co-workers, etc.).

Contributed to class discussions.

Completed assigned readings for class.

Took detailed notes during class.

Worked on a class assignment, project, or presentation with other students.

Worked on a paper or project where you had to integrate ideas from various sources.

Involvement Factor 2 (Co-curricular)

Worked on a campus committee, student organization or project (publications, student government, special event, etc.).

Attended a meeting of a campus club, organization, or student government group.

Managed or provided leadership for a club or organization, on or off the campus.

Became acquainted with students whose interests were different from yours. 
Table 13 Continued

Principle Components Factor Loadings for Involvement Items

Factor Item

Loading

Attended a cultural or social event in the campus center or other campus location.

Used campus recreational facilities (pool, fitness equipment, courts, etc.).

Involvement Factor 3 (Student - Social)

Interacted with other students for social reasons not related to class.

Interacted with other students to give or receive moral support with regard to college.

Became acquainted with students whose age was different from yours.

Became acquainted with students whose family background (economic, social) was different from yours.

Became acquainted with students whose race or ethnic background was different from yours.

Became acquainted with students from another country.

Involvement Factor 4 (Student - Serious)

Had serious discussions with students from a country different from yours.

Had serious discussions with students whose race or ethnic background was different from yours.

Had serious discussions with students whose philosophy of life or personal values were very different from yours.

Had serious discussions with students whose religious beliefs were very different from yours. 
Table 13 Continued

Principle Components Factor Loadings for Involvement Items

Factor Item

Loading

Had serious discussions with students whose political

opinions were very different from yours.

0.75

Involvement Factor 5 (Faculty)

Worked harder as a result of feedback from an instructor.

0.73

Discussed your academic program or course selection

with a faculty member.

Talked with your instructor about information related to a course you were taking (grades, make-up work, assignments, etc.).

Discussed your career plans and ambitions with a faculty member.

Asked your instructor for comments and criticisms about your academic performance.

Worked harder than you thought you could to meet an instructor's expectations and standards.

Worked with a faculty member on a research project.

Discussed ideas for a term paper or other class project with a faculty member.

Socialized with a faculty member outside of class (had a snack or soft drink, etc.).

Participated with other students in a discussion with one or more faculty members outside of class.

constructs. Therefore, the four involvement constructs of academic involvement, cocurricular involvement, social involvement, and student involvement were used for the research. 
The instructions for the development items pulled from the fourth edition of the CSEQ instrument were also modified. Therefore principal component factor analysis was applied to the 21 items related to the development variables included in the survey (i.e., 7 items measuring intellectual development, 5 items measuring personal development, 6 items measuring social development, and 3 items measuring career development). As a result of this analysis, three factors were obtained. Table 14 displays the factor loadings for the college contribution toward development variables. As with the CSEQ results, the personal development and social development items loaded on one factor. For this sample, 5 personal development items and 6 social development items loaded on the first factor and showed loadings with the factor from .60 to .86 . All but one of the 7 items measuring intellectual development loaded on the second factor and showed loadings with the factor from .35 to .82 . The item, "Developing good health habits and physical fitness" loaded on intellectual gains for the CSEQ. However, the results of the factor analysis on this sample, it had a loading of .06 with the intellectual development factor. Instead, for this sample, health loaded onto the personal/social factor. It had a loading of .65 with that factor. There were three items measuring career. All three items measuring career development loaded on the third factor and showed loadings from .62 to .84 . With the exception of health, the items loaded on the same three factors as they did with the CSEQ. The results of this analysis provide evidence to confirm factorial validity for the scales measuring the development constructs. Four college contribution toward development constructs were examined in this research (intellectual development, personal development, social development, and career development). 
Table 14

Principle Components Factor Loadings for Development Items

Factor Item

Loading

Development Factor 1 (Intellectual)

$\begin{array}{ll}\text { Writing clearly and effectively. } & 0.82\end{array}$

Thinking analytically and logically. $\quad 0.78$

Presenting ideas and information effectively when speaking to others.

Putting ideas together, seeing relationships, similarities, and differences between ideas.

Learning on your own, pursuing ideas, and finding information you need.

Using computers and other information technologies.

Developing good health habits and physical fitness. 0.06

Development Factor 2 (Social/Personal)

Developing the ability to get along with different kinds of people.

Developing the ability to function as a member of a team. $\quad 0.80$

Becoming more responsible for your own behavior. $\quad 0.76$

Understanding yourself, your abilities, interests, and personality.

Appreciate and respect other cultures. $\quad 0.75$

Acquiring appropriate social skills for use in various situations. $\quad 0.75$

Developing your own values and ethical standards. $\quad 0.75$

Learning to adapt to change (new technologies, different jobs or personal circumstances, etc.). 
Table 14 Continued

Principle Components Factor Loadings for Development Items

Factor Item

Loading

Becoming a more effective member in society.

Becoming more open to different points of view.

Increasing your spiritual maturity.

Development Factor 3 (Career)

Acquiring background and specialization for further education in a professional, scientific, or scholarly field.

Gaining a range of information that may be relevant to a career.

Acquiring knowledge and skills applicable to a specific job or type of work (vocational preparation).

0.70

\section{Reliability Analyses}

The results of factor analysis should not be used alone when making decisions on inclusion to or exclusion of an item from a measure. Rather, the results should be used in conjunction with what is known about the construct that the items assess (Green, et. al. 2000). Therefore, Cronbach alpha coefficients were calculated for all complete cases of the survey responses. Table 14 displays the alpha coefficient values for this study. For this sample, all coefficients were higher than .75 indicating moderate or higher reliability.

\section{Survey Results}

To measure the independent variables of the study, part A of the instrument asked students to rate the quality of involvement (academic, co-curricular, student, and faculty) 
Table 15

Alpha Coefficients for Involvement and Contribution toward Development Constructs

Construct

Number of Items

Coefficient

Academic Involvement

9

5

12

10

Faculty Involvement

Intellectual Development

Personal Development

Social Development

Career Development
.77

.80

.91

.83

.86

.87

.89

3

on 37 items. The rating scale used was 1 to 7 with 1 being poor quality and 7 being excellent quality. To measure the dependent variables of the study, part B of the instrument asked students to rate the college's contribution toward development (intellectual, personal, social, and career) on 21 items. A five point likert scale was used ranging from none to very much. Appendix I presents tables with descriptive statistics for each involvement item on part A and each development item on part B.

Quality of Involvement

Four involvement areas were measured (academic, co-curricular, student, and faculty). The item with the highest quality rating for academic involvement was for taking detailed notes during class $(M=5.81)$. Developing a role play, case study, or 
simulation for class received the lowest rating of quality for academic involvement $(M=$ 3.76). For co-curricular involvement items, the item with the highest quality rating was regarding attending cultural or social events $(M=4.10)$. Managing or providing leadership for a club or organization received the lowest co-curricular involvement rating of quality $(M=3.33)$. The two items with the highest student involvement quality ratings were becoming acquainted with students from another country $(M=5.79)$ and becoming acquainted with students whose ethnic background was different from yours $(M=5.79)$. Having serious discussions with students whose political opinions were different received the lowest rating of quality for student involvement $(M=4.05)$. Lastly, with regard to faculty involvement, the item with the highest quality rating was for working harder from instructor's feedback $(M=5.46)$. Working with a faculty on research had the lowest rating $(M=2.73)$. Appendix I displays the means and standard deviations for all of the involvement items on the survey.

\section{College Contribution toward Development}

Four development areas were measured (intellectual, personal, social, and career). For intellectual development, the item with the highest contribution toward development rating was for learning on your own, pursuing ideas and finding information $(M=4.26)$. Developing good health habits and physical fitness had the lowest contribution toward intellectual development rating $(M=3.63)$. The item with the highest contribution toward personal development rating was for becoming more responsible for your own behavior $(M=4.29)$. Increasing spiritual maturity had the lowest contribution toward personal development rating $(M=3.55)$. The item with the highest contribution toward social development rating was for appreciating and respecting other cultures $(M=4.44)$. 
Becoming a more effective member of society received the lowest contribution toward social development rating $(M=4.00)$. The item with the highest contribution toward career development rating was for acquiring background and specialization for further education in a professional, scientific, or scholarly field $(M=4.10)$. Acquiring knowledge and skills applicable to a specific job or type of work had lowest contribution toward career development rating $(M=3.79)$. Appendix I displays the means and standard deviations for all development items on the survey.

\section{Perceptions of Quality of Involvement}

One of the purposes of this study was to examine if perceptions of the quality of college involvement differ for nontraditional undergraduate and traditional undergraduate students. Null hypothesis one stated that there were no interaction effects due to the four involvement types and student type (traditional vs. nontraditional). To determine if nontraditional students differed from traditional students in the way quality of involvement was perceived for the four involvement types, a $2 \times 4$ repeated measures ANOVA was employed. Type of student (traditional or nontraditional) was entered as the between-subjects factor and the four involvement types (academic, co-curricular activities, other students, and faculty) as the within-subjects factor.

There was a significant main effect of perceptions of quality of involvement, $F(2.30$, $428.4)=101.64, p<.001$. The significant main effect of perceptions of quality of involvement was further analyzed by pairwise comparisons using the Holm's Sequential Bonferroni method. All six pairwise comparisons were significant. In other words, for all students, ratings of quality differed across the four involvement types. Table 16 shows that the largest difference in ratings of quality was between academic 
Table 16

Means and Standard Errors for Quality of Student Involvement Variables

Involvement Variables

Student Type

Academic

Co-Curricular

Student

Faculty

Traditional $(n=93)$

5.11

$4.16_{2}$

$5.23_{2}$

4.63

$(0.09)$

$(0.16)$

(0.13)

(0.12)

Nontraditional $(n=95)$

5.23

$3.31_{1}$

$4.75_{1}$

4.51

(0.09)

(0.16)

(0.13)

All Students $(n=188)$

$5.17_{d}$

$(0.07)$

$3.74_{\mathrm{a}}$

$(0.12)$

$4.99_{\mathrm{c}}$

(0.09)

$4.57_{\mathrm{b}}$

(0.08)

Note: Means in a row with differing subscripts are significantly different using Holm's Sequential Bonferonni test, $p<.05$. Means in a column with differing numeric subscripts are significantly different using Holm's Sequential Bonferonni test, $p<.05$.

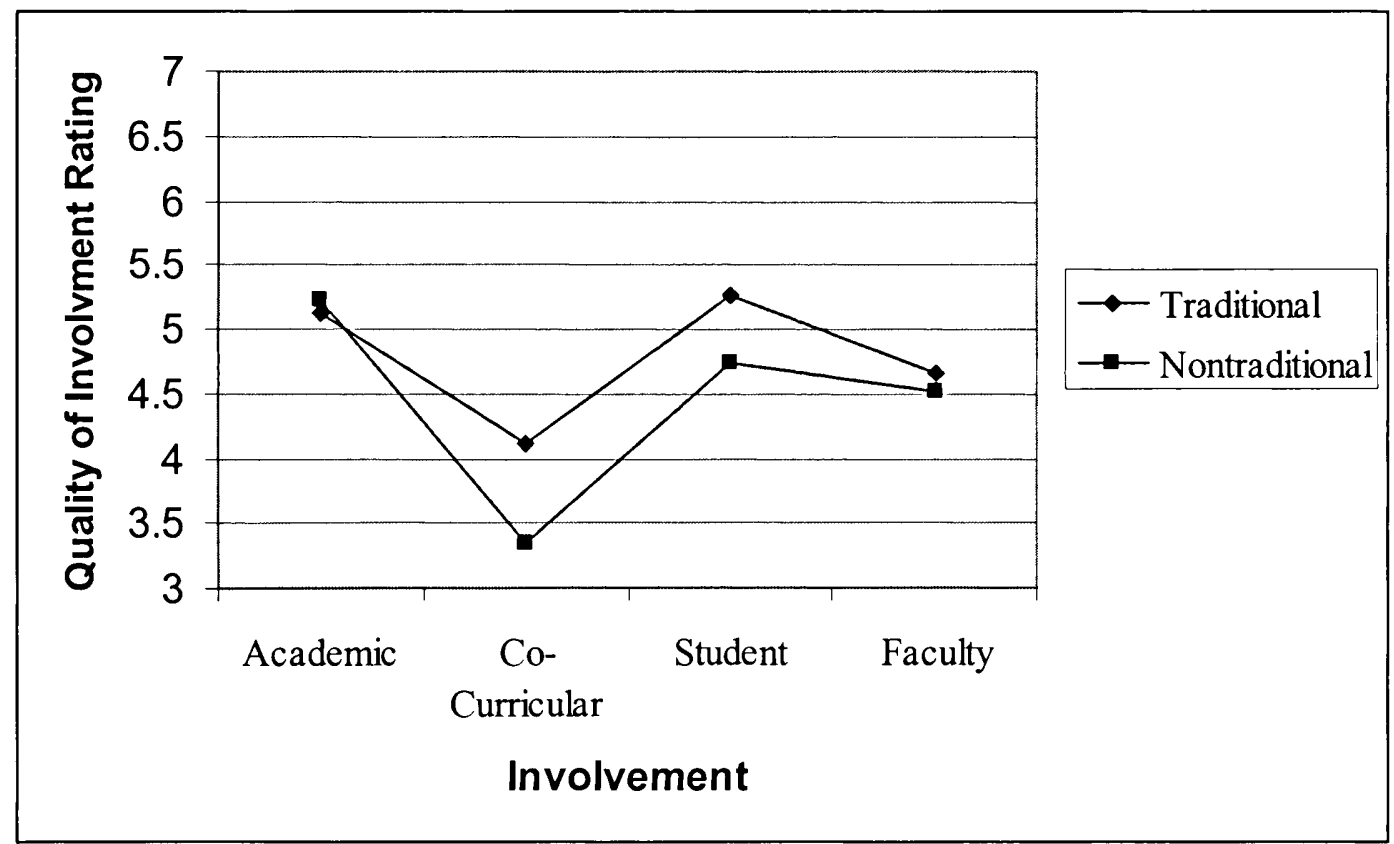

Figure 2. Quality of involvement by type of student. 
involvement and co-curricular involvement $\left(M_{\text {academic }}=5.17 ; M_{\text {co-curricular }}=3.74\right)$. The second largest difference in ratings of quality was between student involvement and cocurricular involvement $\left(M_{\text {student }}=4.99 ; M_{\text {co-curricular }}=3.74\right)$. There was a significant main effect of student type, $F(1,186)=5.41, p<.05$. Traditional students had higher ratings of quality of involvement $\left(M_{\text {traditional }}=4.78\right)$ than nontraditional students $\left(M_{\text {nontraditional }}=4.45\right)$.

The interaction effect between student type and perceptions of involvement was statistically significant, $F(2.30,428.4)=11.09, p<.001$. Therefore, the null hypothesis was rejected. The significant simple main effect of student type within perceptions of quality of involvement was further analyzed by pairwise comparisons using the Holm's Sequential Bonferroni method. Figure 2 illustrates the interaction of quality of involvement by type of student. Traditional $\left(M_{\text {traditional }}=4.16\right)$ students reported significantly higher ratings of quality for co-curricular involvement than nontraditional students $\left(M_{\text {nontraditional }}=3.31\right)$. Traditional students $\left(M_{\text {traditional }}=5.23\right)$ also reported significantly higher ratings of quality for student interactions than nontraditional students $\left(M_{\text {nontraditional }}=4.75\right)$. Although nontraditional students had higher ratings of quality of academic involvement $\left(M_{\text {nontraditional }}=5.23\right)$ than traditional students $\left(M_{\text {traditional }}=5.11\right)$, it was not significantly different.

Perceptions of College Contribution toward Development A second purpose of this study was to examine if perceptions of college contribution toward development differed for nontraditional undergraduate and traditional undergraduate students. Null hypothesis two stated that there were no interaction effects due to the four development types and student types. In order to 
determine if nontraditional students differ from traditional students in the way college contribution toward development is perceived for the four development types, a $2 \times 4$ repeated measures ANOVA was employed. Type of student (traditional or nontraditional) was entered as the between-subjects factor and the four development types (intellectual, personal, social, and career) as the within-subjects factor.

Table 17 displays the means for the involvement variables for traditional, nontraditional, and all students. There was a significant main effect of perceptions of college contribution toward development on both traditional and nontraditional students, $F(2.35,436.28)=4.27, p<.05$. The significant main effect of perceptions of college contribution toward development was further analyzed by pairwise comparisons using the Holm's Sequential Bonferroni method. Three pairwise comparisons were significant. First, as displayed in Table 17 social development $\left(M_{\text {social }}=4.20\right)$ had a significantly higher mean than intellectual development $\left(M_{\text {intellectual }}=4.09\right)$, personal development $\left(M_{\text {personal }}=4.08\right)$, and career development $\left(M_{\text {career }}=4.04\right)$. There was no significant main effect of student type, $F(1,186)=0.43, p>.05$. The interaction effect between student type and college contribution toward development was not statistically significant, $F(2.35,436.28)=0.22, p>.05$. Therefore, the null hypothesis that there were no interaction effects due to the four development types and student type (traditional vs. nontraditional) was not rejected.

Correlations between Involvement Variables and Development Variables The third purpose of this study was to examine if the relationships between the quality of college involvement (academic activities, co-curricular activities, student interactions, and faculty interactions) and college contribution toward development (intellectual, 
Table 17

Means and Standard Errors for College Contribution toward Development Variables Involvement Variables

$\begin{array}{llll}\text { Student Type } & \text { Intellectual } & \text { Personal } & \text { Social }\end{array}$

Traditional $(n=93) \quad 4.04$

Nontraditional $(n=95)$

4.13

$(0.07)$

All Students $(n=188)$
$4.09 \mathrm{a}$

$(0.05)$
4.07

$(0.09)$

4.09

$(0.09)$

$4.08 \mathrm{a}$

(0.06)
4.17

$(0.08)$

4.23

$(0.08)$

$4.20_{\mathrm{b}}$

(0.06)
4.00

4.09

$4.05_{\mathrm{a}}$

(0.06)

Note: Means in a row with differing subscripts are significantly different using Holm's Sequential Bonferroni, $p<.05$.

personal, social and career) differ for traditional undergraduate and nontraditional undergraduate students.

Null hypothesis three stated that the correlation coefficients between the four involvement types and the four development types for traditional students are equal to those for nontraditional students. To determine if the relationships between quality of college involvement (academic, co-curricular activities, student interactions, and faculty interactions) and perceived college contribution toward development (intellectual, personal, social and career) differed for traditional and nontraditional students, Pearson correlations were computed between the four involvement variables and the four development variables for each student type (traditional and nontraditional).

Table 18 displays the Pearson coefficients of correlation between the four involvement variables (academic, co-curricular, social, and faculty) and the four 
development variables (intellectual, personal, social, and career) for traditional students and nontraditional students respectively. Nine correlations were significant for traditional students, $p<.05$. The correlations between involvement and college contribution toward development for traditional students ranges from -.09 to .49 . Ten correlations were significant for nontraditional students, $p<.05$. The correlations between involvement and college contribution toward development for nontraditional students ranged from .03 and .45 .

For traditional students, higher ratings of academic involvement were related to higher ratings of college contribution toward development in all four areas. Also, higher ratings of quality of student involvement were related to higher ratings of college contribution toward development in all four areas.

For nontraditional students, a slightly different pattern was observed. As with traditional students, higher ratings of academic quality were related to higher ratings of college contribution toward development. Higher ratings of quality of student involvement were only related to higher ratings of college contribution toward intellectual development and social development. Unlike traditional students, higher ratings of faculty involvement were related to all four areas of college contribution toward development.

Findings of the Paired Comparisons of Correlations

In order to examine differences in the coefficients of correlation of the involvement variables and the contribution toward development variables between traditional and nontraditional student, $z$ tests were performed on transformed correlations. Table 18 displays the correlations and $z$ tests. No pair of correlations was significantly 
Table 18

Correlations and Tests of Difference between Quality of Student Involvement and

Contribution toward Development for Traditional and Nontraditional Students

Comparisons

Traditional Nontraditional

$z$

$p$

(difference)

Academic-Intellectual

$0.34 * *$

$0.45^{* *}$

$-0.89$

0.19

Academic-Personal

$0.31 * *$

$0.38^{* *}$

$-0.55$

0.29

Academic-Social

$0.42 * *$

$0.35^{* *}$

0.57

0.28

Academic-Career

$0.21^{*}$

$0.31^{* *}$

$-0.74$

0.22

Co-curricular-Intellectual

0.04

0.10

$-0.41$

0.34

Co-curricular-Personal

$-0.02$

0.06

$-0.55$

0.29

Co-curricular-Social

0.15

0.09

0.42

0.34

Co-curricular-Career

$-0.09$

0.03

$-0.84$

0.20

Student-Intellectual

$0.29^{* *}$

$0.22 *$

0.51

0.31

Student-Personal

$0.45^{* *}$

0.21

1.85

0.03

Student-Social

$0.49^{* *}$

$0.31 * *$

1.46

0.07

Student-Career

0.21 *

0.13

0.56

0.29

Faculty-Intellectual

0.20

$0.22 *$

$-0.14$

0.44

Faculty-Personal

0.15

$0.22 *$

$-0.42$

0.34

Faculty-Social

$0.25 *$

$0.26^{* *}$

$-0.07$

0.47

Faculty-Career

0.05

$0.21 *$

$-1.04$

0.15

${ }^{*} p<.05,{ }^{* *} p<.01$ 
different using the Holm's Sequential Bonferroni adjustment, $p<.004$, for overall probability of Type I error, $p<.05$. Therefore, the null hypothesis that the correlation coefficients between the four involvement types and the four development types for traditional students are equal to those for nontraditional students was accepted.

The largest observed difference was between the traditional students' correlation of quality of student involvement and college contribution toward personal development, $r(91)=.45, p<.01$, and the nontraditional students' correlation, $r(93)=.21, p>.05$, which was significant for traditional students but not significant for nontraditional students. The second largest observed difference was between the traditional students' correlations of quality of student involvement and college contribution toward social development, $r(91)=.49, p<.01$, and the nontraditional students' correlation, $r(93)=$ $.31, p<.05$. Both of these correlations were significant but for traditional students it was larger.

\section{Summary}

This chapter presented the findings of this study, including the survey response rate, the characteristics of the participants, the factor structure of the questionnaire, differences between traditional and nontraditional students on involvement variables, differences between traditional and nontraditional on college contribution towards development variables, relationships between involvement variables and development variables for traditional and nontraditional students, and differences between the relationships of involvement variables and college contribution for development between traditional and nontraditional students. The research questions and hypotheses served as the basis for the presentation of the results. 
A factor analysis was conducted to confirm the quality of involvement and college contribution toward development variables being used in the study. With the exception of two items, the items loaded onto factors similar to that of the CSEQ (academic involvement, co- curricular involvement, social involvement, and faculty involvement). In addition, with the exception of one item, the college contribution toward development items loaded on three factors (intellectual, social/personal, and career) confirming the CSEQ factors. In order to demonstrate evidence of reliability for the involvement and development variables being used for the study, the factor analyses were followed by the calculation of Cronbach alpha coefficients. Results indicated moderate or high reliability.

A description of the respondents was provided to ensure that the sample was representative of the population from which it was selected. The sample demographics of gender, ethnicity, and commuter/resident status matched the population. Furthermore, all schools were represented with two schools being slightly underrepresented. In addition, part-time status was underrepresented by $5 \%$. Overall, the sample was representative of the population. In addition to a description of the respondents, percentages of the responses to the seven items used to classify traditional and nontraditional status were provided. After recoding of traditional or nontraditional status, $48 \%$ were labeled traditional and 52\% were labeled nontraditional. Of those labeled traditional, $24.8 \%$ had at least one nontraditional characteristic. Twenty-five percent $(25.2 \%)$ had between two to four nontraditional characteristics. Only $1.9 \%$ of the students had five to seven of the characteristics. Finally, descriptive statistics for the quality of involvement items and the college contribution toward development items were presented. 
A 2 X 4 ANOVA identified significant differences in the means of perceptions of quality for both the traditional and nontraditional students. For all students, ratings of quality differed across the four involvement types. The largest difference was that students rated the quality of academic involvement much higher than co-curricular involvement. Traditional students had higher ratings of quality than nontraditional students. In addition, traditional students reported significantly higher ratings of quality for co-curricular involvement and quality of student involvement than nontraditional students. Although nontraditional students had higher ratings of quality of academic involvement than traditional students, it was not significantly different.

A 2 X 4 ANOVA also identified some significant differences in the means of perception of college contribution toward development. For all students, college contribution toward social development had a significantly higher mean than the means of intellectual development, personal development, and career development. There was no main effect of student type. There were no interaction effects of contribution toward development by student type.

Finally, Pearson coefficients of correlation between the quality of involvement variables and the college contribution toward development variables were conducted for traditional and nontraditional students. Although student involvement had larger correlations with personal development and social development for traditional students, there were no significant differences in the relationships of involvement variables and development variables between the traditional and nontraditional students.

The findings of this study are discussed in Chapter $\mathrm{V}$ along with conclusions and implications derived from the results of this study. 


\section{CHAPTER V}

\section{DISCUSSION}

The preceding chapters included an introduction to the research questions and theoretical framework of this study, a review of the relevant literature, a description of the research methods used in this study, and analyses of the collected data. This chapter summarizes the study, the hypothesis and summary of the findings, discusses the findings as they relate to the literature, and presents limitations, conclusions, implications, and recommendations for further research.

\section{Summary of the Study}

The greater the level of a student's involvement in college, the greater the student's academic and personal development (Astin, 1993). Involvement includes academic and co-curricular experiences, as well as, experiences with other students and faculty. These types of involvement have been positively correlated with positive outcomes such as intellectual, personal, social and career success (Astin, 1993; Graham, 1998; Graham \& Gisi, 2000; Kuh, 1995). Much of this research is limited to traditional students and does not examine quality of involvement. Although nontraditional students make up a large part of the undergraduate population today, there has been little research on the effect of college involvement on nontraditional students. Furthermore, the research does not consider social role characteristics of nontraditional students when defining nontraditional students.

Quality as Transformation explains quality in terms of ongoing transformation or development as a result of the student's college experience (Harvey \& Green, 1993a). Input and output indicators cannot really speak to the quality of a student's collegiate 
experience, particularly as it relates to his or her transformation. When researching quality for student stakeholders, "learners should be both at the center of the process by which learning is evaluated and at the center of the learning process" (Harvey \& Green, 1993a, p. 23). This particular definition of quality ties into Astin's involvement theory. A high quality institution is one that would greatly enhance its students both academically and personally (Astin, 1993). The purpose of education is to enhance and effect change in the students, it also empowers the students and allows them to influence their own transformation. This is done through the academic, co-curricular, student, and faculty involvements in which the student engages. However, because quality has been difficult to define, research investigating involvement typically measures involvement by the number of times a student is involved in activities (Astin, 1993; 1999; Donaldson \& Graham, 1999; Kuh, 1995) rather than the quality of those experiences and how that contributes to students' perceptions of college contribution toward their development.

The purpose of the study was reflected in three research questions. The first question asked if the perceptions of quality of college involvement (academic activities, co-curricular activities, student interactions, and faculty interactions) differed for traditional and nontraditional undergraduate students. The second question asked if perceptions of college contribution toward development (intellectual, personal, social and career) differed for traditional and nontraditional undergraduate students. The third question asked whether the relationships between the quality of college involvement (academic activities, co-curricular activities, student interactions, and faculty interactions) and perceived college contribution toward development (intellectual, personal, social and career) differed for traditional and nontraditional students. 
This research study involved the development of a survey using items from the CSEQ (Pace \& Kuh, 1998) which was administered 400 sophomore level or above undergraduates at a private liberal arts Catholic university in the Southeast. Part A of the survey asked students to rate the quality of academic, co-curricular, student, and faculty involvement. Part B of the survey asked students to rate the college's contribution toward their intellectual, personal, social and career development. A total of 241 usable surveys were returned, yielding a response rate of $60 \%$. Tables 3 through 6 in Chapter IV show the percentages for the demographic variables of the sample. Results indicate that, overall, the sample is representative from the population from which it was drawn on gender, ethnicity, school, resident or commuter status and enrollment status.

Defining traditional and nontraditional students by social characteristics rather than age set the foundation for the research conducted. Table 11 in Chapter IV shows that $48.1 \%$ of the students were defined as traditional and $51.9 \%$ were defined as nontraditional. The first two research questions were answered by conducting $2 \mathrm{X} 4$ repeated measures ANOVAs. Where main or interaction effects were found significant, post hoc tests were conducted and adjusted for using the Holm's sequential Bonferroni method. The third question was answered by first computing Pearson correlations between the four involvement variables and the four development variables for each student type (traditional and nontraditional). Then, Fisher $r$ to $z$ transformations were performed to standardize the correlations. To test for differences in the correlations between the traditional and nontraditional students, $z$ tests were conducted. A Holm's Sequential Bonferroni adjustment was conducted to control for Type I errors.

Results indicated that for all students, ratings of quality differed across the four 
involvement types with the largest difference in ratings of quality between academic involvement and co-curricular involvement. Furthermore, traditional students' rated quality for co-curricular involvement and student involvement significantly higher than nontraditional students. Both traditional and nontraditional students had similar ratings of college contribution toward development. There were different patterns of correlations between involvement and development. Traditional students had the strongest relationships for academic and student involvement with development. Nontraditional students had the strongest relationships for academic and faculty involvement with development. However, no pair of correlations was significantly different between the two student types.

\section{Null Hypotheses}

Null hypothesis one stated that there was no interaction effect due to the four quality of involvement types (academic, co-curricular, social, and faculty) and student type (traditional and nontraditional). This hypothesis was rejected. Traditional students had significantly higher ratings of quality for co-curricular involvement and student involvement than nontraditional students.

In addition, findings indicated that there was a main effect of involvement type. All students rated the quality of involvement different across the four involvement types with the biggest difference between academic involvement and co-curricular involvement. There was also a main effect of student type. Overall, traditional students had higher ratings of quality of involvement than nontraditional students.

Null hypothesis two stated that there was no interaction effect due to the four college contribution toward development types (intellectual, personal, social, and career) 
and student type (traditional and nontraditional). This hypothesis was not rejected. Although the ratings of college contribution toward development varied slightly across the four development types for each student, results showed that there was no significant interaction effect.

In addition, findings indicated that there was a main effect of college contribution toward development. For all students, college contribution toward social development had higher ratings than college contribution toward intellectual, personal and career development. Furthermore, there was no main effect of student type. Neither traditional nor nontraditional students had higher ratings of college contribution toward development.

Null hypothesis three stated that the correlations between the four involvement types (academic, co-curricular, social, and faculty) and the four development types (intellectual, personal, social, and career) were equal for traditional and nontraditional students. This hypothesis was not rejected.

Findings indicated that quality of student involvement and personal development had stronger relationships for traditional students but the difference from nontraditional students was not significant. Also, student involvement and social development had stronger relationships for traditional students but the difference from nontraditional students was not significant.

\section{Perceptions of Quality of Involvement}

While the number of times a student engaged in involvement activities had been researched, perceptions of quality of involvement had not been examined. For all students, ratings of quality differed across the four involvement types. Table 16 in 
Chapter IV shows that the largest difference in ratings of quality were between academic involvement and co-curricular involvement $\left(M_{\text {academic }}=5.17 ; M_{\text {co-curricular }}=3.74\right)$. This seems logical given that students attend college primarily for academic purposes. These findings concur with Graham and Gisi (2000). Although they were measuring the average number of times students were engaged in involvement activities, they also found that larger numbers of participation in academic related activities than cocurricular activities.

Interestingly, students also rated the quality of student involvement and faculty involvement higher than co-curricular involvement. Thus, the quality of a student's interaction with other students and with faculty had ratings of higher quality than particular activities such as participation in clubs and events. Students rated things such as the quality of becoming acquainted with students of a different ethnic background or students from another country much higher than any type of co-curricular activity. They also rated quality of working harder from feedback from an instructor, or talking to an instructor about class related work higher than any co-curricular activities. While research has shown that activities such as talking with a professor about grades etc. might not happen as frequently as academic activities or student interactions (Graham \& Gisi, 2000), it appears the quality of those types of activities is still important to the student. Differences in Perceptions of Quality of Involvement by Student Type

Although Graham \& Gisi (2000) did not find an effect of age when examining involvement and development, this research did find a significant interaction effect between student type and perceptions of quality of involvement. Traditional students rated co-curricular involvement and student involvement significantly higher in terms of 
quality than nontraditional students. Although not significantly different, nontraditional students rated academic experiences higher than traditional students. Following is a more detailed discussion of these differences.

Quality of co-curricular involvement. Traditional $\left(M_{\text {traditional }}=4.16\right)$ students reported significantly higher ratings of quality for co-curricular involvement than nontraditional students $\left(M_{\text {nontraditional }}=3.31\right)$. These findings seem reasonable when considering that Graham and Gisi (2000) found that traditional students had higher participation rates of involvement in college organizations and off campus activities. However, Graham and Gisi (2000) also found that although nontraditional students participated less in these activities, the impact on their development was more so than that of traditional students.

One might assume from those findings that nontraditional students would rate the quality of co-curricular experiences higher. However, the results of this study found otherwise. Rather, nontraditional students rated the quality of their academic experiences the highest, followed by student interactions. While it appears that the co-curricular activities offered are quality activities to nontraditional students, they are not for nontraditional students. Since nontraditional students differ in terms of responsibilities such as family and work, interest in terms of what types of activities they would participate in most likely differs as well.

Quality of Student Involvement. Post hoc tests also indicated that traditional students $\left(M_{\text {traditional }}=5.23\right)$ also reported significantly higher ratings of quality for student interactions than nontraditional students $\left(M_{\text {nontraditional }}=4.75\right)$. These findings support Kuh's (1995) findings on student-peer interactions. He found a large proportion of gains 
in development related to peer interactions. This was particularly true for traditional students. Whitt, et. al. (1999) also found high participation rates in student interactions. This difference between traditional and nontraditional students in the rating of quality of student-peer interactions can be explained for by issues revolving around time. Nontraditional students have responsibilities such as work and childcare and may have less time to be engaged with peers. For example, Lundberg (2004) found that students who work 20 or more hours per week are less engaged with their peers at school. These students can be defined as nontraditional. Still, the results of this research indicated that student interactions had the second highest rating of involvement from nontraditional students. This may be explained for by what Brookfield (1999) calls a theme of 'community' where he describes the importance of peers experiencing college together or as a support for getting through college. Meehan and Negy (2003) also demonstrated that for married students peer support is essential to their academic adjustment in college.

Quality of Academic Involvement. Although nontraditional students had higher ratings of quality of academic involvement $\left(M_{\text {nontraditional }}=5.23\right)$ than traditional students $\left(M_{\text {traditional }}=5.11\right)$, it was not significantly different. However, this slightly higher mean, although not significant provides some support to Bishop-Clark and Lynch's (1992) and Kasworm's (2003) conclusions that classroom and academic activities are center stage for the way in which nontraditional students make meaning of their learning and apply that to their work and lives. This concept is unique to nontraditional students.

Furthermore, while traditional students $\left(M_{\text {traditional }}=4.63\right)$ reported a slightly higher mean when rating the quality of faculty interactions than nontraditional students ( $\left.M_{\text {nontraditional }}=4.51\right)$, there was no statistical significance. This supports the findings of 
Rosenthal, Folse and Alleman (2000) who found no differences in the way traditional and nontraditional students interact with faculty. However, although the perceptions of quality of involvement with faculty may not differ, the way that traditional students and nontraditional students make meaning of those interactions and how it impacts development may differ. This concept will be discussed further along in the discussion. Perceptions of College Contribution toward Development There was a significant main effect for college contribution toward development. For all students, perceptions of college contribution toward development differed across the four development types. Table 17 in Chapter IV shows that social development $\left(M_{\text {social }}=4.20\right)$ had a significantly higher mean than intellectual development $\left(M_{\text {intellectual }}=\right.$ 4.09), personal development $\left(M_{\text {personal }}=4.08\right)$ and career development $\left(M_{\text {career }}=4.04\right)$. These findings differed from Kuh's (1995) work which showed the strongest gains in knowledge and academic skills. The results also differed from the results of Graham and Gisi's (2000) research which found the strongest gains in intellectual development. A summary of the findings for research question two is presented in Table 19.

While both traditional and nontraditional students rated college contribution toward social development higher than other types of development, the reasons may be different. As Kuh (1995) pointed out, for traditional students, social interactions are critical to social development. Traditional students have the opportunity to engage in social interactions with their student peers. On the other hand, nontraditional students may rate social development higher because of the nature of their distinct engagements with other students. As Brookfield (1999), Donaldson et. al. (1999), and Meehan and Negy (2003) found, nontraditional students look to their fellow students for support with 
regard to getting through college. They feel a sense of "community" in terms of supporting and helping each other reach their goals.

There was no significant interaction effect between student type and college contribution toward development. Both traditional and nontraditional students had similar ratings of college contribution toward development. Nontraditional students had higher ratings across the four development types (intellectual, personal, social, and career) but it was not significantly different from the traditional students' ratings. These findings make sense given that regardless of student type, the student's purpose for attending college is to develop intellectually and in other ways. Graham and Gisi (2000) and Lundberg (2004) also found no effect of age on development. Rosenthal, et. al. (2000) also concluded that traditional and nontraditional students were not much different in the way they interacted with faculty or with how that effected their perceptions of satisfaction with faculty.

However, while there appears to be no interaction effect of student type and development, there are different patterns of relationships between quality of involvement and perceptions of college contribution toward development for traditional and nontraditional students.

Quality of Student Involvement and College Contribution toward Development This section discusses the relationship between perceptions of quality of involvement (i.e., academic, co-curricular, student, and faculty) and perceptions of college contribution toward (i.e., intellectual, personal, social, and career). Table 19 provides a summary of the correlation findings. The patterns of these relationships were different for traditional and nontraditional students. Although no cause-effect 
relationship can be inferred from these correlation results, they do contribute to understanding the different patterns of relationships between perceptions of quality of involvement and college contribution toward development for traditional and nontraditional students. Following is a summary of the overall patterns.

\section{Traditional Students}

For traditional students, higher ratings of academic involvement were related to higher ratings of college contribution toward development in all four areas (intellectual,

personal, social, and career). Also, higher ratings of quality of student involvement were related to higher ratings of college contribution toward development in all four areas. Quality of co-curricular involvement for traditional students was not related to any type of college contribution toward development and quality of faculty involvement was only related to college contribution toward social development. Table 19 displays the correlations between quality of involvement and college contribution toward development.

The significant relationships between traditional students' ratings of quality of academic involvement and all four areas of college contribution toward development seem logical given the fact that the primary purpose of higher education revolves around academic activities. However, unlike nontraditional students, traditional students appear to need a more holistic or rounded college experience that includes other types of involvement such as interactions with other students.

Quality of student development was significantly related to all four development areas (intellectual, personal, social, and career). All of these correlations were stronger than for nontraditional students. This is because traditional student have time to interact 
with other students beyond the classroom. These interactions ultimately impact their perception of college contribution toward development. Kuh (1995) and Whitt, et. al. (1999) point out that traditional students experience more social interactions and cocurricular activities than nontraditional students. Also House (2000) concluded that student interactions were significantly related to drive to achieve in college, mathematical ability, and writing ability.

When testing for differences between traditional and nontraditional students' relationships of quality of involvement and college contribution toward development, the largest observed differences were quality of student involvement and college contribution toward personal and social development. This makes sense given that the patterns of relationships differed for traditional and nontraditional students. Traditional students rated the quality of student involvement higher than nontraditional students. Although not significant, these findings provide some support for Kuh's (1995) conclusions that the strongest gains in self-awareness, self-esteem, and autonomy were associated with student peer interactions. He found this to be true especially for traditional aged students. Further, Kuh (1995) found that the strongest amount of gains in social competence of traditional students was related to student peer interactions, particularly for traditional students.

Although not strong relationships, traditional students' perceptions of quality of faculty interactions were only significantly related to college contribution toward social development. There was no significant relationship of quality of faculty interaction with college contribution toward intellectual, personal, or career development. Given that traditional students rated the quality of student involvement and academic experiences 
higher than faculty involvement, this finding is not surprising. House (2000) also showed a weak relationship with hours spent talking to teachers out of class and creativity, drive to achieve, and self confidence in intellectual ability. This finding provides some support for Kuh's (1999) work which found that only about five percent of outcomes reported by students were attributed to interactions with faculty.

\section{Nontraditional Students}

For nontraditional students, a slightly different pattern of correlations was observed. As with traditional students, higher ratings of academic quality were related to higher ratings of college contribution toward development. Higher ratings of quality of student involvement were only related to higher ratings of college contribution toward intellectual development and social development. Like traditional students, there were no significant relationships between co-curricular involvement and perceptions of college contribution toward development. Unlike traditional students, higher ratings of faculty involvement were related to all four areas of college contribution toward development. Table 19 displays the correlations between quality of involvement and college contribution toward development.

The difference in relationship patterns of the nontraditional students from traditional students may be attributable to the fact that the findings of this research and the research of Whitt, et. al (1999) and Lundberg (2004) show that nontraditional students have less time for peer interactions. Also, for nontraditional students the classroom and academic related activities seem to be the center point of learning (BishopClark \& Lynch, 1992; Kasworm, 2003) and their development in terms learning, work, and life. 
Table 19

Correlations between Quality of Student Involvement and College

Contribution toward Development

Relationships

For Traditional For Nontraditional

Academic-Intellectual

YES**

YES**

Academic-Personal

YES**

YES**

Academic-Social

YES**

YES**

Academic-Career

YES*

YES**

Co-curricular-Intellectual

NO

NO

Co-curricular-Personal

NO

NO

Co-curricular-Social

NO

NO

Co-curricular-Career

NO

NO

Student-Intellectual

YES**

YES*

Student-Personal

YES**

NO

Student-Social

YES**

YES**

Student-Career

YES**

NO

Faculty-Intellectual

NO

YES*

Faculty-Personal

NO

YES*

Faculty-Social

YES*

YES**

Faculty-Career

NO

YES* 
Like traditional students, there were significant relationships between the quality of academic involvement and the college contribution toward intellectual development. However, each relationship of academic involvement and each development item (intellectual, personal, social, and career) was stronger for nontraditional students. This can probably be explained by the fact that, as Kasworm (2003) points out, the class is center stage for the nontraditional student and most related to learning and work. These findings also echo Graham and Gisi's (2000) findings that course related activities had a significant effect on intellectual growth.

Also like traditional students, the relationship of quality of academic involvement and personal development was significant. Again, nontraditional students had a slightly higher relationship. An explanation for this difference in relationship pattern can be found in the literature. As Kasworm (2003) points out, nontraditional students make meaning of their learning and apply it to not just learning and work but life as well. Therefore, it would seem that nontraditional students' academic experiences would correlate with personal development. On the other hand, traditional students attribute other student social interactions more to personal development as found in Kuh's (1995) research.

While traditional students had a relationship between quality of student involvement and college contribution toward development, nontraditional students showed weaker relationships for those two variables. As mentioned earlier, because of responsibilities to work and family, nontraditional students have less time to spend with other students. With the class being the center stage for their learning and making meaning of what they learn, peer interactions are limited. However, for nontraditional 
students, there was still a significant relationship between student involvement and social development. This ties back to the sense of community and support that Brookfield (1999) explained as being critical as a means for nontraditional students to get through college. Nontraditional students look to their fellow classmates as people who understand what they are going through and serve as a support system.

Unlike traditional students, quality of faculty involvement was related to all four development items (intellectual, personal, social, and career) for nontraditional students. However, the fact that nontraditional students use the classroom as the focal point of making meaning of learning and applying that to work and life (Kasworm, 2003) and that faculty are a large part of that experience serves as an explanation for this different pattern in relationship between quality of involvement and college contribution toward development for nontraditional students. These findings for nontraditional students do not provide evidence to support the conclusions of Rosenthal, et. al. (2000) that there is no difference in the ways traditional and nontraditional students interact with faculty. On the other hand, the way students make meaning of those interactions may be different.

Results showed that there were no significant differences in the correlations of these items even for those with the largest observed differences between student type (student involvement and personal development, and student involvement and social development). However, involvements that seem to be geared towards the classroom such as academic and faculty involvement were rated higher by nontraditional students. Again, this is due to the fact that the nontraditional student's whole learning experience revolves around the classroom while the nature of the traditional student has more in and out of class experiences. 


\section{Limitations of the Study}

This study is limited due to the fact that the sample $(n=400)$ selected for this study comes from one private liberal arts Catholic university in the Southeast. This allowed for limited generalization. Any conclusions drawn refer to the sample used, but might also apply to similar sized private Catholic liberal arts colleges in South Florida that share similar demographic characteristics. These conclusions should not be applied or generalized for all higher education institutions.

Another limitation refers to the researcher's involvement in the study since the research was conducted at the University where the investigator is employed. To avoid bias, the random selection of courses for participation was provided by the Office of the Registrar rather than selected through the researcher's office. Furthermore, the researcher does not work directly with students, particularly in the classroom or with any student activities. Therefore, there was less likelihood that the students would be less critical in responses. The researcher was clear in communication with the students that this study was being conducted as part of her doctoral requirements at Florida International University.

The method utilized to collect the data for this study, a survey, also generated some limitations. There might be measurement errors since responding students subjectively self-reported on all the variables used in this study. Moreover, even with the follow up procedures described in Chapter IV, the survey response rate was hampered by weather conditions. This may have somehow influenced the students' responses. The attained response rate in this study was $60 \%$, which might introduce bias in the results. Furthermore, it is possible that some students might have decided not to answer the 
questionnaire because of any dissatisfaction with the institution. Had they decided to answer the survey, the mean quality of involvement and college contribution toward development scores might have been lower than the ones reported in this study.

This study included only successful students at the institution who had completed 24 or more credits at the institution. This posed as a limitation because it did not include the perceptions of students who might have been unsuccessful at the institution and left nor did include the perceptions of any students who might have transferred to another institution.

Another limitation refers to the variables being used in this study. Other types of variables such as living on or off campus, amount of hours employed may be related to a student's perception of college contribution toward development.

\section{Conclusions}

Based on the previous discussion, the following conclusions are derived from the findings of this study.

1. For the four quality of involvement types (academic, co-curricular, student, and faculty), all students rate the quality of their academic experiences significantly different with academic experiences receiving the highest ratings of quality and cocurricular receiving the lowest ratings.

2. There is an interaction effect of student type and the ratings of quality of involvement. Traditional students rate co-curricular involvement and student involvement significantly higher in terms of quality than nontraditional students. Although not significantly different, nontraditional students rate academic experiences higher than traditional students. 
3. Both traditional and nontraditional students rate their development across the four items (intellectual, personal, social, and career) similarly. Further, all students rated college contribution toward development significantly different with social development having higher ratings than academic, personal and career development for both traditional and nontraditional students.

4. Traditional students had stronger relationships between quality of academic and student involvement with college contribution toward development while nontraditional students had stronger relationships between academic and faculty involvement with college contribution toward development.

5. When testing for differences (between traditional and nontraditional students) in the relationships of quality of involvement and college contribution toward development, the largest observed difference was between the traditional students' correlation of quality of student involvement and college contribution toward personal development.

6. When testing for differences (between traditional and nontraditional students) in the relationships of quality of involvement and college contribution toward development, the second largest observed difference was between the traditional students' correlations of quality of student involvement and college contribution toward social development.

7. In general, the results show it is reasonably clear that perceptions of quality of students' involvement are related to the perceptions of college contribution toward development. Further, the patterns in those relationships differ by student type. Traditional students had stronger relationships between perceptions of quality of 
academic and student involvement with perceptions of college contribution toward development while nontraditional students had stronger relationships with perceptions of quality of academic and faculty involvement with perceptions of college contribution toward development.

\section{Implications for Theory and Literature}

The findings of this study have the following implications for theory and literature.

1. This study contributed to confirming the validity and reliability of the fourth edition of the College Student Experiences Questionnaire (CSEQ) (Pace \& Kuh, 1998).

2. In general, this study provides additional evidence to support Harvey and Green's (1993a) concept of Quality as Transformation, which explains quality in terms of ongoing transformation or development as a result of the student's college experience. Students' perception of quality of involvement does have an impact on their perceptions of development. It also provides evidence that when researching quality for student stakeholders, "learners should be both at the center of the process by which learning is evaluated and at the center of the learning process" (Harvey \& Green, 1993a, p. 23).

3. The significant positive relationships between perceptions of quality of involvement and perceptions of college contribution toward development provide additional evidence in support of Astin's (1985) involvement theory which states that students must be actively engaged in their environment in order for student learning to take place.

4. The significant positive relationships also provide additional evidence to support Astin's (1985) theory which identifies "the most excellent institutions are those 
that have the greatest impact on a student's knowledge and personal development" (pp. 60-61).

5. The findings of this study provide some evidence supporting differences found in the literature (Bishop-Clark \& Lynch, 1992; Brookfield, 1999; Graham \& Gisi, 2000; Kasworm, 2003; Kuh, 1995; Lundberg, 2004; and Meehan \& Negy, 2003) between traditional and nontraditional students as it relates to involvement, at least in terms of perceptions of quality of involvement. For example, traditional students rate the quality of co-curricular and student interactions higher than nontraditional students. This supports the literature which shows that traditional students are more engaged in those types of involvement. On the other hand, for nontraditional students, the class is the center stage where they make meaning of their learning and apply it to all aspects of their life.

6. In general, the findings of this study provide some support for the theory that there are no differences in perceptions of college contribution toward development between traditional and nontraditional students. Both traditional and nontraditional rate college contribution toward intellectual, personal, social, and career development similarly. These findings concur with Graham and Gisi (2000), Lundberg (2004) and Rosenthal, et. al. (2000).

7. The findings of different patterns of relationships between quality of involvement and college contribution toward development for traditional and nontraditional students provides evidence to support research such as Horn's (1996) and Senter and Senter's (1998) using social role to define traditional and nontraditional students. 
The findings and conclusions of this study have the following implications for practice:

1. For both nontraditional and traditional students academic involvement was significantly related to intellectual, personal, and career development. Therefore, the participating institution should assess the level of academic challenge provided to the students and strive to maintain and improve that level.

2. Traditional students reported a stronger relationship between student involvement and personal and social development than nontraditional students. Therefore, the participating institution should look into ways to encourage more peer interactions for both social purposes as well as academic support.

3. Other research has shown academic involvement to have a stronger impact on career development. Furthermore, research has shown that in addition to intellectual development, nontraditional students make meaning of their learning in terms of work and life. Therefore, the institution may want to find ways to foster gains in career development via academic and/or student services.

4. Nontraditional students showed more gains than traditional students in intellectual, personal, social and career development as a result of faculty involvement than traditional students. The participating institution should be aware of this relationship and develop ways to continue and encourage more student-faculty involvement.

5. Research has shown traditional students are more involved in co-curricular activities such as organizations and campus events. However, the findings of this study 
found no relationship between the quality of those activities and perceptions of college contribution toward development. Findings of an institutional-wide survey, conducted in 2000 at the institution being researched, did indicate that students did not feel there were enough co-curricular experiences offered on campus (Crane, 2000). The institution may want to investigate this further to identify the numbers and types of co-curricular activities available, the quality of these activities, and if other activities might be offered to the students.

6. For the aforementioned implications for practice, and to identify other ways in which the institution can use this data, the institution should convene a group to more closely examine individual items on the survey that might identify areas of strength and areas for improvement in meeting the needs of traditional and nontraditional students.

Recommendations for Future Research

The findings of this research have implications for future student involvement research. Based upon the results of this study, the following recommendations for future research are proposed:

1. One of the limitations of this study was its restriction to one private liberal arts Catholic university in the Southeast. The study could be replicated to include other types of institutions in different regions.

2. Further research may be conducted to compare quantity of involvement and how that relates to perceptions of quality of involvement and also perceptions of college contribution toward development. Such a study would provide a more comprehensive view of whether quantity of participation influences ratings of quality. It would also distinguish if it is the quality of the activity or the number of times that a student 
participates in an activity that has an impact on perceptions of college contribution toward development.

3. The overall development of a student is the product of the combined work of faculty, staff, and administrators working at the institution. A comparative study of the opinions of different types of employees (e.g., faculty, academic advisors, academic administrators, senior administrators, etc.) could be conducted to determine if there are differences the way they perceive quality of involvement and how they perceive the college's contribution towards student development.

4. Further research may be conducted to determine the relationship between other types of college variables such resident/commuter status or number of hours employed outside of college, as well as other potential factors impacting student development not included in this study.

5. The study could be replicated to include alternative means to define traditional and nontraditional students such as age. This would be useful in determining if there are differences in the results when grouped by social status versus age.

Student involvement is an integral part of the college experience. The more researchers learn about this concept, the more able institutions will be in providing enriching experiences for students. This research demonstrated the importance of using social role when defining student type and contributes to involvement theory by showing that traditional and nontraditional students differ in the way they perceive quality of college involvement and how that relates to their development. While traditional students may need more of a rounded college experience that includes social and cocurricular experiences, nontraditional students use the class as their stage for learning. 


\section{References}

Alexander, N., \& Woodruff, R. (1940). Determinants of college success. Journal of Higher Education, 11, 479-485.

Astin, A. W. (1975). Preventing students from dropping out. San Francisco: Jossey-Bass.

Astin, A. W. (1985). Achieving educational excellence. San Francisco: Jossey-Bass.

Astin, A. W. (1993). What matters in college: Four critical years revisited. San Francisco: Jossey-Bass.

Astin, A. W. (1999). Student involvement: A developmental theory for higher education. Journal of College Student Development, 40, 518-532.

Barnett, R. (1992). Improving higher education, total quality care. Society for Research into Higher Education \& Open University Press: Buckingham.

Baxter Magolda, M. B. (1992). Knowing and reasoning in college: Gender-related patterns in students' intellectual development. San Francisco: Jossey-Bass.

Bishop-Clark, C. \& Lynch, J. M. (1992). The mixed-aged college classroom. College Teaching, 40, 114-117.

Brookfield, S. D. (1999). What is college really like for adult students? About Campus, January-February, 10-15.

Chickering, A. W. (1969). Education and identity. San Francisco: Jossey-Bass.

Cooper, D., Healy, M. \& Simpson, J. (1994). Student development through involvement: Specific changes over time. Journal of College Student Development, 35, 98-102.

Digest of Education Statistics, 2002, Chapter 3. (2002). Postsecondary Education. National Center for Education Statistics. Retrieved on July 21, 2004 from http://nces.ed.gov/pubs2003/digest02/ch_3.asp

Donaldson, J. F., \& Graham, S. W. (1999). A model of college outcomes for adults. Adult Education Quarterly, 50, 24-40.

Donaldson, J. F., Graham, S. W., Martindill, W., Long, S., \& Bradley, S. (1999, April). Adult undergraduate students: How do they define success? Paper presented at the Annual meeting of the American Education Research Association, Montreal, Quebec, Canada. 
Donohue, T. L., \& Wong, E. H. (1997). Achievement motivation and college satisfaction in traditional and nontraditional students. Education, 118, 237-243.

Evans, N. J., Forney, D. S., \& Guido-DiBrito, F. (1998). Student development in college: Theory, research and application. San Francisco: Jossey-Bass.

Feldman, K. A., (1969). Studying the impacts of colleges on students. Sociology of Education, 42, 207-237.

Gonyea, R. M, Kish, K. A., Kuh, G. D., Muthiah, R. N., \& Thomas, A. D. (2003). College student experiences questionaire: Norms for the fourth edition. Bloomington, IN: Indiana University Center for Postsecondary Research, Policy, \& Planning.

Graham, S. (1998). Adult growth in college: The effects of age and educational ethos. Journal of College Student Development, 39, 239-250.

Graham, S. W., \& Gisi, S. L. (2000). Adult undergraduate students: What role does college involvement play. NASPA Journal, 38, 99-121.

Green, D. (1994). What is quality in higher education? Buckingham: Society for Research into Higher Education \& Open University Press.

Green, S., Salkind, N., \& Akey, T. (2000). Using SPSS for windows: Analyzing and understanding data ( $2^{\text {nd }}$ ed.). Englewood Cliffs, NJ: Prentice Hall.

Harvey, L., \& Green, D. (1993a). Defining quality. Assessment and Evaluation in Higher Education, 18, 9-34.

Harvey, L., \& Green, D. (1993b). Assessing quality in higher education: A transbinary research project. Assessment \& Evaluation in Higher Education, 18, 143-148.

Horn, L. (1996). Nontraditional undergraduates, trends in enrollment from 1986 to 1992 and persistence and attainment among 1989-90 beginning postsecondary students (NCES 97-578). United States Department of Education, National Center for Education Statistics, Washington, DC: U.S. Government Printing Office.

House, J. D. (2000). The effect of student involvement on the development of academic self-concept. Journal of Social Psychology, 140, 261-264.

Kachigan, S. K. (1991). Multivariate statistical analysis. A conceptual introduction. $2^{\text {nd }}$ Ed.). New York: Radius Press.

Kasworm, C. E. (2003). Adult meaning making in the undergraduate classroom. Adult Education, 53, 81-98. 
Knefelkamp, L., Widick, C., \& Parker, C. (1978). Editors' notes: Why bother with the theory: In L. L. Knefelkamp, C. Widick, \& C. A. Parker (Eds.), Applying new developmental findings (New Directions for Student Services, No. 4, pp. vii-xvi). San Francisco: Jossey-Bass.

Kuh, G. D. (1995). The other curriculum: Out-of-class experiences associated with student learning and personal development. The Journal of Higher Education, 66, 123-156.

Lundberg, C. (2004). Working and learning: The role of involvement for employed students. NASPA Journal, 41, 201-215.

Lynch, J. \& Bishop-Clark, C. (1998). A comparison of the nontraditional students' experience on traditional versus nontraditional college campuses. Innovative Higher Education, 22, 217-229.

Meehan, D. \& Negy, C. (2003). Undergraduate students' adaptation to college: Does being married make a difference? Journal of College Student Development, 44, 670-684.

Miller, P. H. (1993). Theories of developmental psychology ( $3^{\text {rd }}$ ed). New York: W. H. Freeman \& Company.

Pace, R. \& Kuh G. (1998). College Student Experiences Questionnaire (4 $4^{\text {th }}$ ed.). Bloomington, IN: Indiana University Center for Postsecondary Research, Policy, \& Planning.

Pascarella, E., \& Terenzini, P. (1991). How college affects students: Findings and insights from twenty years of research. San Francisco: Jossey-Bass Publishers.

Pike, G. (1995). The relationship between self reports of college experiences and achievement test scores. Research in Higher Education, 36(1), 1-21.

Rosenthal, G. T., Folse, E. J., \& Alleman, N. W. (2000). The one-to-one survey: Traditional versus non-traditional student satisfaction with professors during oneto-one contacts. College Student Journal, 34, 315-320.

Sanford, N. (1962). The American college: A psychological and social interpretation of higher learning. New York: John Wiley \& Sons.

Senter, M. S., \& Senter, R. (1998). A comparative study of traditional and nontraditional students' identities and needs. NASPA Journal, 35, 270-280.

Spitzer, T. M. (2000). Predictors of college success: A comparison of traditional and nontraditional age students. NASPA Journal, 38, 82-98. 
SPSS for Windows, Rel. 12.0.0. 2003. Chicago: SPSS Inc.

Strange, C. (1999). Student development: The evolution and status of an essential idea. Journal of College Student Development, 40, 570-589.

Tam, M. (2001). Measuring quality and performance in higher education. Quality in Higher Education, 7, 47-54.

Terenzini, E. T., Theophilides, C., \& Lorang, W. G. (1984). Influences on students' perceptions of their academic skill development during college. Journal of Higher Education, 55, 621-636.

Wendorf, C. (1997). Manuals for univariate and multivariate statistics. Retrieved on October 29, 2004 from http://www.uwsp.edu/psych/cw/statmanual.

Whitt, E. (1994). Encouraging adult learner involvement. NASPA Journal, 31, 309-318.

Whitt, E., Edison, M., Pascarella, E., Nora, A, \& Terenzini, P. (1999). Interactions with peers and objective and self-reported cognitive outcomes across 3 years of college. Journal of College Student Development, 40, 61-78.

Woodside, B., Wong, E., \& Weist, D. (1999). The effect of student-faculty interaction on college students' academic achievement and self concept. Education, 119, 730733.

University of Wisconsin-Milwaukee (2002). Factor analysis. Retrieved on October 29, 2004 from http://www.uwm.edu/ edari/methstat/factor.htm. 
APPENDIX A 


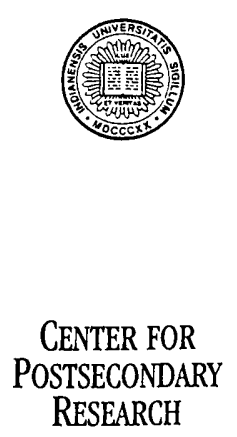

April 20, 2004

Dawn Broschard

9440 Live Oak Place, \#204

Fort Lauderdale, FL 33324

Dear Dawn,

Enclosed is an invoice in the amount of $\$ 100.00$ for permission to adapt CSEQ items for your dissertation. Our agreement includes the following:

(1) That the survey form and any papers, reports, or publications generated with the survey data indicate that permission to borrow/adapt items from the CSEQ was granted by the Indiana University Center for Postsecondary Research.

(2) That such permission is granted for one-time use only, and only as indicated in your attached proposal and email.

(3) That you send copies of your dissertation and any papers, reports, or publications making use of the data to the IU Center for Postsecondary Research, attention: George Kuh

Many thanks and best regards for your study.

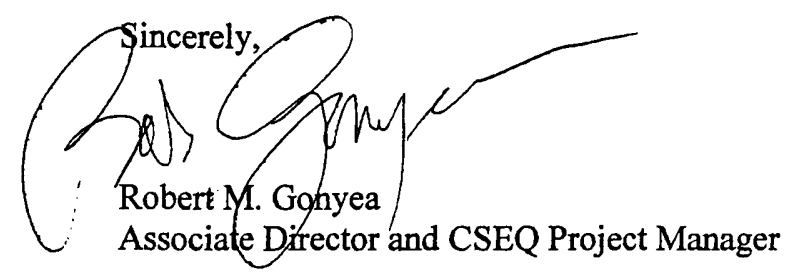

COLLEGE STUDENT

EXPERIENCES QUESTIONNAIRE

RESEARCH PROGRAM

Eigenmann Hall, Suite 419

1900 East Tenth Street

Bloomington, Indiana

47406-7512

812-856-5825

Fax: 812-856-5150

cseq@indiana.edu

www.iub.edu/ cseq 
APPENDIX B 
Variable

Name

\section{Academic Involvement}

COURSE 1

COURSE2

COURSE3

COURSE4

COURSE5

COURSE6

COURSE7

COURSE8

COURSE11
Completed the assigned readings for class

Took detailed class notes during class

Contributed to class discussions

Developed a role play, case study, or simulation for a class

Tried to see how different facts and ideas fit together

Summarized major points and information from your class notes or readings

Worked on a class assignment, project, or presentation with other students

Applied material learned in a class to other areas (your job, internship, interactions with others) in class discussions or assignments

Worked on a paper or project where you had to integrate ideas from various sources

\section{Co-Curricular Involvement}

FACIL3

FACIL6

CLUBS 1

CLUBS2

CLUBS5
Attended a cultural or social event in the campus center or other campus location

Used campus recreational facilities (pool, fitness equipment, courts, etc.)

Attended a meeting of a campus club, organization, or student government group

Worked on a campus committee, student organization, or project (publications, student government, special event, etc.)

managed or provided leadership for a club or organization, on or off the campus 
STACQ1

STACQ2

STACQ3

STACQ4

STACQ5

STACQ6

STACQ7

STACQ8

STACQ9

STACQ10

STACQSD11

STACQSD12
Became acquainted with students whose interests were different from yours

Became acquainted with students whose family background (economic, social) was different from yours

Became acquainted with students whose age was different from yours

Became acquainted with students whose race or ethnic background was different from yours Became acquainted with students from another country

Had serious discussions with students whose philosophy of life or personal values were very different from yours

Had serious discussions with students whose political opinions were very different from yours Had serious discussions with students whose religious beliefs were very different from yours Had serious discussions with students whose race or ethnic background was different from yours Had serious discussions with students from a country different from yours

Interacted with other students for social reasons not related to class

Interacted with other students to give or receive moral support with regard to college

\section{Faculty Interactions}

$\mathrm{FACl}$

FAC2

FAC3

FAC4
Talked with your instructor about information related to a course you were taking (grades, makeup work, assignments, etc.)

Discussed your academic program or course selection with a faculty member Discussed ideas for a term paper or other class project with a faculty member Discussed your career plans and ambitions with a faculty member 
FAC5

FAC6

FAC7

FAC8

FAC9

FAC10
Worked harder as a result of feedback from an instructor

Socialized with a faculty member outside of class (had a snack or soft drink, etc.)

Participated with other students in a discussion with one or more faculty members outside of class

Asked your instructor for comments and criticisms about your academic performance

Worked harder than you thought you could to meet an instructor's expectations and standards Worked with a faculty member on a research project

\section{Intellectual Development}

GNWRITE

GNSPEAK

GNCMPTS

GNHEALTH

GNANALY

GNSYNTH

GNINQ
Writing clearly and effectively

Presenting ideas and information effectively when speaking to others

Using computers and other information technologies

Developing good health habits and physical fitness

Thinking analytically and logically

Putting ideas together, seeing relationships, similarities, and differences between ideas

Learning on your own, pursuing ideas, and finding information you need

\section{Personal Development}

GNVALUES

GNSELF

GNADAPT

GNSPIRSD1

GNRESPSD2
Developing your own values and ethical standards Understanding yourself, your abilities, interests, and personality

Learning to adapt to change (new technologies, different jobs, or personal circumstances, etc.) Increasing your spiritual maturity Becoming more responsible for your own behavior 


\section{Social Development}

GNOTHERS

GNTEAM

GNVIEWSD1

GNRESPSD2

GNSOCISD3

GNMEMSD4
Developing the ability to get along with different kinds of people*

Developing the ability to function as a member of a team*

Becoming more open to different points of view Appreciate and respect other cultures Acquiring appropriate social skills for use in various situations

Becoming a more effective member in society

\section{Career Development}

\section{GNVOC}

GNSPEC

GNCAREER
Acquiring knowledge and skills applicable to a specific job or type of work (vocational preparation) Acquiring background and specialization for further education in a professional, scientific, or scholarly field

Gaining a range of information that may be relevant to a career

*listed in CSEQ as personal development (CSEQ does not have a factor for personal development) 
APPENDIX C 


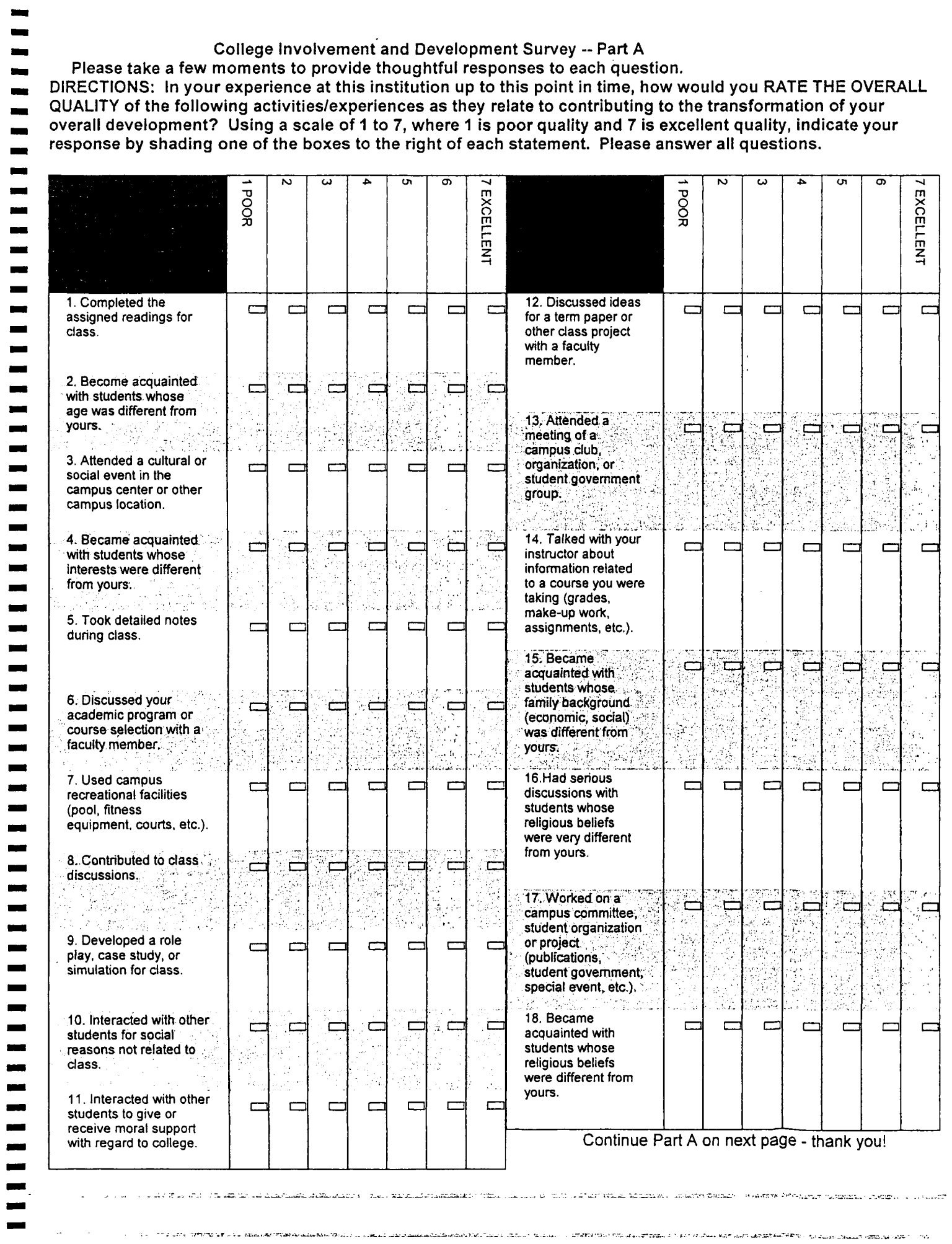




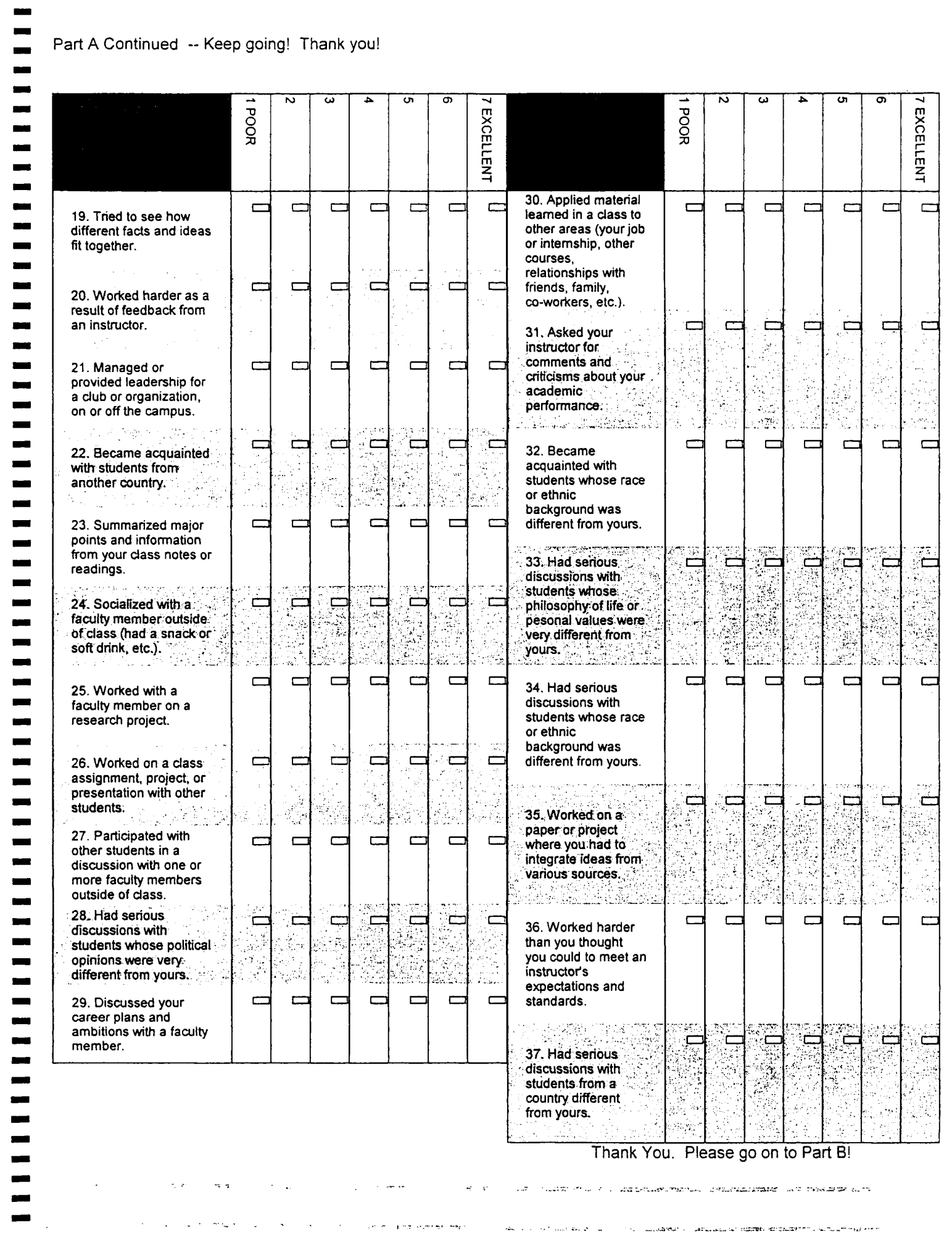


PART B - In thinking about your college experience up to now, please indicate the extent of the - COLLEGE'S CONTRIBUTION (through your college experiences both in and out of class) TOWARD

- YOUR DEVELOPMENT of the following items. Indicate your response by shading in one of the boxes - to the right of each statement. Please answer all questions.

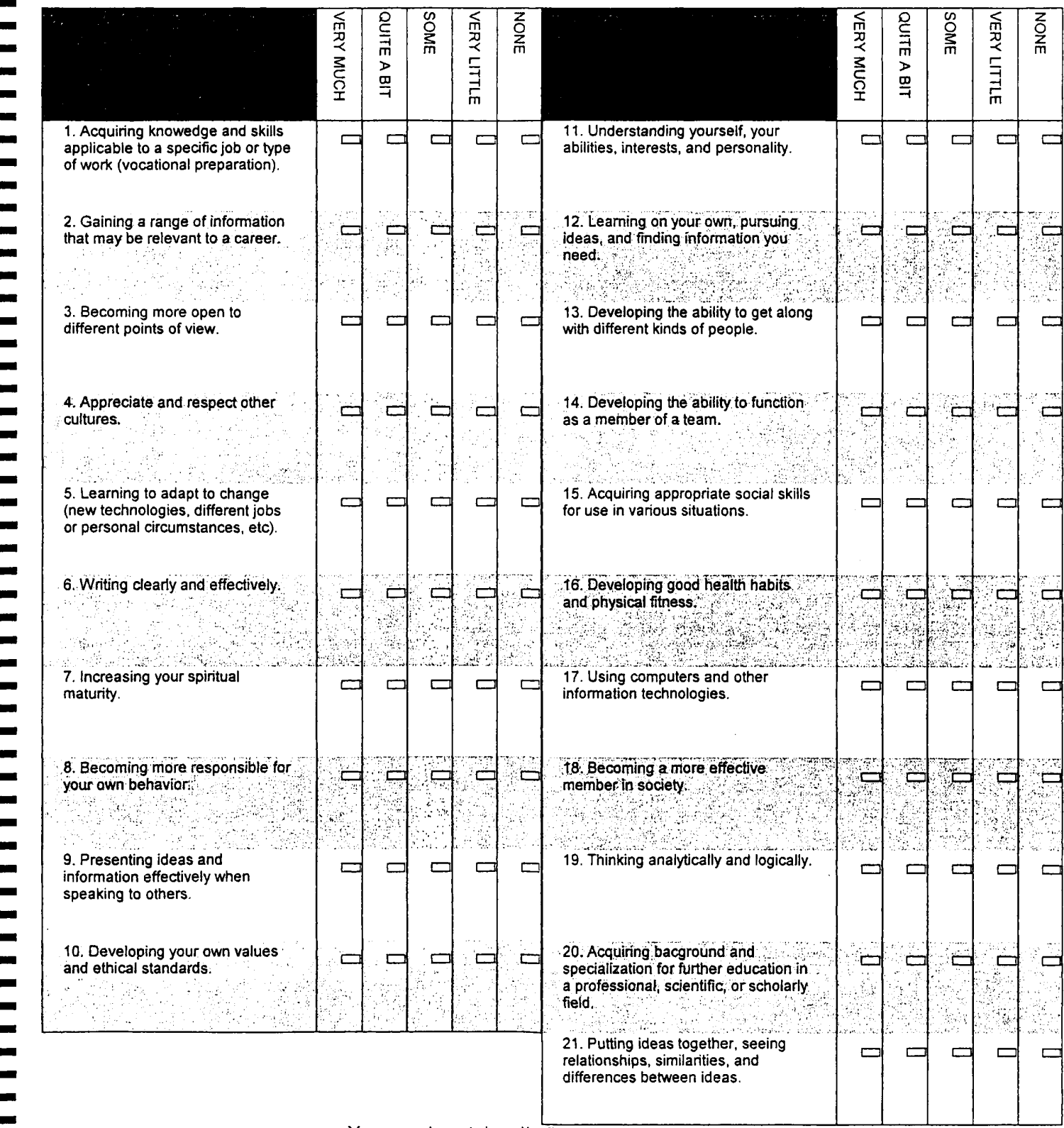

You are almost done!! Please continue to the last page!

Thank you! 


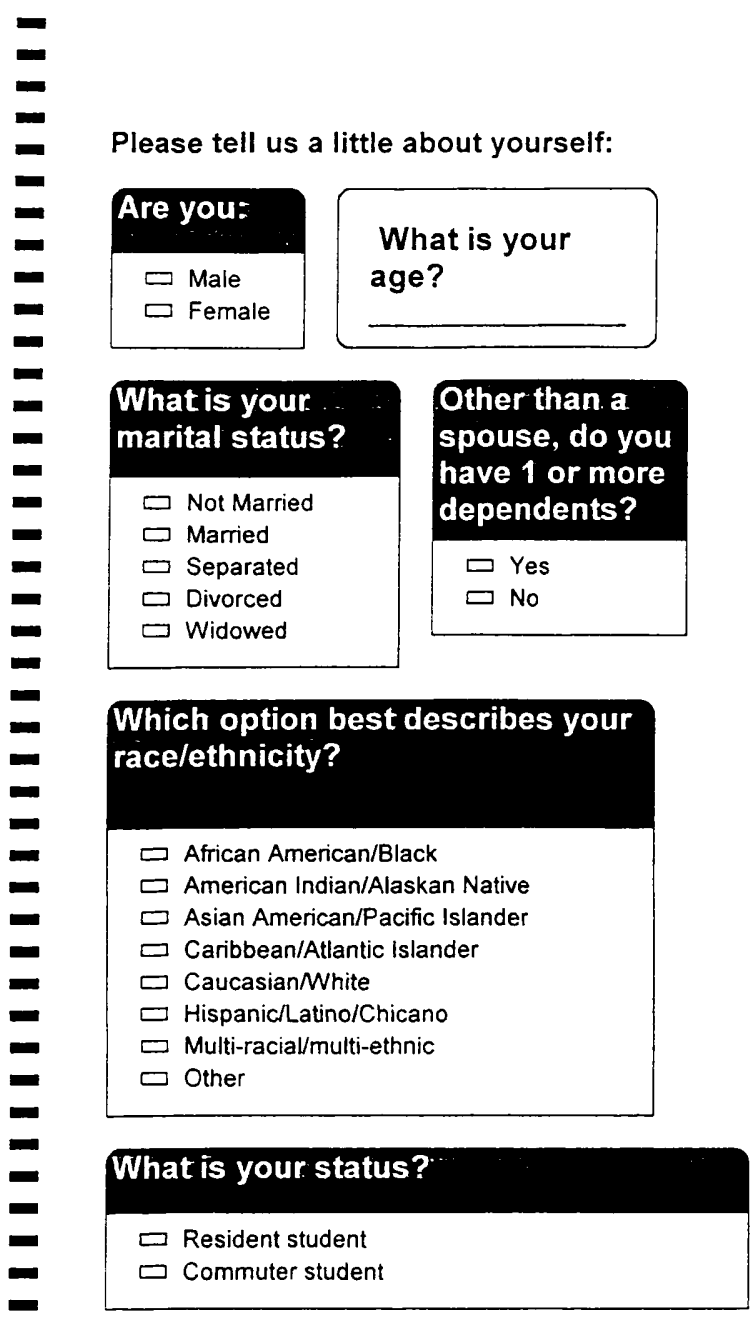

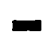

$$
\square \text { Yes }
$$$$
\square \text { No }
$$

\section{How dd you complete high school?}

$\square$ HS Diploma

$\square$ GED

$\square$ Other

\section{What is your employment status?}

$\square$ not employed

$\square$ Part-time

$\square$ Full-time

What is your classification?
$\square$ first year
$\square$ sophomore
$\square$ junior
$\square$ senior

What School do you attend?
$\square$ Arts \& Sciences
$\square$ Business
$\square$ Education
$\square$ Human Performance \& Leisure Sciences
$\square$ Natural and Health Sciences
$\square$ Nursing
$\square$ Social Work

Other than during the summer, at any point do you attend college part-time for the academic year?

$\square$ Yes

$\square$ No

Are you considered financially independent for purposes of being eligible for financial aid?

$\square$ Yes

$\square$ No

How many credit hours are you taking this term?

$\square 6$ or fewer

प 7 - 11

ㅁ $12 \cdot 14$

$\square 15-16$

$\square 17$ or more

THANK YOU so much for your participation and helping me complete my degree!! Best wishes for your success! 
APPENDIX D 


\section{PILOT STUDY INSTRUCTIONS FOR RESPONDING}

I am conducting a study as part of my doctoral requirements at FIU. The attached survey is tentatively scheduled to be administered to a random selection of sophomore, junior, and senior students at Barry University. It is the primary assessment instrument in an investigation designed to measure how student involvement in various activities affect their perceptions on the college contribution towards intellectual, personal, social and career development.

Please reflect on your present experiences as an undergraduate student, the quality of your experiences, and your perceptions of how the college experiences have had an impact on your academic, personal, social and career development and respond to each item according to the survey instructions (as you normally would if you received this as a "regular" survey). Be alert to the clarity of wording of instructions and items when answering and formulate judgments about the importance and relevance of each item. Note anything that is unclear or ambiguous, and don't be shy about including comments on the survey itself.

When you have finished the survey, complete the attached rating sheet asking for your opinion about the survey and indicate any changes you think should be made. Feel free to add additional items that you consider to be important goals for attending college or special types or areas of focus in your interactions with faculty. When you are through, Your instructor will collect them. When you are complete, please place the survey and rating sheet in the envelope furnished for your convenience. Your instructor will collect them.

This information will remain confidential and will be used only to determine the instrument's relevance and the extent to which your responses concur with the other students selected for this pilot test.

Thank you very much for your interest and help! Should you have any questions about this survey, please feel free to contact me at 305-899-4571.

Sincerely, Dawn Broschard, Principal Investigator Florida International University 
APPENDIX E 
Overall Rating of Survey

Please take a few moments here to respond to the following questions regarding the survey you just completed.

1. Are the instructions and wording of the items on the survey clear?

Yes

No

Please note any changes you think are necessary.

2. Please add any additional items that you believe are:

a. Important experiences at college.

b. Other types of development that are important.

3. Please indicate other modifications, additions or deletions that, in your opinion, should be made to this survey. 
APPENDIX F 
1B. Please note any changes you think are necessary. Comments:

1. Very clear

2. There was no indication of how to select, shade, tick?

3. If giving in summer, indicate semester taken - credits differ.

4. I think that it is fine as it is. It is well explained.

5. None

6. Should have areas for comments or explanations.

7. Indicate questions refer to current semester or overall.

8. I didn't read instructions for part b, would be helpful to have same scale as poor to excellent.

9. None

10. Learning to think critically, expanding your view point, learning valuable skills to be used in the workplace.

11. Improve on food and prices need to be lower because the education is already expensive.

12. No further changes necessary.

13. None

14. None

2A. Please add any additional items that you believe are important experiences at college. Comments:

1. Getting involved in community service with my peers from school was a very important experience for me.

2. To me the most important experience at college is to know that one can feel like you can come to faculty member and be able to communicate openly without feeling inferior. One should feel comfortable to see advisor, talk about goals/ dreams/ask advice

3. Better preparations and orientations

4. Reasons for nonparticipation

5. Professional writing courses need to be added as a requirement. Many professors assume students already know how to effectively write.

6. Attending cultural events, learning about others' lives, similarities, differences, ability to work as a team, focus on finding solutions to problems even if not own solutions

7. More student activities to allow college to be a more fun experience, scholarship opportunities, class size

8. Availability of library and computers

9. Try to get rid of mosquitos in bathrooms outside

10. Group meetings

11. Meeting people with various backgrounds

12. Dorm life 
2B. Please add any additional items that you believe are other types of development that are important. Comments:

1. None

2. None

3. What effect does participation have on the individual?

4. ability to see glass as half full vs. half empty, positive, optimistic outlook in studies and importance of obtaining a degree to assist with financial situation and world.

5. None

6. None

7. More cultural awareness activities.

3. Please indicate other modifications, additions or deletions that, in your opinion, should be made on this survey. Comments:

Straight forward

I honestly don't see anything.

None

None

Delete the 4 th question on the right column on the 2 nd to last sheet from this one. None 
APPENDIX G 


\section{MEMORANDUM}

To:

Dawn Broschard

CC:

Dr. Janice Sandiford

File

From:

Chris Grayson, Coordinator Institutional Review Board

Date: July 28, 2004

Proposal Title: College Involvement and Academic and Personal Development of Nontraditional Undergraduate Students

Approval \# 031504-04

The Institutional Review Board has approved the following modification(s):

Data collection will be changed from a random sample of students to be mailed surveys, via the postal service, to a random cluster sample of classes, which will be distributed in classes.

$>$ Information letters include new instructions explaining the procedures for the new data collection method.

There are no additional requirements in regards to your study. However, if there are changes in the protocol after you commence your study that may increase the risks that the human subjects are exposed to, you are required to resubmit your proposal to a Representative of the IRB for review. If you have any questions please contact your Representative or the IRB Coordinator at $348-2494$ or by email at irbiacuc@,fiu.edu. 
To: $\quad$ Ms. Dawn Broschard

From: Deborah Jones Ph.D., Chair

Date: December 10, 2003

Protocol Number: 03-09-073

Protocol Title: College involvement and academic and personal development of nontraditional undergraduate students

Dear Ms. Broschard:

The Board has found your proposal to be exempt from further review and you may proceed with data collection. Please notify the Board in writing of any future changes to your proposal.

Regards,

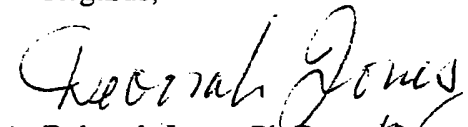

M Deborah Jones, Ph.D.

Barry University

$11300 \mathrm{NE} 2^{\text {nd }}$ Ave

Miami Shores, FL 33161

dljones@mail.barry.edu

If you have any questions, please contact the Chair at 305-899-4576.

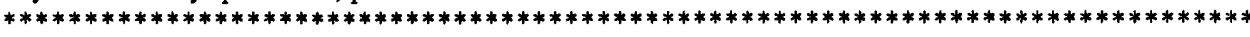

Note: The investigator will be solely responsible and strictly accountable for any deviation from or failure to follow the research protocol as approved and will hold Barry University harmless from all claims against it arising from said deviation or failure. 
Broschard, Dawn

From:

Sent:

Gibson, Ann

To:

Friday, August 13, 2004 9:53 AM

Subject:

Broschard, Dawn

RE: IRB question

Dawn - I reviewed your changes yesterday. Everything looked ok to me. Avril Brenner will be sending a letter to you on behalf of the IRB.

Best wishes for a successful project!

Ann L. Gibson, $\mathrm{PhD}$

Department of Sport and Exercise Sciences

Chair, Institutional Review Board

Barry University

11300 NE 2nd Avenue

Miami Shores, Florida 33161-6695

\author{
----Original Message--... \\ From: Broschard, Dawn \\ Sent: Friday, August 13, 2004 9:44 AM \\ To: Gibson, Ann \\ Subject: RE: IRB question \\ Thanks! Dawn \\ Dawn Broschard \\ Barry University \\ Asst. Vice President for Planning and Assessment, \\ Director, Institutional Research \\ 11300 Northeast Second Ave., Box INRE \\ Miami Shores, FL 33161-6695 \\ 305-899-4571
}


August 27, 2003

Dawn Broschard

9440 Live Oak Place, \#204

Ft. Lauderdale, FL 33324

Dear Dawn:

This is to inform you that your proposal to conduct survey research has been approved at Barry University. Please be sure to submit your proposal to the IRB.

At your convenience we will need to talk about the details of the project.

Keep in touch.

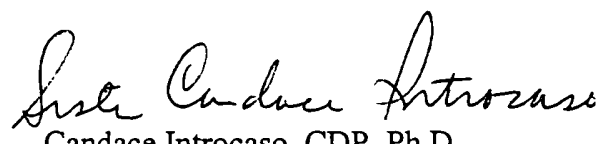

Candace Introcaso, CDP, Ph.D.

Vice President for Planning and Assessment 
APPENDIX H 


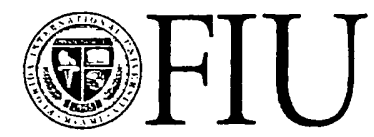

FLORIDA INTERNATIONAL UNIVERITTY

Miamis public research university

Student Involvement and Academic and Personal Development

August $30,2004^{n}$

Dear Barry University Student:

I am a doctoral candidate at Florida International University and I am conducting research to fulfill my graduation requirements.

As an undergraduate student at Barry University, you and 349 others have been selected as part of a random sample from the main campus undergraduate body of approximately 2595 to answer the enclosed survey designed to assess how student involvement in various activities affects their perceptions on the college contribution towards their development. This study is anonymous and your participation is completely voluntary. You will receive no direct benefit from participation in this study, although your participation may help to improve the quality of student services. In addition you will be helping me complete my degree.

Should you agree to participate, simply complete the survey and return it the provided envelope. There are no risks or costs to you by completing this survey and participation should take no more than 15-20 minutes of your time. All data will be kept locked in a file in my home office. To ensure anonymity please do not write your name on the survey or envelope.

I thank you in advance for your participation. Should you choose not to participate, you do not need to return this survey. Should you have any questions, please feel free to contact me at 305-899-4571 (by email at dbroschard@mail.barry.edu.) or Dr. Sandiford, at 305-348-3996. If you have any questions or concerns about being in the study you may call Dr. Gerstman at $305-$ 348-3115 or 305-348-2494 or you may also contact Ms. Avril Brenner at 305-899-3020.

Please take a few moments to provide thoughtful responses to each question. Once you have completed the survey, place it in the provided envelope. I will collect all envelopes once everyone has completed the survey.

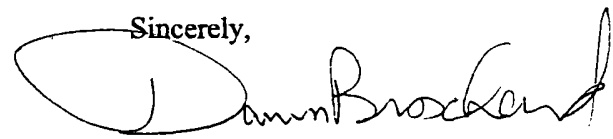

Dawn Broschard

Principal Investigator

Doctoral Candidate, Florida International University

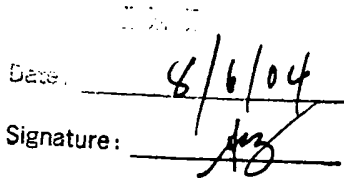

University Park • Miami, Florida 33199 


\section{APPENDIX I}


Item

$$
n
$$

$S D$

\section{Academic}

Took detailed notes during class.

Applied material learned in a class to other areas (your job or internship, other courses, relationships with friends, family, co-workers, etc.).

Summarized major points and information from your class notes or readings.

Worked on a paper or project where you had to integrate ideas from various sources.

Worked on a class assignment, project, or presentation with other students.

Tried to see how different facts an ideas fit together.

Contributed to class discussions.

Completed assigned readings for class.

Developed a role play, case study, or simulation for class.

\section{Co-curricular}

Attended a cultural or social event in the campus center or other campus location.

Used campus recreational facilities (pool, fitness equipment, courts, etc.). 
Attended a meeting of a campus club, organization, or student government group.

Worked on a campus committee, student organization or project (publications, student government, special event, etc.).

Managed or provided leadership for a

club or organization, on or off the campus.

238

\section{Student}

Became acquainted with students whose race or ethnic background was different from yours.

Became acquainted with students from another country.

Became acquainted with students whose family back- ground (economic, social) was different from yours.

Became acquainted with students whose age was different from yours.

Interacted with other students for social reasons not related to class.

Had serious discussions with students whose race or ethnic background was different from yours.

Had serious discussions with students from a country different from yours.

Became acquainted with students whose interests were different from yours.

Interacted with other students to give or receive moral support with regard to college.

Had serious discussions with students whose philosophy of life or personal values were very different from yours. 
Had serious discussions with students whose religious beliefs were very different from yours.

Had serious discussions with students whose

political opinions were very different from yours. 237

Faculty

Worked harder as a result of feedback from an instructor.

Worked harder than you thought you could to meet an instructor's expectations and standards.

Talked with your instructor about information related to a course you were taking (grades, make-up work, assignments, etc.).

Discussed your academic program or course selection with a faculty member.

Discussed your career plans and ambitions with a faculty member.

Discussed ideas for a term paper or other class project with a faculty member.

Asked your instructor for comments and criticisms about your academic performance.

Participated with other students in a discussion

Socialized with a faculty member outside of class (had a snack or soft drink, etc.).

Worked with a faculty member on a research project.

Note: For all items 1 = poor quality, 7 = excellent quality. 
Item

$$
n
$$

$S D$

\section{Intellectual}

Learning on your own, pursuing ideas, and finding information you need.

Using computers and other information technologies.

Putting ideas together, seeing relationships, similarities, and differences between ideas.

Thinking analytically and logically.

232

Presenting ideas and information effectively when speaking to others.

Writing clearly and effectively.

Developing good health habits and physical fitness. 236

Personal

Becoming more responsible for your own behavior.

Learning to adapt to change (new technologies, different jobs or personal circumstances, etc.).

Understanding yourself, your abilities, interests, and personality.

Developing your own values and ethical standards. 
Social

Appreciate and respect other cultures.

Developing the ability to get along with different kinds of people.

Becoming more open to different points of view.

235

4.16

Developing the ability to function as a member of a team.

Acquiring appropriate social skills for use in various situations.

232

4.06

1.00

Becoming a more effective member in society.

234

4.00

1.02

Career

Acquiring background and specialization for further education in a professional, scientific, or scholarly field.

Gaining a range of information that may be relevant to a career.

Acquiring knowledge and skills applicable to a specific job or type of work (vocational preparation).

Note: For all items, $1=$ none, $5=$ very much. 
VITA 


\section{VITA}

\section{DAWN MARIE BROSCHARD}

1993

BA, Psychology

Bloomfield College

Bloomfield, New Jersey

$1993-1997$

1996-1997

Assistant Registrar Bloomfield College

Bloomfield, New Jersey

Adjunct Faculty

Bloomfield College

Bloomfield, New Jersey

1997

MS, Applied Psychology; Research

Stevens Institute of Technology

Hoboken, New Jersey

1998

Adjunct Faculty

Research Associate

Palm Beach Community College

Lake Worth, Florida

1998-2000

Research Associate

Broward Community College

Fort Lauderdale, Florida

2000

Researcher/Consultant

Broward County Public Schools

Fort Lauderdale, Florida

2000-2005

Asst. Vice President for Planning \& Assessment, Director of Institutional

Research

Barry University

Miami Shores, Florida 